\title{
Effect of Early Feedback on New Product Performance
}

by

\section{Nerva Joseph Joachim}

\begin{abstract}
A thesis submitted to the Faculty of Graduate Studies Research in partial fulfillment of the requirements for the degree of Master of Applied Science in Technology Innovation Management
\end{abstract}

Department of Systems and Computer Engineering

Carleton University

Ottawa, Canada, K1S 5B6

May, 2012

(C) Copyright 2012, Nerva Joseph Joachim 
Library and Archives

Canada

Published Heritage

Branch

395 Wellington Street

Ottawa ON K1A ON4

Canada
Bibliothèque et

Archives Canada

Direction du

Patrimoine de l'édition

395 , rue Wellington

Ottawa ON K1A ON4

Canada
Your file Votre référence

ISBN: $978-0-494-94249-9$

Our file Notre référence

ISBN: $978-0-494-94249-9$
NOTICE:

The author has granted a nonexclusive license allowing Library and Archives Canada to reproduce, publish, archive, preserve, conserve, communicate to the public by telecommunication or on the Internet, loan, distrbute and sell theses worldwide, for commercial or noncommercial purposes, in microform, paper, electronic and/or any other formats.

The author retains copyright ownership and moral rights in this thesis. Neither the thesis nor substantial extracts from it may be printed or otherwise reproduced without the author's permission.
AVIS:

L'auteur a accordé une licence non exclusive permettant à la Bibliothèque et Archives Canada de reproduire, publier, archiver, sauvegarder, conserver, transmettre au public par télécommunication ou par l'Internet, prêter, distribuer et vendre des thèses partout dans le monde, à des fins commerciales ou autres, sur support microforme, papier, électronique et/ou autres formats.

L'auteur conserve la propriété du droit d'auteur et des droits moraux qui protege cette thèse. $\mathrm{Ni}$ la thèse ni des extraits substantiels de celle-ci ne doivent être imprimés ou autrement reproduits sans son autorisation.
In compliance with the Canadian Privacy Act some supporting forms may have been removed from this thesis.

While these forms may be included in the document page count, their removal does not represent any loss of content from the thesis.
Conformément à la loi canadienne sur la protection de la vie privée, quelques formulaires secondaires ont été enlevés de cette thèse.

Bien que ces formulaires aient inclus dans la pagination, il n'y aura aucun contenu manquant. 


\begin{abstract}
The advance in science and technology makes enormous computational power available to all disciplines. The semiconductor industry has taken advantage of this progress by putting at our reach complex experimentation technologies to provide early feedback on codesign hardwaresoftware applications. Researchers have increasing interest in reducing the cost and accelerating the time-to-market of FPGA-based NPD platforms exploiting these tools. Thus we examine:
\end{abstract}

- What is the effect of early feedback on NPD performance?

The approach that we use to address this problem consists in building a prototype and developing three scenarios to reason about how to partition a codesign system application and why either a microcontroller or an FPGA is the best choice in a point of view of business, science and technology.

The implication of this research is the need to manage collaboration in an interdisciplinary research and the learning and development of new skills based on managerial and technical feedback. 


\section{Acknowledgements}

Over the course of this creative research I have learned a lot not only about management science and electrical engineering but also successful business ecosystem. Julio and Sandra have shown to me life is simple even with the complexity of its constituents. The joint effort of Carleton University and Ottawa University have taught me, one must keep an arm on what one's asking for because when these progressive and liberal institutions get involved in solving research problems one may find oneself with a new beautiful problem of not having enough space to acknowledge all contributors. I am pleased to acknowledge Professor Riadh W. Y. Habash at Ottawa University who has kindly devoted talented students from his class in extended electronic projects connected to building part of our platform, John Perins and Allan Stewart who have helped me constructing the mechanical and electronic components of the prototype for laboratory testing.

Succeed in such enterprise is more complex than having capability for the fact that great minds are the product of their environments in which the complementary mechanisms vary the making, breaking and handicapping of their evolutionary outcome. This new product development would not be possible without the grateful involvement of: Professor Michael Weiss, University of Carleton, who has helped me bringing lights and clarity in defining the objective of this thesis. I enjoy the research related to feedback, flexibility and new product development that we have worked on. Professor Emad Gad, I am thankful to you for giving me the environments at University of Ottawa, and the necessary resources to succeed such as funding and laboratory. I think I get inoculated with the virus of interdisciplinary research and the FPGA-based motion control platform is just a beginning. Professor Antonio Bailetti, I remember the first class that I attended with you at Carleton University; your presentation reminded me a professor philosopher 
who had to say "No one should cross the door to attend my class if they come for a degree or a diploma". What you said to all these bright students that captured my attention could be resumed as "We are situated in the crescendo part of the S-curve and we are here to: educate great minds for creative business, innovate with industry and academia, and launch and grow business". You continued to say, "At the end of your engagement with the TIM program you will have a delta knowledge positive as your instrument to go out in the world and do good". Professor Bailetti, thank you very much for the lifelong teaching that I have received from you. M. Julio Pimentel and Ms. Sandra Pimentel are giant people among men and women of good character and good will. If you were ambassadors I would say, you have succeeded your diplomatic mission of finding a win-win solution between new product development in management science and FPGA-based automatic control in electrical engineering. You have put countless resources to reassure me of a dear and important value for my fellow "Canadians and/et Canadiens" which is hope. When the hard reality is analogous to a nightmare that no one would want to envisage even in a dream I have never chosen the fear. And, I have always kept my confident march toward the future counting you are a hope bearer and an ordeal breaker. Please receive my heartfelt thank you.

I devoted this thesis to my family abroad for whom distance and time have impacted the feedback love that we inherited from our late parents.

I dedicated this work and all strengths that have shaped my success to my late parents, Marie Jeanne and Joseph E. Joachim who have given me early in life all the necessary instruments to succeed in life.

Nerva Joachim 
Table of contents

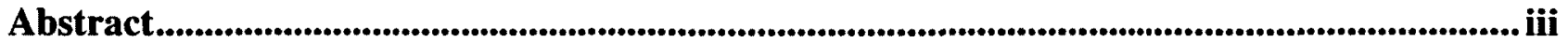

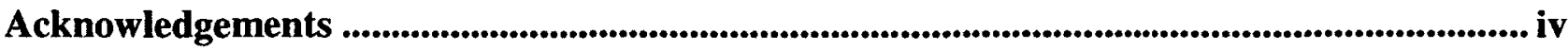

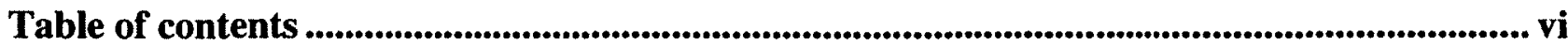

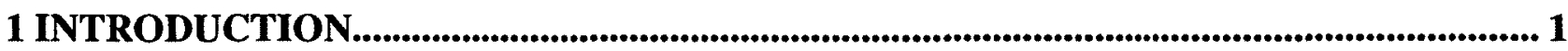

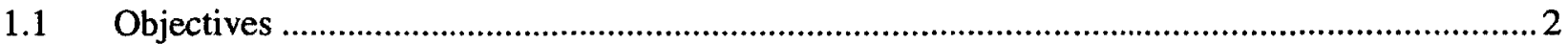

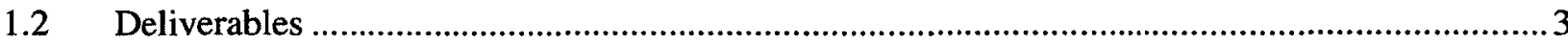

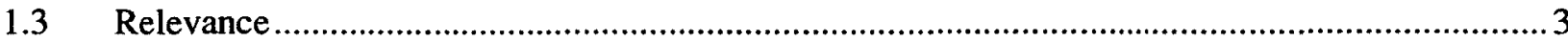

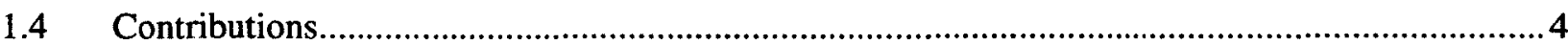

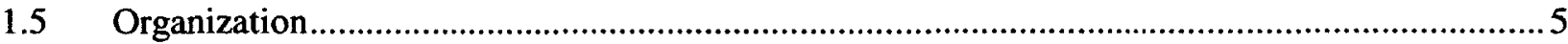

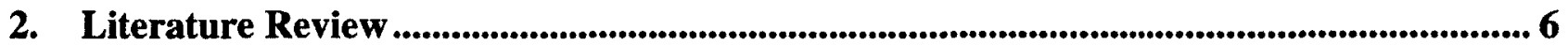

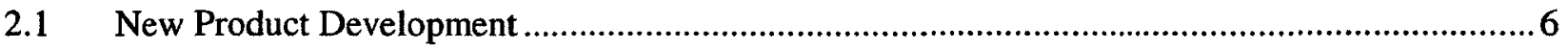

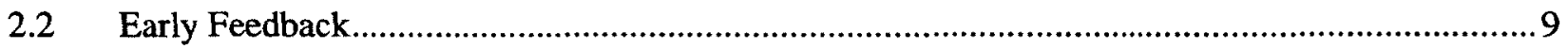

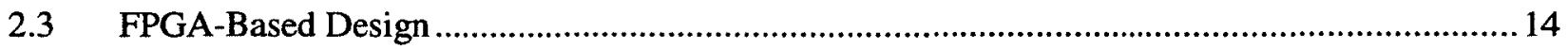

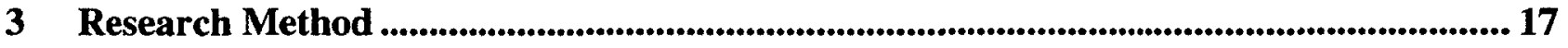

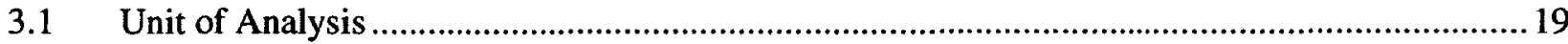

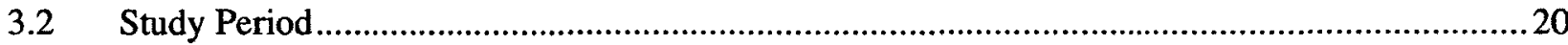

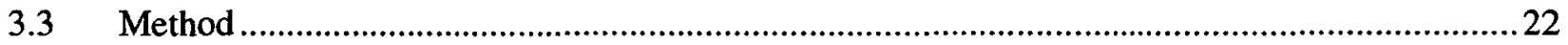

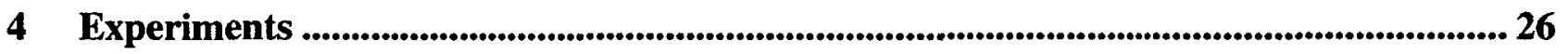

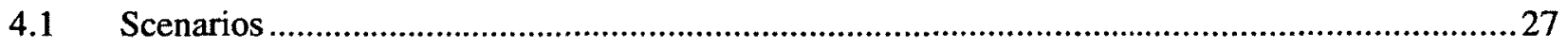

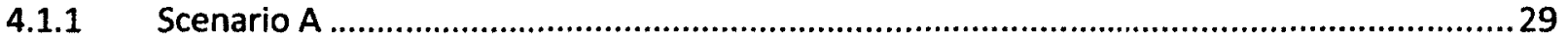

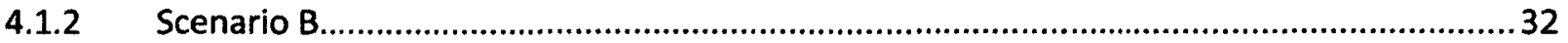

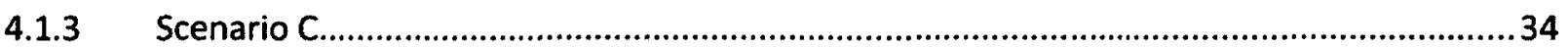

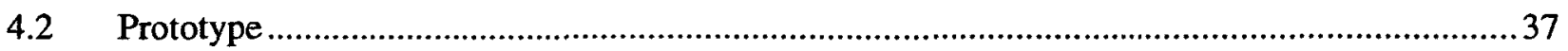




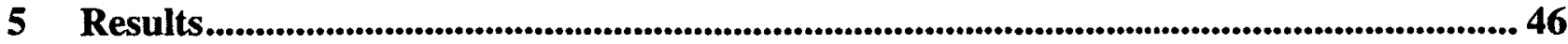

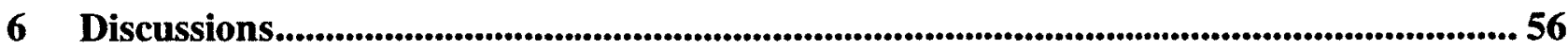

7 Conclusions, Limitations and Future Research .......................................................................... 63

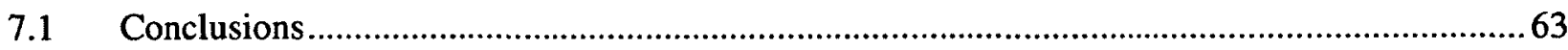

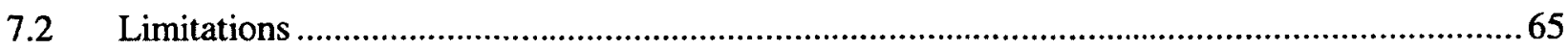

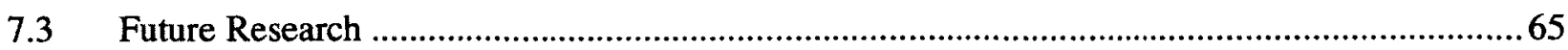

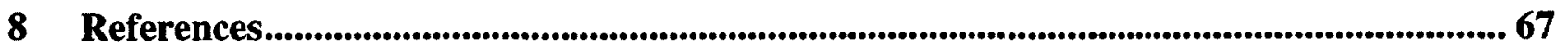

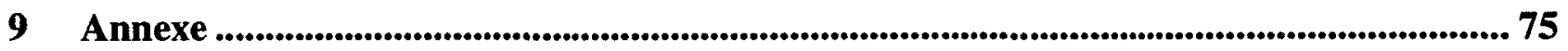

9.1 Annexe 1, Measurements from TI Microcontroller-based System .............................................75

9.2 Annexe 2, Measurements from the FPGA-based System …………………………....................96

9.3 Annexe 3, Models used for Measurements from Matlab Simulation ......................................... 118

9.4 Annexe 4, Selected History of Control and Motor …….......................................................... 121

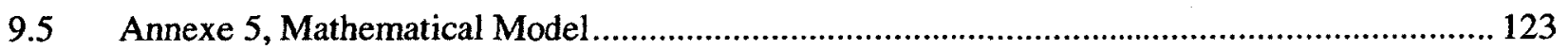




\section{List of figures}

Figure 1: Point of parity and point of flexible difference ……................................................. 19

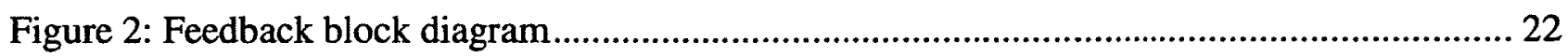

Figure 3: Early feedback of FPGA-based motion control platform ............................................... 29

Figure 4: Shifting Experimentation Business Model for Product Development .......................... 37

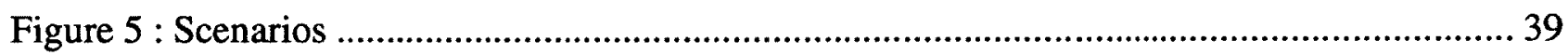

Figure 6 : Stellaris Microcontroller architecture ......................................................................... 40

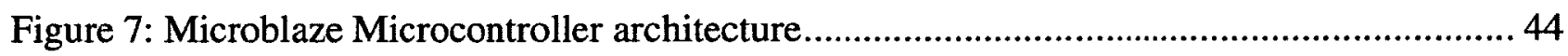

Figure 8 : Top-down design with augmenting libraries.............................................................45

Figure 9: GUI and assembly view for high level motion control system design ...........................46

Figure 10 : Automatic Control of motor drivers for flexible scenarios of process control ...........48

Figure 11 : Classification of electric motor ............................................................................. 50

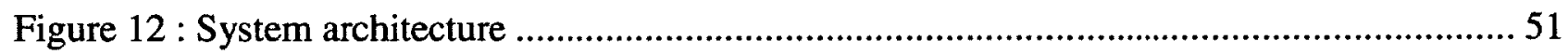

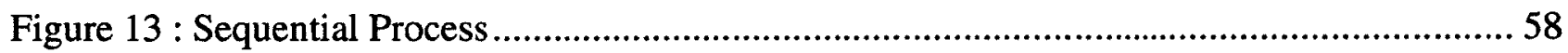

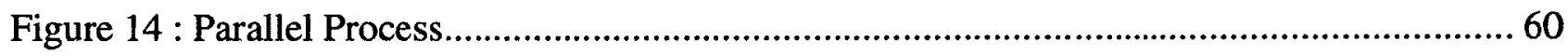

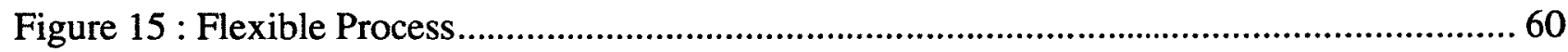

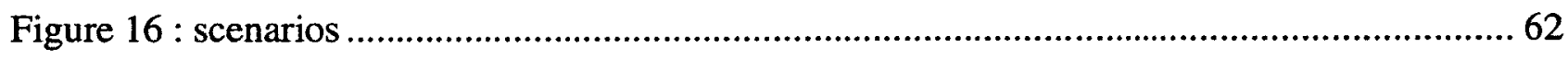

Figure $17:$ Interplay among layers of surrogate applications................................................... 71

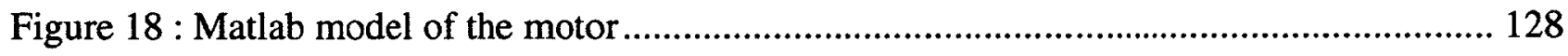

Figure 19 : Matlab model of the deceleration block ................................................................. 129

Figure 20 : Matlab Model of the acceleration block................................................................ 130

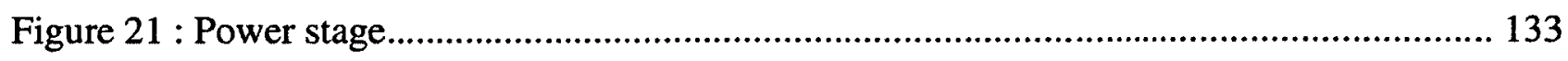

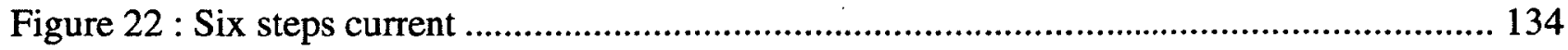




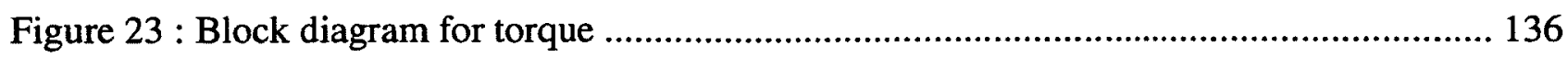

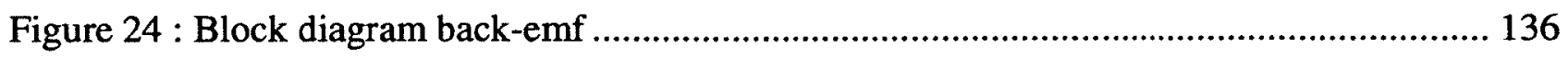

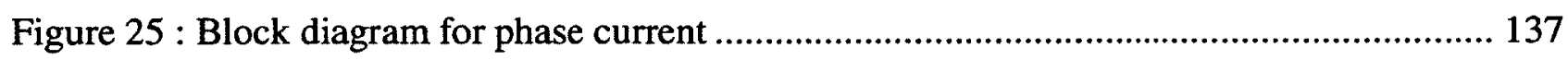

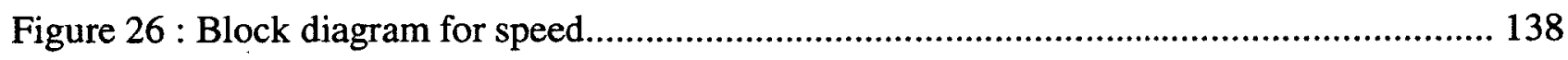

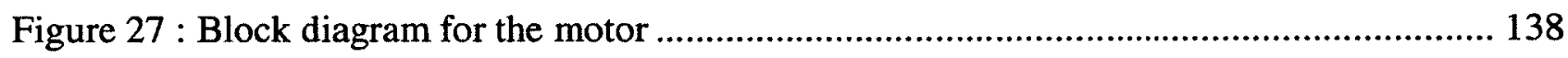

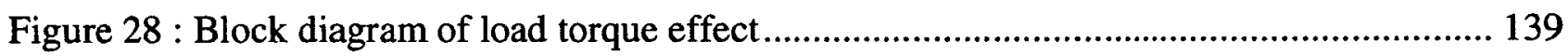




\section{List of Tables}

Table 1: Codesign hardware and software feedback tools........................................................... 32

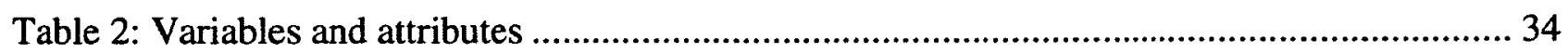

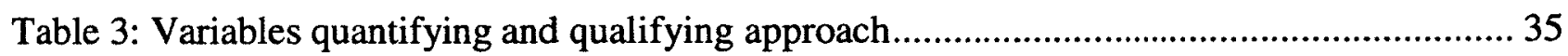

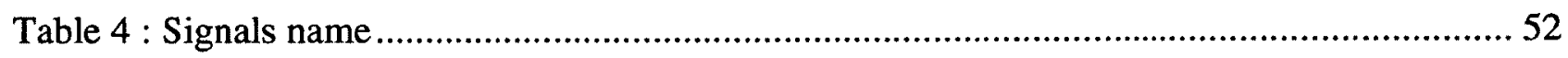

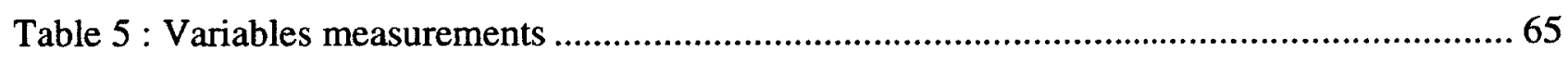

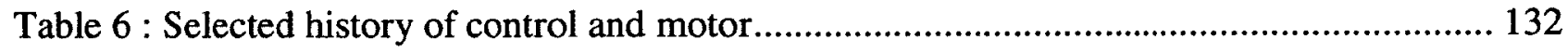

Table 7 : Motor equation parameters definition .................................................................... 135 


\section{INTRODUCTION}

Scientific instruments, airplanes, cars, climate monitoring, microcontrollers, Field Programmable Gate Array (FPGA) and so on; constitute compelling examples of New Product Development (NPD) that demonstrate in this technology and information era virtual prototyping is no longer a curiosity. It is an early codesign for systems and applications that materializes a transformative innovation change where engineers seek feedback from customers then they exploit the capability and the capacity of experimentation technologies to solve customer's problems by reducing the cost, time-to-market, complexity and increasing the flexibility and quality of a firm's NPD. This feedback is a trade-off between value for customer and reciprocal value for a firm and the early codesign is part of a process that can be resumed as "no product can be a product without first having been an idea subsequently shaped through experimentation, (Thomke, 2003)." The author's reasoning scheme, such as learning and innovation, is a perspective that sustains our objective of showing the effect of early feedback in new product development for motion control platform based on FPGA. These devices have "become one of the key digital circuit implementation media over the last decade, (Kuon, Tessier and Rose, 2007)." They are well positioned to leverage well-established goal and methodology of the codesign approach (Getov, Hoisie, Wasserman, 2011) for embedded systems. These authors point out that computational science is central to progress in nearly every scientific and engineering and social discipline; as a result we add that the advance in science and technology allows complex systems (Simon, 1962) to come to light and at the same time it is easier to model, simulate, prototype, test and prove these complex systems and problems that once were mystery or resource prohibitive for a firm. Thanks to this capacity of complexity and capability of solving complex problems one must emphasize early feedback (Dellarocas, 2003, Smith, 
2007, Dorf, Bishop, 2011) and flexibility (Gerwin, 1987, Thomke, 1997, Saleh, Mark and Jordan, 2009) as instruments to reduce cycle time that is too long, to condition the road to success for the malleable organization and adaptive process suggested by (Eseinhardt, Tabrizi, 1995). In the specific case of FPGA-based codesign one must use the tools such as Computer Aided Engineering (CAE), Computer Aided Design (CAD) in the search of feedback experimentation (Thomke, 2003) for successful new product development that ultimately brings value for customers by allowing them to save money and deliver NPD faster. The uniqueness of the present early feedback and flexibility consist of providing early information or prototype to assist internal collaborators such as other departments and external partners such as customers and suppliers in their process of decision making to solve their late needs or uncertainties and we have to put these prototypes early in the hand of customers to reduce their development cost and time-to-market.

\subsection{Objectives}

Our objective will consist of answering the following question:

What is the effect early feedback on NPD performance?

The process to answer this question links our research to New Product Development coordination, performance, modularity, flexibility and experimentation. We hope this process will also relate research in management science with NPD in the semiconductor industry end contribute to reduce cycle time. 


\subsection{Deliverables}

We will deliver the following:

- Three scenarios that elucidate codesign tradeoffs between hardware and software for microcontroller and FPGA based systems

- Simulation results related to performance analysis and a comparison table to illustrate the advantages and disadvantages of the above three scenarios between a commercial product currently sold for motor control applications and the one resulting from our research.

\subsection{Relevance}

This research can serve as a tool to:

Introduce to students a hardware realisable motion control system tightly coupled with software algorithms and modeling. It has the capability to open the use of FPGA to those working on applications previously based on microcontrollers, DSP and microcomputers. We believe students care about learning new technologies that stimulate their intellectual capabilities and enhance their learning curve by leveraging their previous knowledge and practical experience.

Help business growth by providing a flexible research and development toolkit with high potential to reduce the total cost of ownership of an FPGA-based product development in comparison to the commercial microcontroller-based motion control for complex NPD.

Reduce time-to-market and help diminishing the risk of obsolescence of successful products for industry. And, simplify the development process of FPGA based motion control product development in a way such as by using advanced simulators, CAD tools, and our motion control 
cores library; engineers, researchers and managers of small companies with hardware and/or software experience and skills would find there are no barriers in using FPGA.

Use a prototype to raise credibility:

- In business interaction with bankers, investors, funding agencies, entrepreneurs and potential customers in respect to practical solution to real problem.

- In respect to academia, our research is appropriate to provide an easier environment for teaching, learning and research directly related to motion control and power electronics. Indirectly as a platform, it has the flexibility to get customized and adapted easily to dynamic and emerging technological applications needs.

\subsection{Contributions}

We seek to contribute in demonstrating that investment in infrastructure that supports early feedback can increase the performance of an FPGA-based motion controller in the sense highlighted by (Thomke, 2001). We will articulate this contribution with the three scenarios and a prototype that will provide the following benefits to customers:

- Increase the development process speed by reducing time to design, build, test, simulate and market of NPD through customers and experiments feedback.

- Reduce the development cost and increase product quality by improving the implementation process and the accuracy of cores library already tested by third party.

- Expand the capacity of firm through tools and processes that increase the number of experiments and architecture alternatives that can be tried 
- Intensify the learning gained through the management of the amount of information and early feedback that a flexible FPGA-based platform can generate.

- Demonstrate that an early feedback FPGA-based platform is an experiential model (Eisenhardt, Tabrizi, 1995) that can increase the ability of an organization to make complex information useful and cost effective.

\subsection{Organization}

Taking in account the interdisciplinary (Repko, 2008) of the present research, in the next section we will position our view on the question "What is the effect of early feedback on NPD performance?" In the light of this managerial and technological positioning we will review the early feedback in the management literature. Our main interests are early feedback in New Product Development, analog and digital system design based on FPGA in a codesign embedded hardware and software development environments. Having the FPGA-based motion control in the heart of this inquiry we will visit also the literature of control theory. In chapter three we will also present our constructive research method. Next, in chapter four, we will describe three scenarios as part of our experiments. We will also describe the technical setup and performance results obtained from the experiments. This Chapter is a technical examination of our FPGAbased motion control technology. This will create an opportunity to expand on how an FPGAbased platform fits in a motion control market. Chapter five will host our experimental results followed by a discussion in chapter six. Lastly, we will conclude with significant issues that could require additional investigations to further validate our FPGA-based motion control platform and propose prospective research in early feedback. We will also discuss the fitness of FPGA in the implementation of complex control algorithms as applied to mechatronics, robotics and dynamical systems. 


\section{Literature Review}

\subsection{New Product Development}

The purpose of this chapter is to review the academic research on NPD to find a gap where the pursuit of our objective on the effect of early feedback on new product development performance for FPGA-based platform can contribute to this body of knowledge. Notwithstanding the multiplicity of interests cover by NPD our current investigation will be concerned essentially about the relationship between early feedback and NPD performance. Loch and Kavadis, 2008 resume the breadth of NPD in the foreword and introduction of Handbook of New Product Development as "The problems associated with NPD are so different (short- and long term, individual and group, deterministic and uncertain, technology dependent, etc.)". They expand on the multidisciplinary aspect of NPD to state precisely "Creativity results from the combination of seemingly unrelated events". Our understanding of NPD takes root from Ulrich and Eppinger (2004), they define NPD as "the set of activities beginning with the perception of a market opportunity and ending in the production, sale and delivery of a product." This definition resonates with the fact that we have perceived a new market opportunity in automatic, robotic, power electronics and motion control for industries related to aerospace, automotive, biomedical and energy. Our response is an FPGA-based platform product which is part of the present case study being analysed in the thesis. Such response and business initiative are strategic for an entrant and incumbent alike; it helps the former to get a foothold in a bourgeoning market and the latter to retain their competitive advantage. An NPD can also be an adaptive (Eisenhardt, Tabrizi, 1995) process for a firm competing in highly dynamic environments such as high technology. However, a product is one option among others in a highly competitive and uncertain environment of NPD. Firms need to win sustainable market share through good 
management applied theories; this is what brings us to agreement with Wheelwright and Clark (1992) when they define NPD as "the effective organization and management that enable an organization to bring successful products to the market, with short development times and low development costs". In the spirit of low development cost and NPD process we lock our attention on (Ulrich, 2008), the author shares his view on nine enabling processes and technologies that change the way user, custom and institutional designs are adopted. It is worthwhile mentioning them because we have experimented with almost all of them over the course of this FPGA-based platform development research:

- Templates: In EDK and matlab we have used a variety of templates to get quick technological feedback thus producing and consuming information to seek further feedback from colleagues and professors. We also provide mini applications that end users can later use as template themselves to differentiate their own offer from our product.

- Design grammars: this is the rare one that we haven't used directly. However, in the IP cores that we developed we have followed systematic rules to make it easy for users developing interface wrappers in EDK to connect and communicate to them.

- Search automation: This design is small but complex, thus automation process in EDK and matlab have helped increasing the feedback frequency in our design.

- Rapid prototyping: We have built many prototypes such as hardware, software, subsystems, systems and virtual prototypes using the experimentation technologies to get low cost feedback and flexible interactions with partners and potential customers in this project. 
- Flexible production: "means of producing artifacts with relatively low fixed cost (Ulrich, 2008)." This is a well-placed inspiration and good coincidence related to our focus on flexibility of early feedback for product development performance.

- Tourmants: This is the only one our work doesn't fit in it.

- Open source: Part of EDK is open source. Xilinx has many open source application notes to support ISE and EDK for FPGA users like us.

- Design kits: Usually an FPGA-based development product is not trivial in term of infrastructure required for experimentation technologies. Xilinx has developed many domain applications platforms tools kits, such as industrial, driver assistance, medical and so on; to encourage user, custom and institutional designs.

- User goup: this is one support channel that we have used during the development of our platform.

New Product Development is the oxygen in a business environment; very few companies can survive without filling up their market territory with the clean breathing air of their product portfolio. We say few, because exceptional adoption can happen with customer's fidelity selection or monopole. We acknowledge that undertake NPD is a creative (Fleming, Mingo, 2008) and complex process (Simon, 1962, Sosa, Mihn, 2008) and source of uncertainty (Loch, Terwiesch, 2008) for which firms need to get prepared. Here, this preparedness involves NPD flexible business processes (Thomke, 1997, 1998, Gerwin, 1993, Eisenhardt, Tabrizi, 1995) as summarized by (MacCormack, Verganti, Iansiti. 2001) "Select an NPD architecture that maximizes product performance and facilitates development process flexibility." Faithful to the previous suggestion we specify in figure 1 a very high level architecture of the controller's codesign block diagram. It highlights the product vision instead of the detailed feature-by-feature 
level. This vision consists of isolating the point of parity with the microcontroller such as the common high level software that controls the common hardware for power driver, motor and general peripheral (status, switches and so on). At the lower level we place the flexible point of difference blocks which are included inside the FPGA; for instance the controller module can be configured and reconfigured based on the needs to simulate microcontroller or logic design.

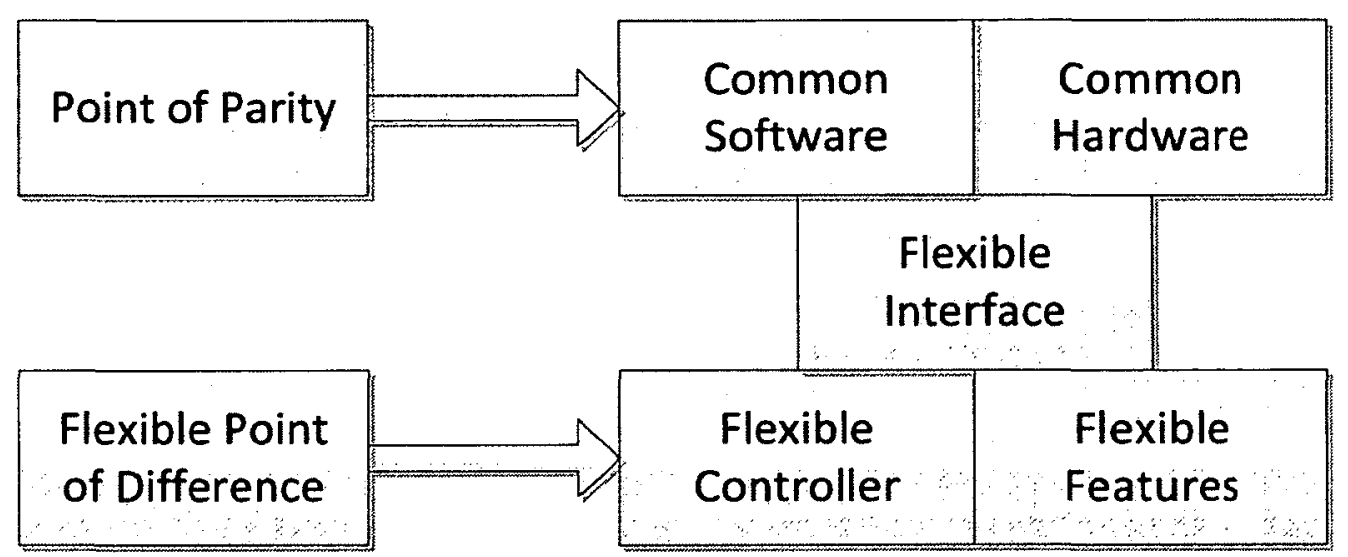

Figure 1: Point of parity and point of flexible difference

\subsection{Early Feedback}

Managing New Product Development is a multi-level evolutionary theory (Loch and Kavadis, 2008). Across different generations, significant evolution can occur at each and all levels, for that matter (MacCormack, Verganti, Iansiti. 2001) suggest, firms must be flexible to "respond to new information, or risk developing a product that is obsolete the day it is launched." Our interpretation of this argument is that firms must be sensitive to feedback from customers, technologies and their process capacity and capability if they want to develop high standard performance products that create positive and early feedback and encourage the adoption of their brand. In the management literature, scholars and professionals have an unanimous mantra resonating that "Customer is the alfa and the omega" which (Thomke, and von Hippel, 2002) describe as "Listen Carefully to what your customers want and then respond with new products 
that meet or exceed their needs". In the current era of Information and Communication Technology (ICT) it is appropriate to leverage the Technology Information Management (TIM) to create value for our customers and grow business, for instance $\mathrm{CAD}, \mathrm{CAM}$ and $\mathrm{CAE}$ have contributed in reducing cost and time-to-market in numerous economics activities. In the present study, we will survey the experimentation technologies and investigate how these technologies can assist in delivering effective and flexible NPD through testing, experimentation and feedback.

The concept of Feedback (Sterman, 1989, Ashford, Blatt, VandeWalle, 2003, Dellarocas, 2003, Thomke, Smith, 2007, Dorf, Bishop, 2011) is a construct that is both popular and academic. Academically, it is used to conceptualize intellectual representation in electronic (amplifier feedback), control systems (close loop feedback), management and marketing (employee and customer feedback, test and experimentation), psychology (communication feedback and behaviour) and so on. A popular and literal usage of feedback often defines it as a process whereby part of a system's output is returned to its input; or simply as a response to an inquiry or experiments. It appears in the present literature that learning about or from feedback is highly dependent on its context, time, location, and in brief its experimental and applied environment. Here, we examine feedback in relation to the response time and coordination process necessary to succeed a NPD. Response time means the speed at which early information or prototype is available to assist others and customers in their NPD decision and risk management. There are three keywords in the previous definitions that deserve specific attention: information, prototype, customers; they suggest a human interface and a technological interface. The former is related to communication in an NPD and later in our case is related to control theory and experimentation technologies. 
The technological aspect of feedback is in the heart of the present inquiry and will be treated in the following sections. Brown and Eisenhardt (1995) have shown in their research that communication is an important success factor in NPD, on this basis we contend that all contributor in NPD need to know how to give feedback. (Sosa and Mihn, 2008) argue that communication is an information processing perspective under which product development organization transform a set of inputs, from external partners such as customers, into a set of outputs for products design and production plans to achieve firm's strategy of NPD. This internal and external communication becomes a determinant factor of NPD and research and development performance. Other external communication research regarding the voice of customers (Griffin and Hauser, 1993) and lead users, innovations (Von Hippel, 1986, 2005) constitute other external feedback information processing.

What is early feedback?

In the present context the qualifier early in front of feedback gives rise to an intellectual conception of feedback whereby the data or information acquired during an experiment or a milestone is a time variant outcome. Thus, if this outcome can be collected and made available to other partners to assist them in planning their risk management or project coordination as close as possible to the initial time of each milestone this information can be classified as early feedback. Other than this time constraint early feedback is the same as feedback well developed in academic literature we have consulted.

In the case of a physical machine and system such as a motor control, feedback is the measured and actual signal output that comes back at a specific system entrant to get compared with a desired system input. On the other hand, when a customer is in the center of a service process 
evaluation, feedback is the response of the customer to an offer. In all, for a basic modeling feedback is analogous to a full duplex transmit and receive communication. This communication channel procures a competitive advantage to organisations which can: exploit the data, information and knowledge or explore measured and interpreted actions for the benefit of developing product that solve real problems for customers. Based on the previous definition, a management perspective of feedback involves three levels of information exchange, external, internal and technological which can be conceptualized in the following block diagram,

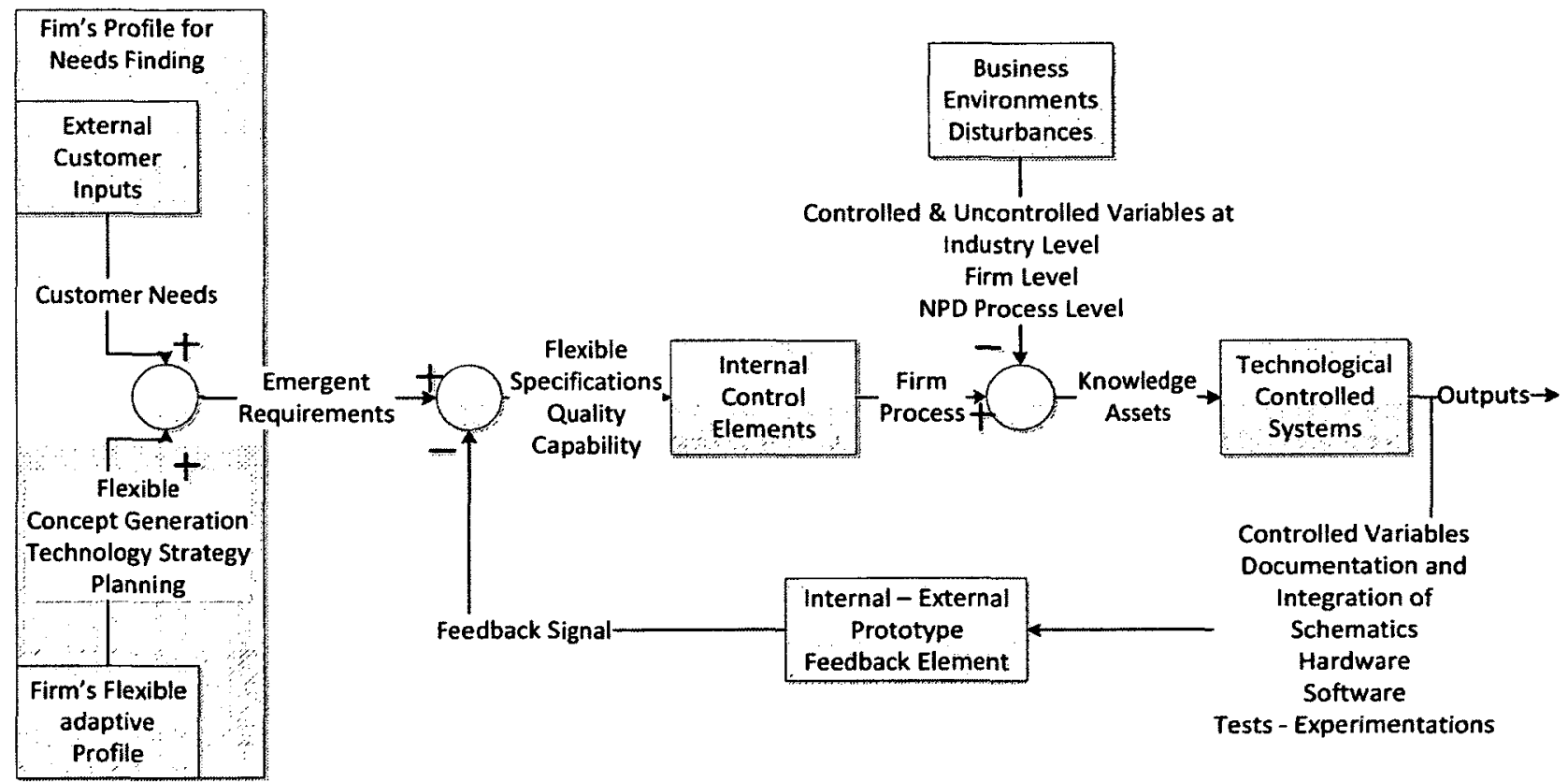

Figure 2: Feedback block diagram

The feedback element in the previous block diagram is a filter or a transfer function which converts the output variables into a suitable one which ensures that the deliverables are at the level understandable by the customer. Usually the prime feedback is prototype and documentation. The controller consists of a comparator and control elements. The comparator compares the feedback signal obtained from firm's profile output based on the external customer 
inputs and the flexible concept generation, technology strategy and planning from which emerge the product requirements that would be in turn transformed through flexible specifications, firm process and firm knowledge resource based value and the disturbances in the business environments. The deviation can be quantified as the observed capability of the firm and qualified as the controllable quality the firm can offer. In a close loop control the quality and capability deviation can be controlled through suitable parameters manipulation or control of the controller. This manipulation may involve resource allocation, signal amplification, process reengineering and any other suitable business function.

Why feedback is important?

Building useful intelligence and knowledge to create and innovate with successful NPD is not a simple and straightforward process. Resources such as time and money can have a metamorphosis relationship with innovators in the sense that time and money can be the best collaborators in NPD success and the worst adversary in unsuccessful NPD. Feedback becomes like a technological instrument. As such, we use (Thomke, 2003) arguments, it is the most efficient way to explore and exploit a complex and uncertain space by conducting experimentations to identify independent and dependent variables which could help in building insights about tests design that would eventually lead to unlock the mystery surrounding a system, a market or a process. Our focus consists in demonstrating that early feedback in NPD needs a synergy between the following three coordination components to be successful:

Internal (Hillbarand, Biemans, 2003): it is related to cooperation, interaction and communication exchange between team members. 
External (Hillbarand, Biemans, 2003): it is related to cooperation, interaction and communication exchange with customers and measuring what they value in the product

Technological (Thomke, 2003): it concerns tools that allow us to create models that are close to the end product. It allows us to use simulation to create test cases scenarios almost the same as a real time prototype.

\subsection{FPGA-Based Design}

The objective that we pursue in the FPGA-based platform and examination is threefold: flexibility, early feedback and performance. In a technical search for a programmable logic device to achieve such goals, we have a variety of choices: microcontrollers, microprocessors, DSPs, FPGAs and ASICs. We have found commercial microcontroller-based motor controllers, however we decide to choose an FPGA-based approach for assets management in our platform (Robertson and Ulrick (1998)). These devices have a flexible architecture that allow designers to develop products that meet multiple objectives such as, customer needs conjointly with firm strategy, customization, production process, differentiation and so on as stressed in the school of thoughts of (Krishnan and Ulrich (2001), Ramdas (2003)). The rationale behind this choice is the following: we have seen a market opportunity for mechatronics, automatic, robotic, motion control and industrial power control in various industries such as aerospace, automotive, biomedical and energy. Based on our experience and our comprehension of innovation (Christensen, (2004), Betz, (2003), Roberts, (2002)), this market opportunity is still uncertain and the best programmable devices that offer flexible options to deal with this uncertainty are FPGAs. In this context, our choice of FPGAs is in accordance with (Patterson, 2010), "they offer the best of both worlds, having the flexibility of software but also the ability to run 250 times as fast as software simulators." We can manage our options in this uncertain market by using 
FPGAs to simulate prototypes and toolkits that simulate and define a point of parity among these future customers. They will use our offer or collaborate with us at their convenience to mix their point of difference with our platform. Among all other industries who have benefited from experimentation technologies (Thomke, 2003, Monmason and Cirstea, August 2007), the integrated circuits industries have had the greater impact be it modeling, simulation, rapid prototyping, development kit and so on. Inside this pool of success some devices are in better position than others. For instance, ASICs become more complicated for firms who are not in very high volume market thus more and more ASICs designs are migrating to FPGAs (Kuon, Tessier, Rose, 2007) which once were used as proof of concepts. Regarding Microcontrollers and DSP, it is hardly conceivable they can offer flexibility and performance that microprocessors have never offered or promised. This argument gives the incentive to underline with (Patterson, 2010) "Chipmakers are busy designing microprocessors that most programmers can't handle". They hope "someone will be able to figure out how to program" these complex chips with rigid architecture. The FPGAs have a compelling feedback and flexibility advantage over ASICs. They sustain this advantage through performance and keeping the design simple with the same fabric offer in regards to other programmable logic devices such as microcontrollers, microprocessors and DSPs. They have a learning advantage (Thomke, 2003) over the ASICs for the fact that a team can build experience by exploring various ideas before making a selection; FPGA designers can afford having a design wrong the first time. To the contrary, ASIC designers have to be right the first time; otherwise the cost is unsustainable for a profitable business.

There are two dominant players in the FPGAs market (Altera and Xilinx). The FPGAs used to be devices that serve as arbitrators connecting peripherals that need complex communication bus 
control interface with their controllers. For instance Coreconnect and AMBA often used in Xilinx system on chip design are among few busses architecture reported in (Dubey, Argawal, Vasantha, 2007). Currently, these devises integrate many common digital subsystems such as multipliers, DSP, microcontrollers which make them flexible enough as system on chips. An example of such devices is Virtex 7 from Xilinx and designers must use CAD tools to work effectively with these devices. Xilinx and Altera provide tools that support designers using their chips. In our case we use the ISE and EDK which contains XPS and SDK (Xilinx). The flexibility of an FPGA in comparison to a microcontroller is that, it is easier to explore more modular design architectures to solve a customer problem. At the same time, we keep the option to modify a potential solution, with manageable perturbations, if customer requirements change based on new market needs. In this context, a modular architecture will facilitate reusability of modules among subsystems. Nowadays, FPGAs have a higher gate density, soft microcontroller core thus they can target large market of application-specific standard products (ASSPs) for the same or even higher performance in time and cost (Dubey, Argawal, Vasantha, 2007). 


\section{$3 \quad$ Research Method}

In the present state of the management literature, we relate more with the research done by (Thomke, 2003) in the semiconductor industry. In terms of control theory, we draw much of our references from (Palm III, 2010; Dorf and Bishop, 2011). However, because of the particular interest and the specific context, early feedback using FPGA-based motion control platform, in which we work our research design is constructive. From our literature review, this design can be resumed as a New Product Development research with success factors related to:

- full duplex communication among focal firm, customers and partners

- adaptive response through FPGA-based motion platform to market and technology and - pursuit of knowledge.

Thus our research method will draw on the idea, we have learned that the natural sciences (biology, mathematics, physic, ...), social sciences (economics, political sciences, psychology, ...) and applied professions (business, law, medicine, engineering, ...) have a common ground when it comes to research because "scientific inquiry comes down to making observations and interpreting what you've observed (Babbie, Benaquisto, (2002))." Consequently, in this current inquiry, our study is specified as the following:

What is to be observed and studied?

We will use known and shared observation and analysis method in technology innovation management to study the effect of early feedback on NPD performance. In that spirit, a case study research about FPGA-based motion control platform is used for convenience and usefulness between science, technology and management. 
When?

We have seen, since 2008 up to now, signs of a bourgeoning profitable business for increasing the adoption use of this particular technology in some traditional industries: aerospace, automotive, biomedical, instrumentation and energy.

How?

We have launched an interdisciplinary (Repko, 2008) research with the collaboration of two universities Carleton University and Ottawa University, National Sciences and Engineering Research Council of Canada (NSERCC), a private high technology firm Kylowave inc., Lead To Win (LTW) and Ontario Centre for Research and Innovation (OCRI). This business and science and technology research ecosystem can be conceptualized as shown in figure 3:

For what purpose?

We want to evaluate the effect of early feedback on NPD performance through parameters such as the time to market, the cost, the exploration and complexity of alternative solutions and scenarios for an FPGA-based motion control platform. 


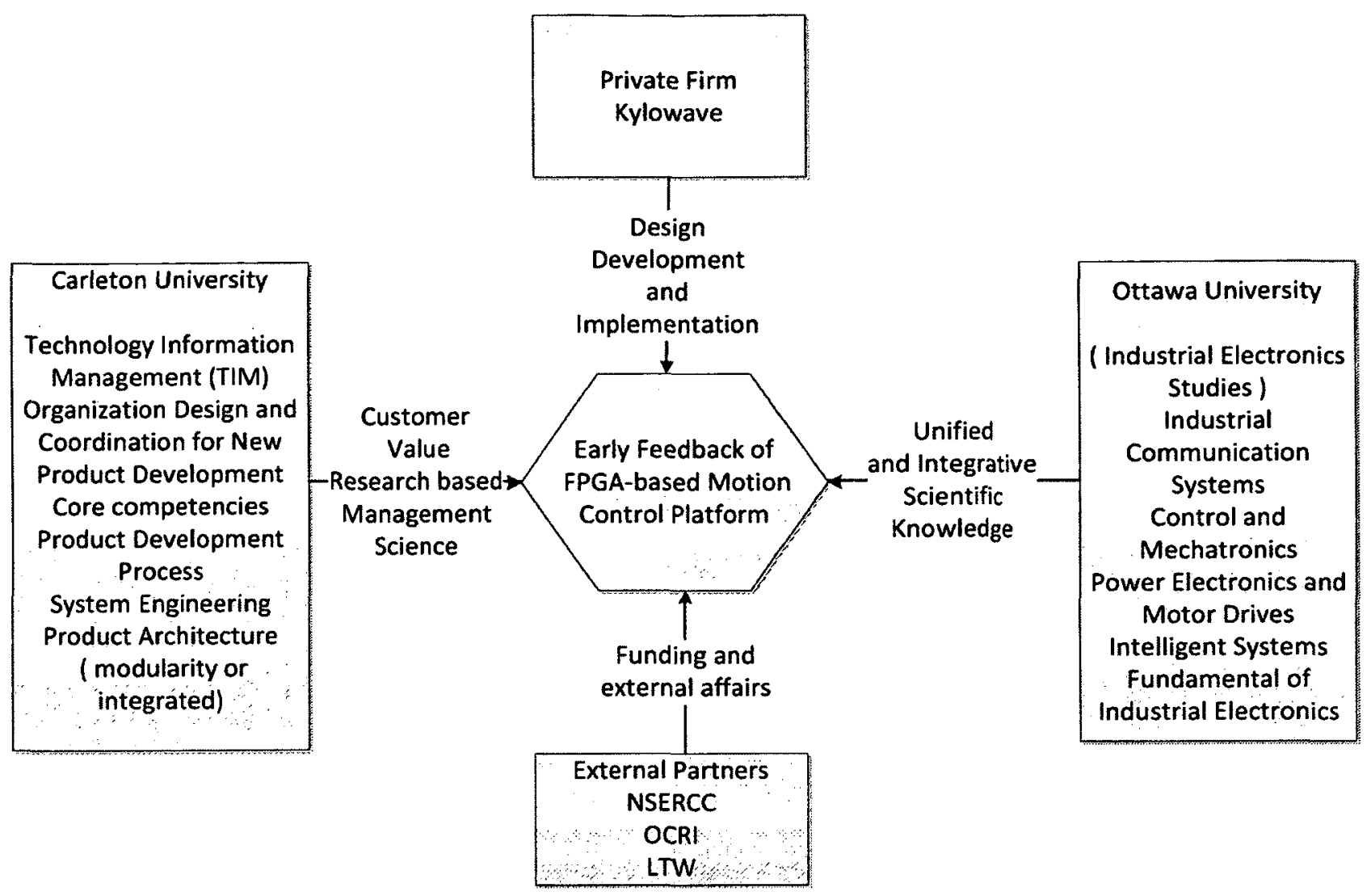

Figure 3: Early feedback of FPGA-based motion control platform

\subsection{Unit of Analysis}

It is the aim in this research to study the effect of early feedback on the performance of NPD using Programmable Logic Devices and specifically the case of FPGA-based motion control as our unit of observation. However, the performance metrics, such as cost, time-to-market, exploration and complexity, we want to explore, describe and explain, guide our choice of unit of analysis to the following three scenarios that will be developed later.

- An BLDC NPD based on a Stelaris microcontroller.

- A Xilinx based microcontroller core that implements the basic functionalities of an BLDC motor control. 
- A Xilinx based microcontroller that implements an equivalent BLDC motor control with flexible and complex functionalities that use third party library.

\subsection{Study Period}

Considering our unit of observation the programmable logic device FPGA, and our unit of analysis the three scenarios, during the time period from 2010 to 2012 and our interest in early feedback for flexible FPGA-based platform, our study period was concerned with:

- A review of the literature related to NPD, feedback and FPGA technology

- An exploration of the tools in table 1 that foster feedback. These tools are necessary to researchers for a better understanding in how and why an FPGA-based platform is a determinant factor in a flexible NDP that accelerates time-to-market, lowers cost and facilitates experimentations early and often even when customer problem is complex.

During this research period, we have conducted multiple experiments that lead to a versatile flexible prototype to launch a start-up business with an NPD FPGA-based platform customized for motor control applications. This platform can also be used in an academic environment to teach the following academic subjects in an integrated platform environment: digital electronic design, analog electronic design, microcontroller and microprocessor architecture, system design, programming, electrical machines, mechatronics, power electronic, control and system simulation. 


\begin{tabular}{|c|c|c|c|c|}
\hline Feedback tools & $\begin{array}{l}\text { Category \& } \\
\text { Time }\end{array}$ & $\begin{array}{ll}\text { Summary of } \\
\text { feedback }\end{array}$ & $\begin{array}{l}\text { Format of solicited } \\
\text { feedback }\end{array}$ & $\begin{array}{l}\text { Format of } \\
\text { feedback response }\end{array}$ \\
\hline $\begin{array}{l}\text { Matlab, } \\
\text { Simulink and } \\
\text { SimPower } \\
\text { Systems }\end{array}$ & $\begin{array}{l}\text { Modeling \& } \\
\text { Simulation } \\
\text { R2009b }\end{array}$ & $\begin{array}{l}\text { High Level } \\
\text { Language for } \\
\text { Technical } \\
\text { Computing }\end{array}$ & $\begin{array}{l}\text { Enter models, } \\
\text { program or circuits }\end{array}$ & $\begin{array}{l}\text { Visualize system } \\
\text { response outputs in } \\
\text { graphics }\end{array}$ \\
\hline ISE 10.1 & $\begin{array}{l}\text { Hardware } \\
\text { design tools }\end{array}$ & $\begin{array}{l}\text { Support digital } \\
\text { Xilinx } \\
\text { hardware } \\
\text { development }\end{array}$ & $\begin{array}{l}\text { Provide } \\
\text { schematics, } \\
\text { bench }\end{array}$ & $\begin{array}{l}\text { Synthesize, } \\
\text { implement, verify, } \\
\text { simulate, program }\end{array}$ \\
\hline $\begin{array}{l}\text { Xilinx } \quad \text { SDK } \\
10.1\end{array}$ & $\begin{array}{l}\text { Software } \\
\text { design tools }\end{array}$ & $\begin{array}{l}\text { Support Xilinx } \\
\text { software } \\
\text { development }\end{array}$ & $\begin{array}{l}\text { Provide the } \\
\text { hardware }\end{array}$ & $\begin{array}{l}\text { Generate driver in } \mathrm{C} \\
\text { for Xilinx hardware } \\
\text { IP }\end{array}$ \\
\hline XPS 10.1 & $\begin{array}{l}\text { Codesign } \\
\text { hardware and } \\
\text { software tools }\end{array}$ & $\begin{array}{l}\text { Support } \\
\text { Embedded } \\
\text { codesign for } \\
\text { Xilinx FPGAs }\end{array}$ & $\begin{array}{l}\text { User provide Xilinx, } \\
\text { custom or third party } \\
\text { IPs }\end{array}$ & $\begin{array}{l}\text { Get a user interface } \\
\text { to design high level } \\
\text { hardware and } \\
\text { software }\end{array}$ \\
\hline $\begin{array}{l}\text { Keil uVision4 } \\
\text { Tools }\end{array}$ & $\begin{array}{l}\text { Software } \\
\text { tools }\end{array}$ & $\begin{array}{l}\text { Support ARM } \\
\text { embedded } \\
\text { software }\end{array}$ & $\begin{array}{l}\text { Provide } \\
\text { programming files }\end{array}$ & $\begin{array}{l}\text { Use only for search } \\
\text { feedback } \\
\text { information in this } \\
\text { case }\end{array}$ \\
\hline $\begin{array}{l}\text { Universal } \\
\text { Frequency }\end{array}$ & $\begin{array}{l}\text { BK Precision } \\
1823 \mathrm{~A}\end{array}$ & $\begin{array}{l}\text { Measure } \\
\text { Frequency and }\end{array}$ & $\begin{array}{l}\text { Input a signal to the } \\
\text { frequency meter }\end{array}$ & $\begin{array}{l}\text { Get a readable digit } \\
\text { display of the }\end{array}$ \\
\hline
\end{tabular}




\begin{tabular}{|c|c|c|c|c|}
\hline Meter & $\begin{array}{l}2.4 \mathrm{GHz} \\
\text { measurements } \\
\text { tools }\end{array}$ & $\overline{R P M}$ & & frequency \\
\hline $\begin{array}{l}4 \frac{1}{2} \text { Digit True } \\
\text { RMS Digital } \\
\text { Multimeter }\end{array}$ & $\begin{array}{l}\text { BK Precision } \\
\text { 2831D } \\
\text { measurements } \\
\text { tools }\end{array}$ & $\begin{array}{l}\text { Measure } \\
\text { resistor, } \\
\text { voltage, } \\
\text { current and } \\
\text { continuity }\end{array}$ & $\begin{array}{l}\text { Connected the leads } \\
\text { of the instrument to } \\
\text { resistor, voltage, } \\
\text { current, diode }\end{array}$ & $\begin{array}{l}\text { Get a readable } \\
\text { display of the value } \\
\text { of the resistor, } \\
\text { voltage, current and } \\
\text { diode }\end{array}$ \\
\hline $\begin{array}{l}\text { DC Regulated } \\
\text { Power Supply }\end{array}$ & $\begin{array}{l}\text { BK Precision } \\
\text { 1670A }\end{array}$ & $\begin{array}{l}\text { Provide } \\
\text { voltage supply }\end{array}$ & $\begin{array}{l}\text { Enter the desired } \\
\text { supply voltage }\end{array}$ & $\begin{array}{l}\text { readable display of } \\
\text { supply voltage }\end{array}$ \\
\hline $\begin{array}{l}\text { Digital } \\
\text { Oscilloscope }\end{array}$ & $\begin{array}{l}\text { Tektronix } \\
\text { TPS 2024 } \\
200 \mathrm{MHz} \\
2 \mathrm{GS} / \mathrm{s}\end{array}$ & $\begin{array}{l}\text { Measure } \\
\text { waveforms }\end{array}$ & $\begin{array}{l}\text { Input waveforms to } \\
\text { oscilloscope }\end{array}$ & $\begin{array}{l}\text { Acquire, scale and } \\
\text { measure waveforms }\end{array}$ \\
\hline RDK-BLDC & Motor control & $\begin{array}{l}\text { LM3S8971 } \\
\text { microcontroller }\end{array}$ & $\begin{array}{l}\text { Receive Hall sensors } \\
\text { information }\end{array}$ & $\begin{array}{l}\text { Provide motor } \\
\text { phase voltage }\end{array}$ \\
\hline $\begin{array}{l}\text { XUP VirtexII } \\
\text { Pro }\end{array}$ & Motor conrol & $\begin{array}{l}\text { VirtexII FPGA } \\
\text { conroller }\end{array}$ & $\begin{array}{l}\text { Receive Hall sensors } \\
\text { information }\end{array}$ & $\begin{array}{l}\text { Provide motor } \\
\text { phase voltage }\end{array}$ \\
\hline
\end{tabular}

Table 1: Codesign hardware and software feedback tools

\subsection{Method}

Close to our unit of analysis and our understanding of early feedback, the following four steps method is used in this investigation. 
1) Select scenarios and variables

a. Review the management literature to identify success factors related to feedback in NPD.

b. Relate these factors to FPGA-based NPD.

2) Develop prototype

a. Acquire and modify a commercial microcontroller-based motor control to make it flexible to be controlled either by a microcontroller or an FPGA.

b. Used various tools (simulation, hardware and software design analysis and implementation) in our laboratory to collect performance data indicated in the literature.

3) Evaluate prototype by conducting tests in two stages

a. Use the previous modified prototype to do tests that allow us to compare the commercial product with our scenarios.

b. Build and test new prototype with more flexible functionalities.

4) Create a table comparing the scenarios along the variable referred in step one.

The data were collected through matlab simulation and various codesign tools highlight in table 1 and a prototype real-time output. They are concentrated on the comparison between a commercial microcontroller-based motor control and an FPGA-based NPD. We use these data to analyse three scenarios. The Xilinx development tools ISE and XPS were used because these tools contain hundreds of cores freely available to Xilinx customers. Those cores are flexible hardware and software libraries that allow one to implement and customize modular subsystems of a microcontroller. This is a multibillion dollars industry for an entrant in search of a technology to support a creative customer value proposition for feedback, flexibility, time-to- 
market, costs, quality, exploration and low complexity. The attribute values that we assign to these variables are indicated in the following table 2, variables and attributes:

\begin{tabular}{|l|l|}
\hline Variables & Attributes \\
\hline Feedback & Early - Late \\
\hline Flexibility & Low - Medium - High - Very High \\
\hline Time-to-market & Early - Late \\
\hline Costs & Cheap - affordable - Expensive - Very \\
& Expensive \\
\hline Quality & Low - Medium - High - Very High \\
\hline Exploration & Close - semi-close - semi-open - open \\
\hline Complexity & Low - Medium - High - Very High \\
\hline
\end{tabular}

Table 2: Variables and attributes

The next table, variables quantifying approach, highlights a synopsis of epistemological position and methods that guide our scientific and management philosophy endeavour to assign a value to each variable in the preceding table. As shown, sometimes we use more than one approach to assign a value to a variable.

\begin{tabular}{|l|l|l|}
\hline Variables & Epistemology / Approaches & Methods \\
\hline Time to market, & Rational choice / Qualitative & Competitors Observation, \\
feedback & & Simulation \\
\hline Quality, Complexity, & Realism / Qualitative & Market observation \\
\hline
\end{tabular}




\begin{tabular}{|l|l|l|}
\hline flexibility, feedback & & Intuition / Experience \\
\hline Performances, & Positivism /Quantitative & Experiments, Mathematical \\
flexibility & & modeling, Simulation, \\
& & $\begin{array}{l}\text { graphics analysis, } \\
\text { Prototyping }\end{array}$ \\
\hline
\end{tabular}

Table 3: Variables quantifying and qualifying approach 


\section{Experiments}

Information-based technologies have shown evidence to be a disruptive innovation (Christensen, 2004) in various socio-politico-economic activities for instance in "Online feedback mechanisms" to "intensify the interdependencies between organizations, their customers, their partners, and their competitors (Dellarocas, 2003). We have used them through Xilinx development tools ISE, EDK which contains XPS and SDK, and Matlab for modeling and simulation tools. These tools make it easier to "Experimenting early and often (Thomke, 2003)" and build very early in a NPD, "hardware-software codesign as a central strategy in achieving more hardware development (Shalf, Dan, Curtis, 2011)".

These experiments provide early data from which team members can infer the technical resource capabilities of the company to deliver the product. These insights can be exploited to "anticipate customer needs, get into the customer experience (Smith, 2007)" and reconcile them with the company resource capabilities to design an adaptive feedback that can suggest a possible solution to engage with the customers and partners in refining their requirements for a flexible NPD. This is an iterative process that can accelerate development time and foster innovation when coordination factors are endogenous. We can have the same benefits when coordination factors are exogenous, however in this particular case we need to be vigilant to not overload our capacity. In an exogenous market context, a strategy of shifting the locus of experimentation is in order for conquering market segments with applications specific toolkits that stimulate customer innovation through learning and experimentation that put in action customer's core skills in using our useful libraries that help them experiment early and often (Thomke, 2003). In the following sections of this chapter we apply Thomke's shifting experimentation model in figure 5 to describe the three scenarios and prototype that clarify and quantify our claims. 


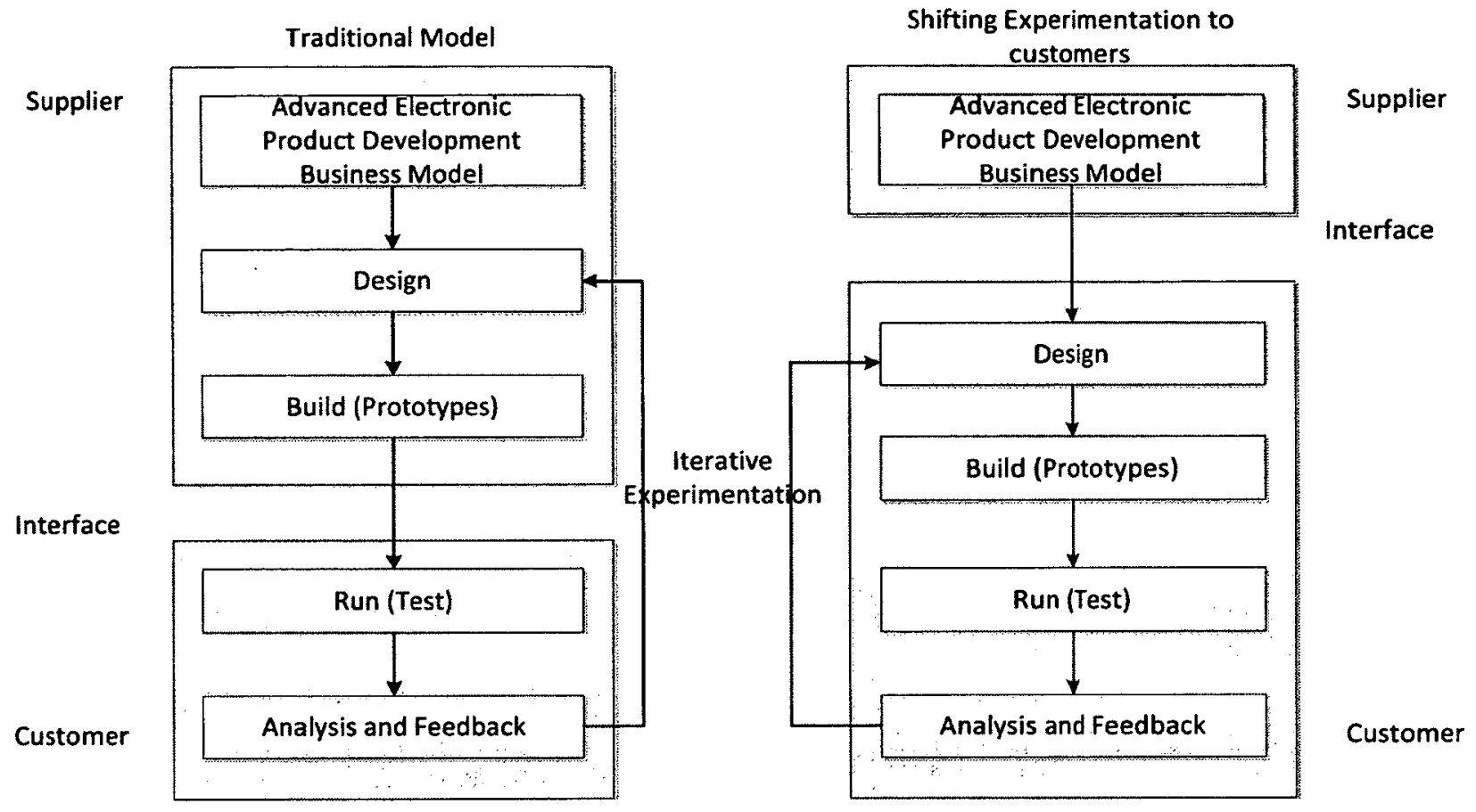

Figure 4: Shifting Experimentation Business Model for Product Development

\subsection{Scenarios}

The three scenarios in figure 5 accentuate an obvious technical test strategy to conduct our research. It is worthwhile to stress that these scenarios must be understood much more broadly than their apparent meaning suggests. They show the flexibility of our NPD process, consisting of embedding knowledge in FPGA technology and used it as an integrated platform either as digital controller for data path control where speed is critical or as a microcontroller if complex data manipulation process is more important. They are also an example of a technology strategy (De Meyer and Loch, 2008) that aligns our technical functions in developing an FPGA-based motion control and our resource-based value (Rumelt (19984), Wernerfelt (1984) and Barney $(1986,1991))$ to succeed in this new market. The microcontroller development kit that we use is "RDK BLDC" from Texas Instruments. The following characteristics of the Xilinx FPGA development environment have enabled us to carry the experiments for the scenarios. 
The FPGA is highly configurable thus we exploit this flexibility to design the modular components of the microcontroller which enables us to experiment with it as if it were a microcontroller.

The information-based experimentation technologies such as ISE and EDK from Xilinx are very advanced and they constitute solid foundation for developing FPGA-based system on chip (SOC). They enable us to leverage various hardware and software communities such as ARM, Microblaze and GNU software. They allow us to simulate the exact controllers, peripherals and functions needed for the motion control application with already available applications framework skeleton.

The above characteristics were possible with the use of affordable development kit tools sold by Xilinx and its partners. We use the University Program Development board "XUP Virtex-II Pro Development System". 


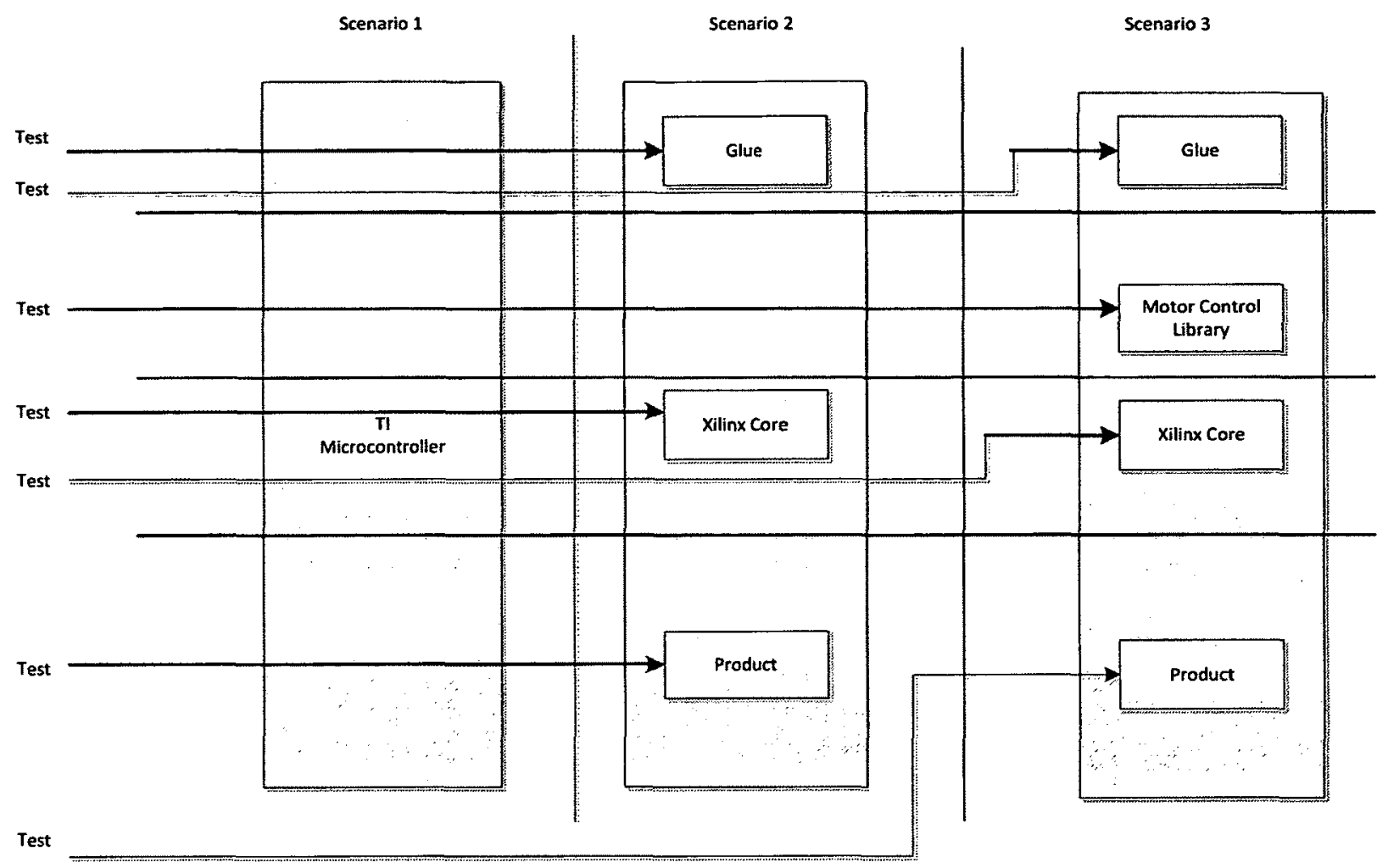

Figure $5:$ Scenarios

\subsubsection{Scenario A}

The objective in this section is to examine the architecture of the microcontroller-based motor control system in a way that qualifies and quantifies the feedback a system engineer can get from the use of these devices. In that sense, scenario A is one case of our unit of analysis in which the microcontroller-based RDK BLDC motor development kit from TI is used to gain first hand understanding regarding a BLDC motor control. This approach consists in conducting research in a controlled environment to experiment with dependent and independent variables to get feedback about the whole system we are working with. The controlled environment here is the microcontroller for which its architecture and its internal peripheral components that are already built by a manufacture for a family of applications are presented in figure 6 . In the actual case it is the Stellaris family of microcontroller from Texas Instruments. 


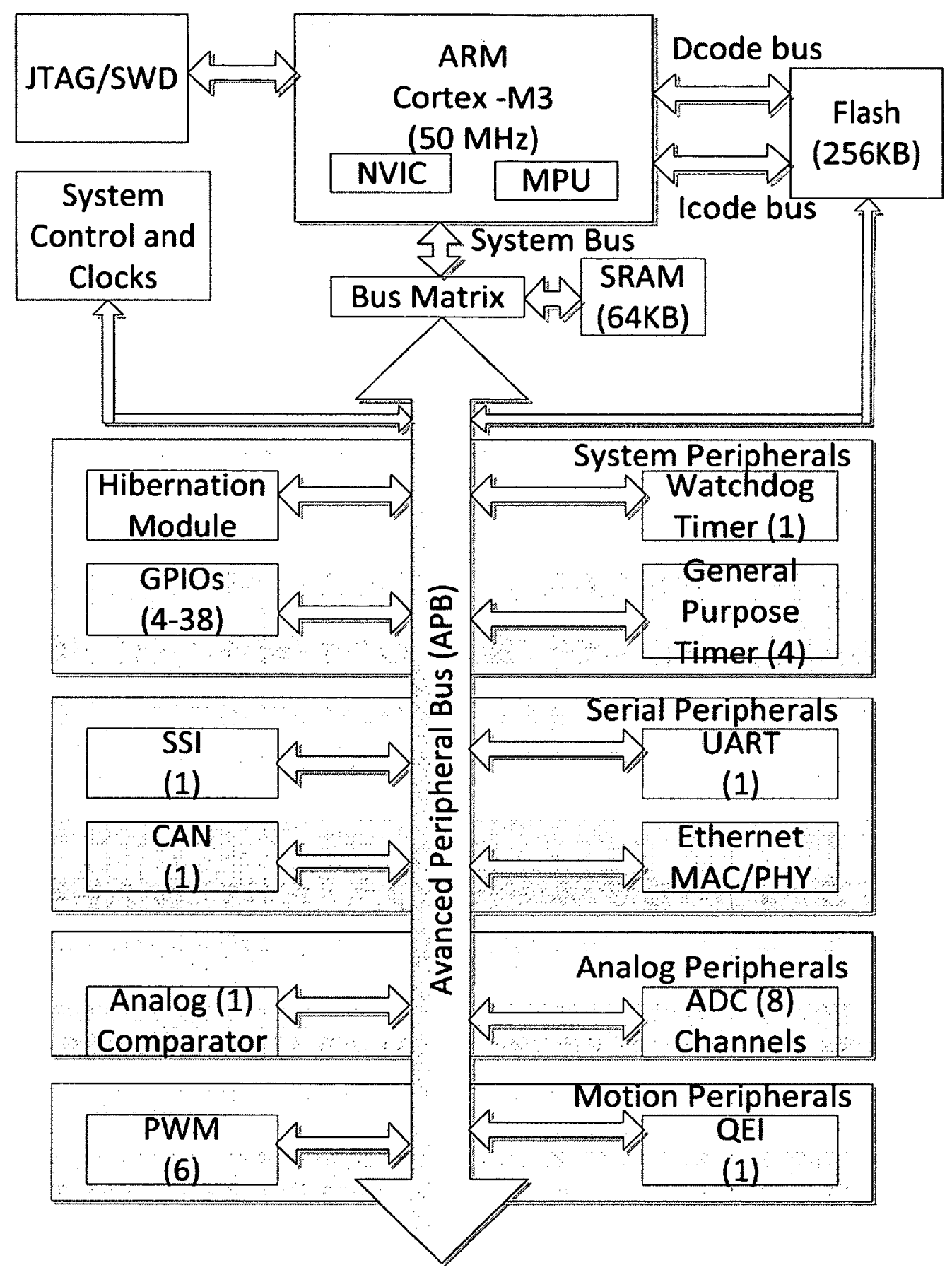

Figure 6: Stellaris Microcontroller architecture

(from Stellaris LM3S8971 datasheet) 
The characteristics features highlighted in the TI Stellaris family microcontroller are far from specific to this microcontroller. They are standard components of a computer or intelligent system which includes processor, memory and input, output. We call this platform kit controlled environment only because its hardware was prebuilt by a third party which is Texas Instruments in this case. The user can concentrate on the control algorithm and software development for the specific motor application. In the beginning of an embedded system codesign such dedicated architecture and pre-built peripherals have great value for manager, technical team and customer because of its quick feedback response. However, as we progress in the design their controlled core value can become very quickly their core rigidity if the project becomes volatile as a result of emerging customer's needs. In uncertain project environments these devices become limited for feedback, flexibility and scalability because we can only use them as prescribed in their datasheet specifications which can't have provisions to solve all specific issues we can encounter in an ex-post design. They may offer more than we need, but it is not always that more is better. For instance, this microcontroller supports four types of peripherals for serial communication, we could use only the UART but some resources were rigidly allocated to the Ethernet support. Referring to the comparison between traditional advanced electronic product development feedback and shifting the locus of experimentation in Figure 4 Business Model, scenario A belongs to the traditional typology in which the microcontroller hardware represents the unit for which the supplier leads with advanced development, design and building prototypes. The customers develop software to run and test their application and eventually use a feedback link with the supplier if the analysis of test results fails.

In the experiments we want to use metrics that are important in motor control no matter what scenario is in use, for that matter we support the observations of (Toliyat, Abolhassani, Niazi, 
Hao, 2001) "High-performance motor drives are characterized by the need for smooth rotation down to stall, full control of torque at stall, and fast accelerations and decelerations.". Thus in scenario A, we use the TI BLDC-GUI to send command, through the Ethernet port, to the microcontroller-based motor controller in what we call "TI mode" to control its speed, torque and analyse its dynamic behaviour to get information regarding its acceleration and deceleration.

\subsubsection{Scenario B}

The motor controller is an intelligent control electronic system and as such it requires a processor for its computing power. However, in this scenario instead of using a dedicated prebuilt hardware microcontroller or DSP; we opt for a soft core microcontroller, Microblaze from Xilinx. As it was in scenario A, the choice of a microcontroller for an embedded design is a decision trade-off that takes in account many factors and among them are: performance, cost, flexibility and obsolescence. For instance, an emergent way to mitigate obsolescence and preserve legacy products "is to own a soft core processor and embed it in an FPGA fabric (Parnel, Bryner, 2004)". In this scenario B, we take advantage of the software infrastructure Xilinx offers to its customers using the microblaze microcontroller. At the same time the locus of experimentation is shifted to accommodate emerging customer needs because the hardware peripherals are no longer fixed as they were in scenario A. This current scenario facilitates a bottom-up design process where an engineer can start with an idea and test various design options with what currently available in an experimentation technology tools. For instance as shown in Figure 7 we have used the Xilinx libraries to do two tasks:

First, we replicate a minimum and testable computing environment of the Stellaris microcontroller in scenario A with equivalent components in Scenario B for Xilinx without our motor control libraries. For example, to the ARM processor we correspond Microblaze, we 
instantiate a serial port, timer and general purpose input and output analogous to the ones in scenario A, PLB, dlmb, ilmb bus and BRAM blocks stand for their counterpart APB, Dcode, Icode, SRAM and Flash.

Second, we developed some software tests that simulate some functionalities of the motor that we want to control; when we got some good enough and satisfied results we used these learning insights to move to scenarios $\mathrm{C}$ and build custom libraries dedicated to solve a specific anticipated customer problem.

The case in scenario A was flexible with respect to the software development in the beginning of a project. Scenario B presents a new perspective for codesign of hardware and software on the same chips. However, the beginning of such project may be a difficult task if we don't have the right tools and experimentation technologies for feedback. Same as before, here the architecture of the programmable logic device is a key enabler for flexibility and feedback. At this stage, we didn't develop much custom libraries yet; we generally used Xilinx libraries provided with the ISE and EDK. What changes in this set up is the fact that the FPGA allows a designer to implement the specific needed hardware for the specific application with a choice of a soft core microprocessor such as Microblaze.

As stated previously regarding important metrics for test design, it is the speed, torque that are the direct command from the controller to the motor. The speed was calculated based on the monitoring of the hall sensors and the torque was induced to the BLDC motor attaching its shaft to another DC motor's shaft. We used the serial port to send command to communicate with the controller. 


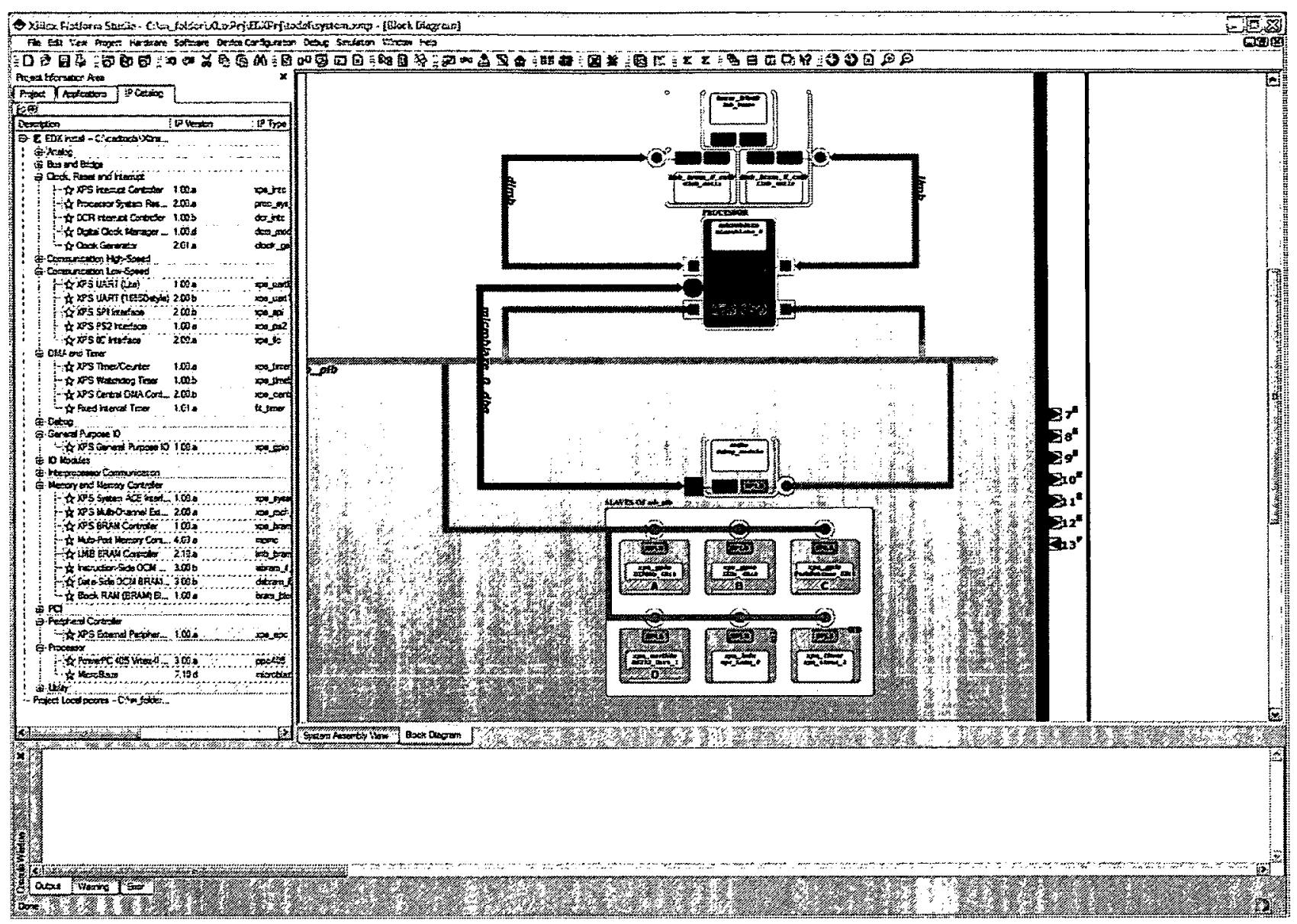

Figure 7: Microblaze Microcontroller architecture

\subsubsection{Scenario C}

This scenario is built on the bottom-up ground work of scenario B to facilitate a top-down design process where an engineer will get some requirements for a customer need and follow the topdown design process to augment what is available in an experimentation technology tools such as the following one in figure 8 . Here, the computing environment remains the same with Microblaze constituting the computing power. We don't show the Microblaze in the following figure because it keeps the same architecture as in scenario B. We show the PLB bus with the various libraries for motion control that we have developed under the IP catalog project information area. 


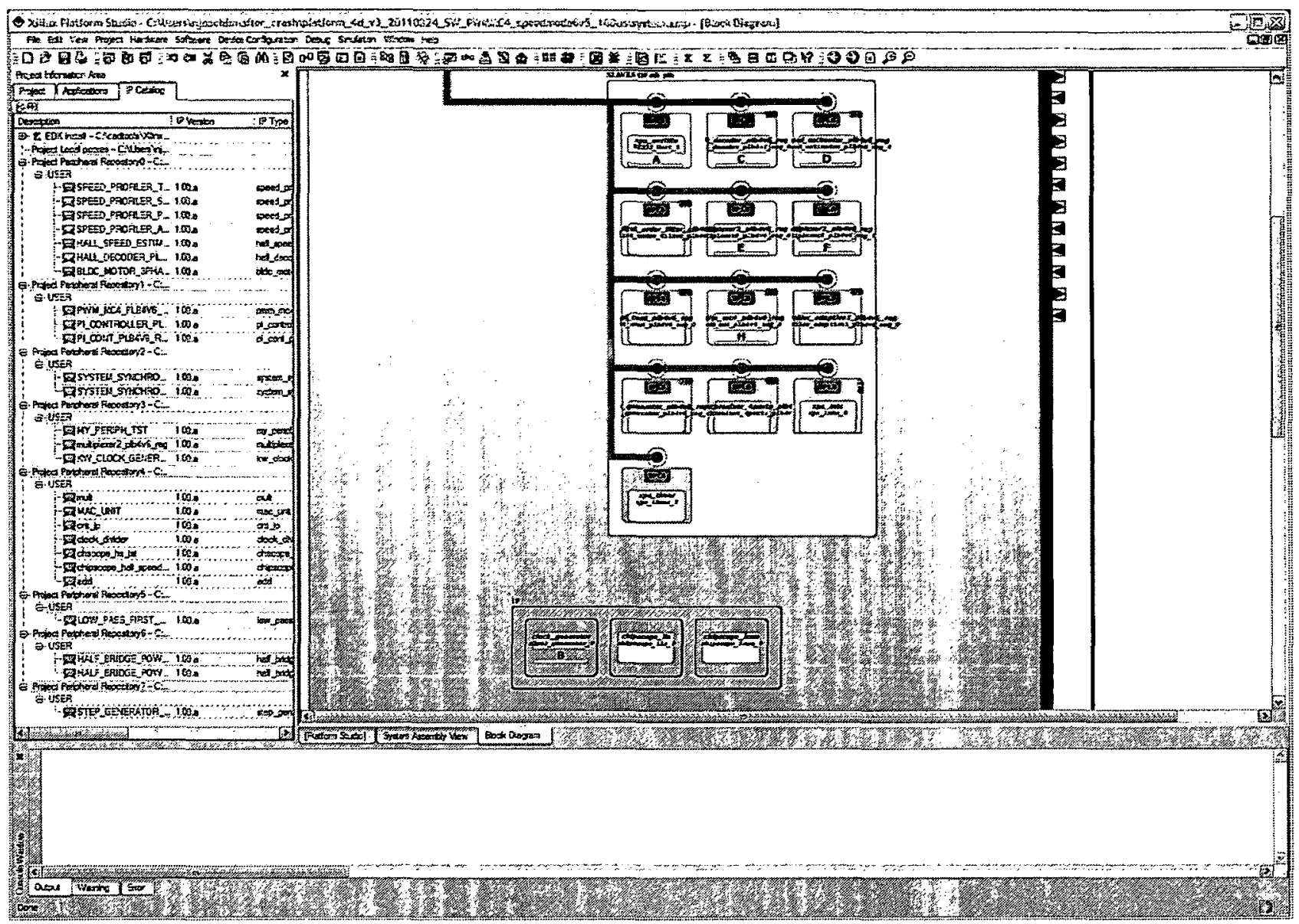

Figure 8 : Top-down design with augmenting libraries

The approach in scenario $C$ is a way to use a GUI Figure 9 to allow a system engineer to work at very high level to develop complex system FPGA-based platform. Thus our market offer for FPGA-based motion control will lower the time-to-market for our customers. Analogous to the findings of (Shalf, Quilan, Janssen, 2011) but in a smaller scale, than their giant capabilities of FPGA-accelerated hardware emulation platform, developing a motor controller with our development kit can be done in days instead of months of parallel development of hardware and software. In the following figure, we show an example of high level motor controller design. Assuming that the system engineer has a high level schematic of the needed motor controller, now each library component under IP Catalog can be seen as a chip. The system engineer needs 
to bring only the needed chips and connect the specific related pins as shown in the design window under Ports. For instance, Hall_io net is connected between chip hall_decoder_plb4v6_reg_0 and chip hall_speed_estimator_plb4v6_r.... The connections to get a specific behaviour are relinquished to the system engineer based on the system needs. This is exactly our understanding of applying Thomke's concept of shifting the locus of experimentation.

Here also for experiments, we develop an automatic mini-application to test the speed and torque as we did in scenario $\mathrm{A}$ and $\mathrm{B}$

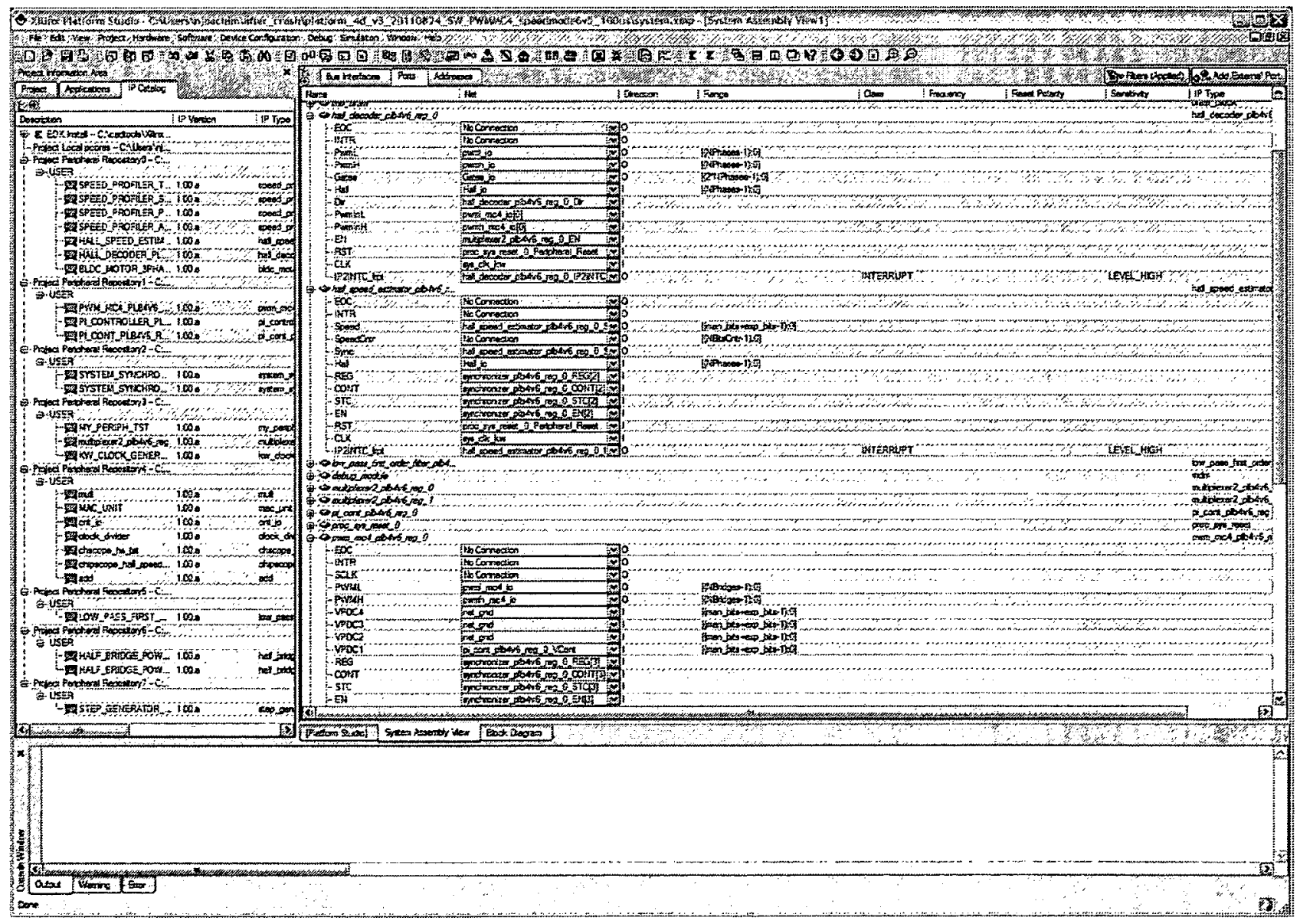

Figure 9: GUI and assembly view for high level motion control system design 


\subsection{Prototype}

In this section we will describe the technical processes and setup that help producing the results which in turn allow the measurements of the performance of the prototype system that we have modified and used to carry the research and compare our market offer with the commercial reference board. The scientific and technological advancement in motor design, high power electronic control and research and development in hardware-software codesign for complex mixed analog-digital signal processing have paved the road for designing high performance electromechanical systems for flexible applications platform to control applications such as wind turbine, robotic and mechatronics. Figure 10 depicts a general block diagram that illustrates a very high level of the hardware-sotfware codesign of such platform describing our prototype. It contains a power source that can be for instance a DC or AC power supply or a renewable energy source from solar or wind energy source, a DC-AC power converter, a BLDC motor, the process itself that can be any scenario related to wind turbine, robotic control and mechatronics and an FPGA-based controller platform which bears all the intelligence of the system such as Proportional Integral Controller (PI), Pulse Width Modulator (PWM) and data manipulation and signal processing. 


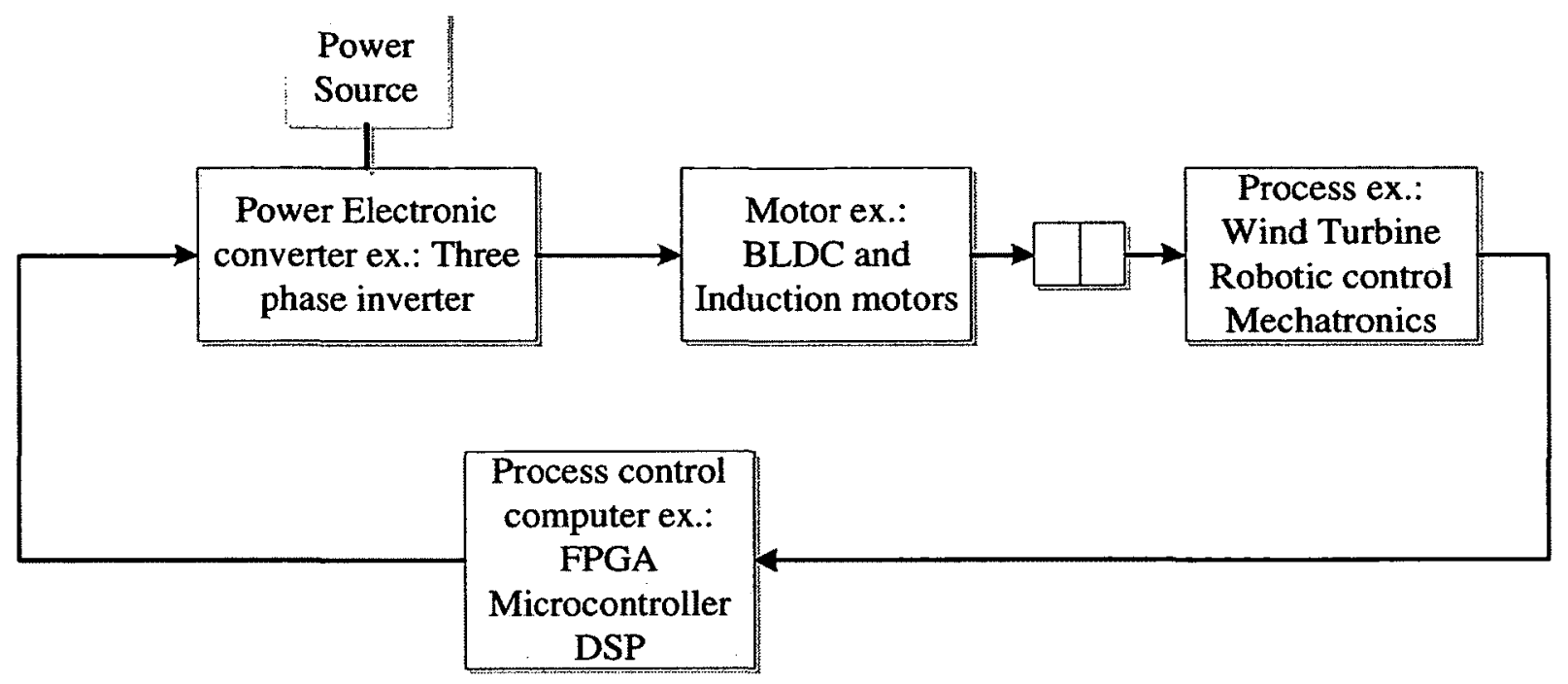

Figure 10: Automatic Control of motor drivers for flexible scenarios of process control

The value proposition with this prototype is to bring a hardware-software codesign platform to commercial and academic customers where the performance and value of this offer lie around the following parameters: flexible high performance product that encourages feedback and accelerates the development time and time-to-market for customers, reduce the development costs and design complexity, allowing users to explore many design scenarios that can contribute to the quality of their end product. Thus, in an analogy to the mission needs evoking by (Shalf, Quilan, Janssen, 2011) our value to the customers is a prototype that combines the following three elements:

- Highly configurable, cycle accurate simulation of node architecture from our motion control or third party libraries in a Xilinx Platform Studio XPS and Chipscope environment

- Novel automatic extraction and high performance motor drive interconnect traces using the Embedded Development Kit (EDK) platform from Xilinx 
- Scalable simulation of massive interconnection networks using tools such as Simpower system and Simulink in matlab, LabVIEW in National Instruments and the EDK, SDK in the Xilinx XPS platform environment.

\section{Motor Technology}

Electric Motors are widely used in many aspects of life such as consumers, industrial, medical, environmental, transportation, and military. Researchers from various sciences and engineering disciplines have paid attention and devoted countless research studies to these machines. Progress in electric motor technology is now stimulated (Gieras \& Piech, 2000) by material engineering, power electronics and control and robotics, computer sciences and genetic algorithm, electric cars and aerospace and energy saving technology. This overlapping technical value networks for these machines procure to them some complementarities that make them useful in so many industries. There are many types of motors as presented in the classification of electric motors in figure 11 (Hanselman, 1994), but the two main categories are direct current (DC) motors and alternating current (AC) motors (Palm III, 2010). In the present study we are interested in controlling permanent magnet alternating current (PMAC) motors. This category of motors is divided in two types (Toliyat, Cambell 2004), the first one is PM synchronous motor (PMSM) which produces a sinusoidal back emf (electromotive force) it should be supplied with sinusoidal current. The second type which is called BLDC (Brushless DC) motor, it produces a trapezoidal back emf and requires a quasi-rectangular shape current every electrical 120 degrees turn. This last category of motors plays an important role in mechatronics and robotic control thanks to its high reliability, high efficiency, brushless means less maintenance and reduced environmental footprints. We will compare the automatic control results of such devices by using 
our FPGA-based prototype system with the use of a commercial microcontroller-based namely TI BLDC kit.

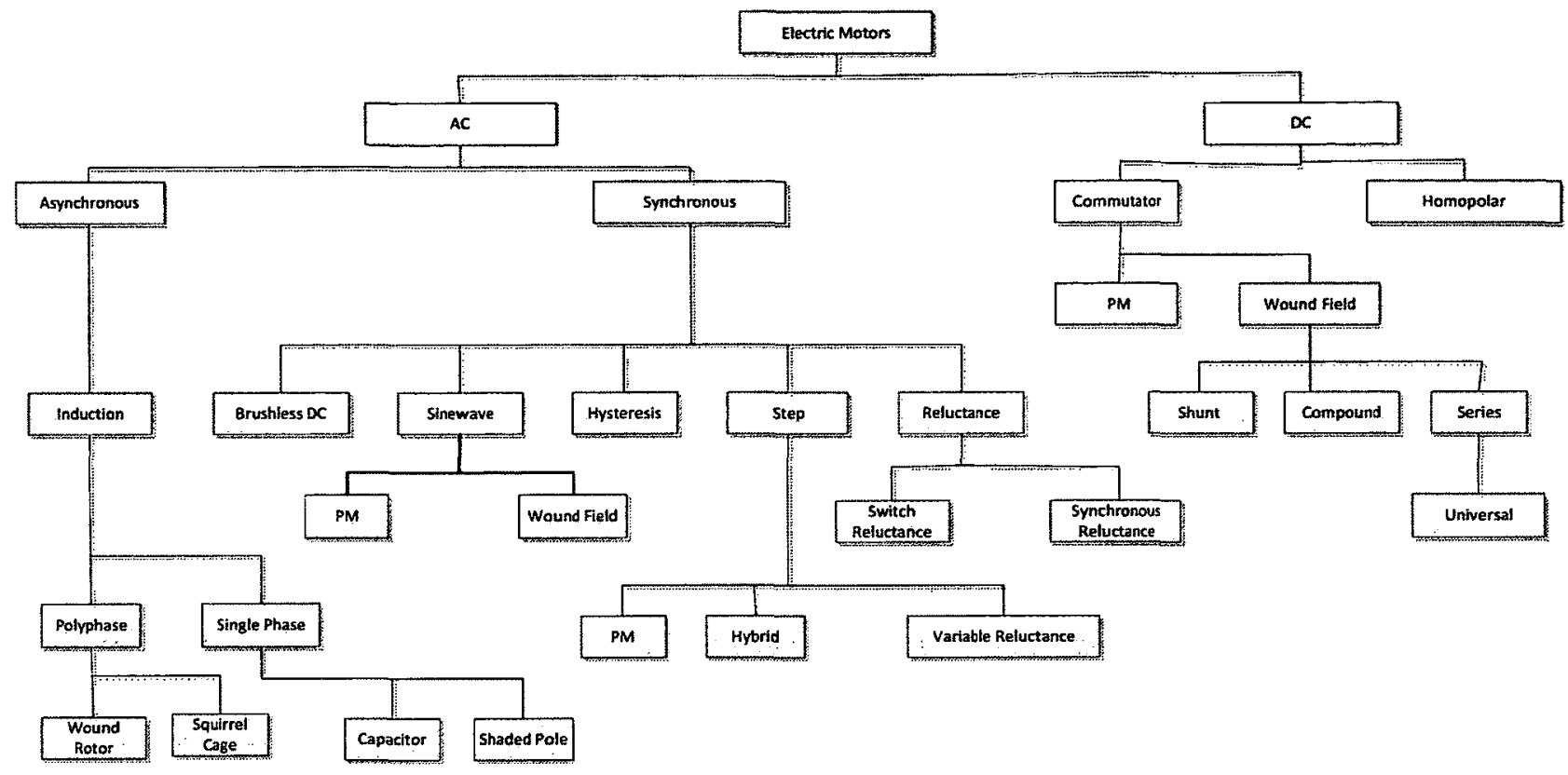

Figure 11 : Classification of electric motor

\section{Brief and selected history of control and motors}

In all human activities we look for sciences to understand and control our immediate and even visionary environments based on general, unified and indiscriminate laws of physics and nature. It is important to underline here that history, social sciences and philosophy are also essential body of knowledge that keep a record of the past from which we can learn and helps us reflecting on the current state of our evolution and its perfectibility. The lessons learned help raising awareness, correcting historical mistake, improving historical inherited success and widening our thinking on testing evidence of business value proposition that is the greater good product for a firm. Thus we can engineer today's solution with respect to our legacy and contribution to the success of future generation. The advance in control theory is outstanding especially in the 
second half of the $20^{\text {th }}$ century when we transitioned from classical control theory to modern control theory. However, we have learned from scientific historian that Automatic feedback control has fascinating history for more than 2000 years (Bennett, 1996). It is worth mentioning, this scientific field is influenced by and covered a wide body of knowledge among them biological, economic, political and engineering. In this perspective (Bennett, 1996) observes, "This diversity poses difficulties for historians of the subjects". Our historical perspective in annexe 3 is presented as a synoptic table filled with some selected chronological (Bennett, 1996; Dorf \& Bishop, 2011; Dukkipati, 2005; NASA) automatic control achievements close to our dual goals technic and economic.

\section{System Architecture}

We choose the system architecture in figure 12 similar to TI because it is a dominant concept in system architecture for motor control. The point of difference of the system depicted in figure 12 is knowledge-based embedded in the control electronic FPGA subsystem which provides the following capabilities implanted in a plurality of subsystems with frontier bridge through signals described in table 4 for a three phase motor control:

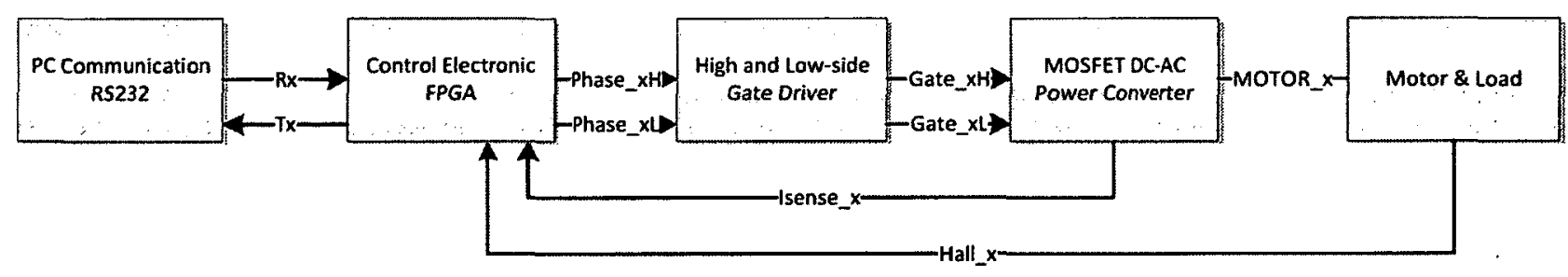

Figure $12:$ System architecture 


\begin{tabular}{|c|c|c|}
\hline Signals name & Module input/output & Function \\
\hline $\mathrm{Tx}$ & FPGA transmit port & RS232 interface \\
\hline $\mathrm{Rx}$ & FPGA receive port & RS232 interface \\
\hline Isense_x & FPGA input from converter & $\begin{array}{l}\text { Measured current, } \mathrm{x} \text { stands for } \\
\text { phase A, phase B, phase C }\end{array}$ \\
\hline Hall_x & FPGA input from motor & $\begin{array}{l}\text { Measured Speed and position, } \\
x \text { stands for } A, B \text {, and C }\end{array}$ \\
\hline Phase_xH & $\begin{array}{l}\text { FPGA output to high and low } \\
\text { gate side driver }\end{array}$ & $\begin{array}{l}\text { Input driver, } \mathrm{x} \text { stands for } \mathrm{A}, \mathrm{B} \text {, } \\
\mathrm{C} \text {, and } \mathrm{H} \text { for high }\end{array}$ \\
\hline Phase_xL & $\begin{array}{l}\text { FPGA output to high and low } \\
\text { gate side driver }\end{array}$ & $\begin{array}{l}\text { Input driver, } \mathrm{x} \text { stands for } \mathrm{A}, \mathrm{B}, \\
\mathrm{C} \text {, and } \mathrm{L} \text { for low }\end{array}$ \\
\hline Gate_xH & Gate driver output, & $\begin{array}{l}\text { turn on and off the top power } \\
\text { MOSFETs }\end{array}$ \\
\hline Gate_xL & Gate driver output, & $\begin{array}{l}\text { turn on and off the bottom } \\
\text { power MOSFETs }\end{array}$ \\
\hline Motor_x & Power converter output & $\begin{array}{l}\text { Power motor phase A, phase B } \\
\text { and phase C }\end{array}$ \\
\hline
\end{tabular}

Table 4 : Signals name

\section{Mathematical model and simulation}

The following argument for the mathematical model defined in annexe 9.5 is relevant based on two accounts: 
- Our deliverables that use three scenarios to expose the codesign tradeoffs between hardware and software, the relevance of simulation in complex control systems design and the integration of research and development in NPD sealed with a prototype stamp.

- The advance in science and technology has increased the complexity of analysis and design of modern control system. In this vein, William L. Brogan reports in (Dorf, 2006) there is a "naïve trial and error approach to design control systems" ... "This approach could be dangerous and uneconomical, if not impossible". In the case of the "Effect of Early feedback on New Product Development Performance", the arguments of the author steal the show in the current FPGA based motion control; because controllable and uncontrollable subcomponents of the motor driver make it almost impossible to predict the performance of the system without investing in experimentation technologies even in isolating context such scenarios A, B, C. We subscribe to another powerful proposition of William L. Brogan in (Dorf, 2006), “A more rational approach to control system design uses mathematical models" ..."A model is used to predict performance ... and answer various what-if questions in a safe and efficient manner". In this school of thought we have used the model as a common currency to explore and exploit the resources in scenarios $\mathrm{A}, \mathrm{B}$ and $\mathrm{C}$ for common market conditions which are: performance of processing computer unit, quality, feedback, flexibility, complexity, time to market based on experimentation knowledge gained from the modeling phase of the prototype system.

To fully relate the mapping of scenarios A, B, C in the current prototyping and modeling it becomes imperative to explore here the competing value of prototyping and modeling for modern complex control systems such as an FPGA-based motion control for instance. In general, control systems are interdisciplinary and the control strategy and algorithm are transparent to 
technology. In the present case, this transparency is applied to the three scenarios such, scenario one a TI microcontroller (Stellaris ARM microprocessor) environment, scenario two a Xilinx core microcontroller (microblaze without a motion control library) and scenario three a Xilinx core microcontroller (microblaze with a motion control library). Also, it is noteworthy to mention the technological progress, particularly in simulation tools for complex systems modeling, procures astonishing model fidelity to system architects. However, we should always be on guards when it comes to competing value of prototype and model. We should keep in mind that the high fidelity models help in what we called earlier feedback and common market conditions (flexibility, complexity, $\ldots$ answer to what-if questions). This fidelity, in often general and unified analysis, doesn't imply in any way or shape that we don't need prototype. It means

we have the flexibility to delay the prototype sometime late in the process. Also, it is not the prototype that has the burden to justify modeling results; to the contrary scientists, engineers and system architects should always thrive to load the complexity of the real world in a non-ideal model as close as the technology would allow it to be until we have the prototype. This is a sine qua non condition to justify and claim reliable process in achieving high fidelity models.

\section{Modeling Approach and Control Strategy}

We have mentioned earlier that the permanent magnet AC motor that we are using is a BLDC motor with trapezoidal back-EMF (electromotive force). The control strategy for the BLDC motor aims to maintain a constant motor torque by using a six-step current control algorithm Pulse Width Modulation (PWM) that turns on and off each of the motor drive phase leg in the annexe 9.5 in Figure 21 in a way that quasi-rectangular shaped currents are fed into the motor in synchronism with the constant part of back-EMF as shown in figure 22 in the annexe 9.5 (six steps current). This modeling approach of the BLDC motor drive is a simple one that fits our 
current needs. However, for a holistic review of modeling such systems we have found (Keyhani, 2011; Mohan, Undeland, Robins, 2003; Yazdani, Iravani, 2010 ) commendable.

In figure 21 and 22 in the annexe 9.5, it appears that two switches in one phase leg can't be turned on at the same time. Thus, in our BLDC motor drive controller only two phases are energized with drive current. The switching sequence of the energized two phases, in a mandatory effort to avoid overcurrent and system failure, as shown in annexe 9.5 are (T5, T6) $(\mathrm{T} 6, \mathrm{~T} 1)(\mathrm{T} 1, \mathrm{~T} 2)(\mathrm{T} 2, \mathrm{~T} 3)(\mathrm{T} 3, \mathrm{~T} 4)(\mathrm{T} 4, \mathrm{~T} 5)$. This sequence and switching states represent one example of modeling approach and control strategy. Now we can raise the competing value between scenarios A, B and C. If we need the flexibility of a configurable control strategy, scenario $\mathrm{C}$ will always win in the context of the prototype that we have built over the course of this study because a simple microcontroller would need considerable memory to manage the complexity price of configurability and parallelism required by some control algorithm and strategy. In resume, this modeling approach and control strategy have contributed in building the models in figure 18,19 and 20 in annexe 9.5 for the matlab model we have developed to show one modeling approach that we have used for experimentation and prototyping for scenarios comparison. It includes the PI controller and a speed profiler. 


\section{$5 \quad$ Results}

In order to carry the comparison between the microcontroller-based system, and the two Xilinx FPGA-based system platforms, we have led our research and simulations in directions that allow us to seek results in accordance to two intertwined goals:

- Management that contributes to reduce time-to-market, diminish cost, foster feedback and improve quality.

- Science and technology, even though there is an overlap between the previous results, here we emphasize on flexibility, exploration and complexity

These two, business and science and technology, interests pertaining to the range of decisions regarding organization structure, team composition, process and technological assets of a firm are in the heart of the process that shades light on the effect of early feedback on NPD performance. It is not surprising for anyone that scientists, engineers and their collaborators need to be at the forefront of technology to succeed in high performance computing collaborative projects like Research Accelerator for Multiple Processor (RAMP), (Shalf, Quilan, Janssen, 2011). To a lesser degree we can't work efficiently to develop the present FPGA-based motion control platform on a Xilinx Virtex-6 or 7 for example without investing in experimentation technology such as Xilinx Platform Studio (XPS) or equivalent ones. In contrast, what may come as a surprise in some business cycles is the human dimension in management that is associated with a firm's performance in terms of time-to-market, cost, feedback and quality. We have reached a point of no return where high performance computing machines are among the best tools to multiply and reap the benefice of science to tackle some problems that can challenge the future of our welfare and environment. However these machines need a bootstrap knowledge that will always be embodied in people. As (Boutellier, Grassman, von Zedtwitz, 2000) remind us, " 
... people have emotions. The management of these emotions is the key to unleash a cooperative effort in the development team". Joining the authors in this logic we can equate this cooperative to what they call "the stimulus or depressant to the performance of the team".

\section{Managerial and technical results context of the three scenarios}

Leading thinkers in NPD have dissenting opinions with respect to tasks coordination in NPD. Some schools of thought view these activities as sequential others as parallel or adaptive and so on. We retain the flexible development process of (MacCormack, Verganti, Iansiti, 2001). The sequential perspective of NPD is a prevailing management practice because once an industry has reached a dominant design point for a certain product generation a sequential approach can become a de facto competitive process by saving management from the chaos of early solution to moving targets that are evolving customer's needs. Normally, it takes many years of research and development to reach primarily the dominant design and furthermore the serialization of a product development process. In a case study of the firm Leica Microscopy (Boutellier, Grassman, von Zedtwitz, 2000) report it has taken the company over twenty years to build the upstream and downstream knowledge capabilities to navigate successfully a sequential management flow as depicted in the following figure. 


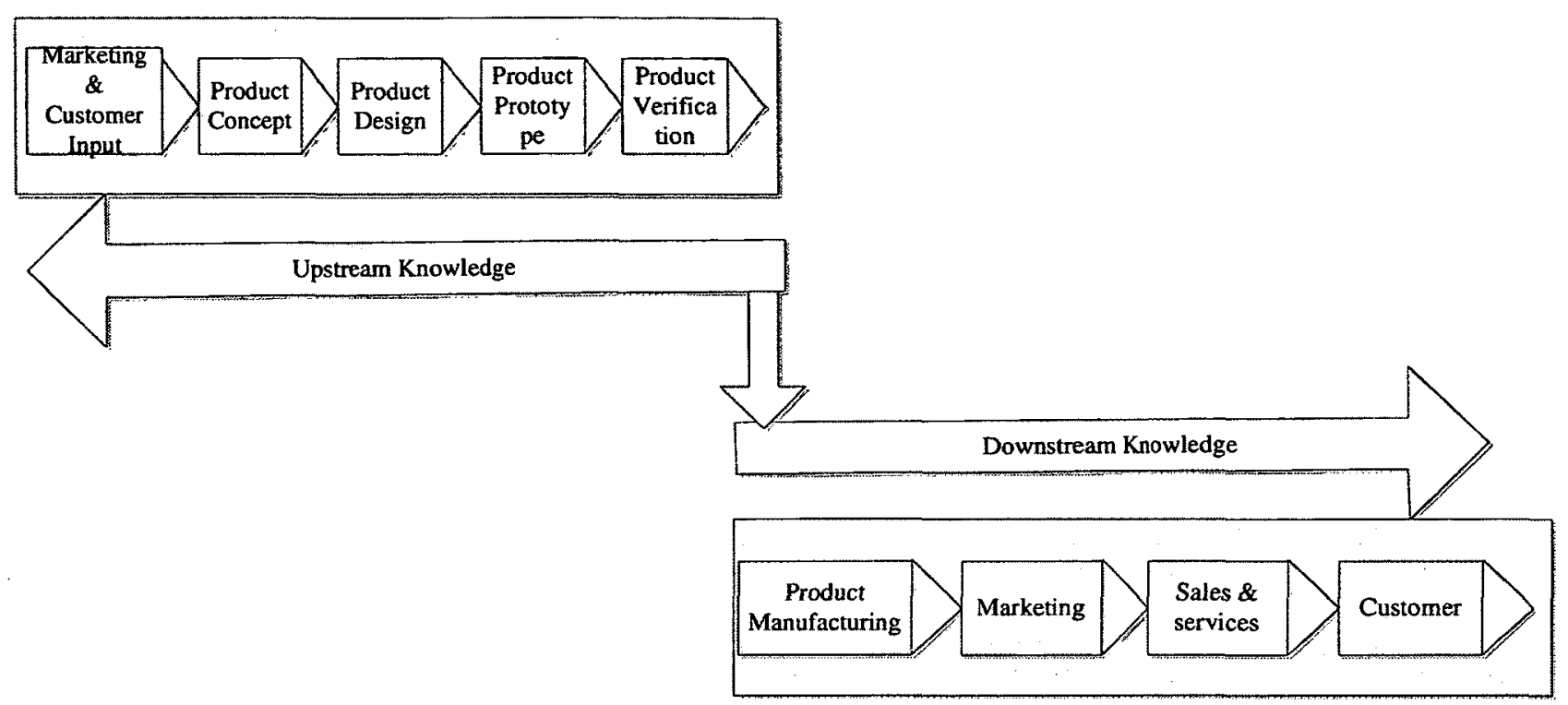

Figure 13 : Sequential Process

Overlooking the competence building between process stages make a sequential product development a dangerous process which we classify as, a handicapping management style in high technology, applicable in predictable business context where market, customers' needs and technologies are well known. Out of the previous ideal market field there will be no salvation for such management flair in a dynamic environment where customer requirements and technologies are emerging sometime from chaos and competitors are moving unpredictably to consolidate enviable market shares for which only high skills negotiation and innovation can save a product generation, sometime even a firm, from extinction. The handicap in a sequential NPD is felt when the upstream and downstream relationship is enforced rigorously. Then, at business unit level if a next in line stage has to wait for the previous one to carry on its critical business round as illustrated in the above figure this would have a domino effect to slow all other units in the chain and represent an invisible barrier for the other business units. 
Scholars have figured out some defects in a sequential NPD and a parallel alternative was proposed where all stages are autonomous as opposed to the previous heteronomous sequence. We use autonomous here as an intellectual construct where each stage has a self-determination over its business decision which implies a strict control on will of the input, output communication links with its neighbour. Heteronomous is a dependency relationship with an input neighbour where a stage needs the information from its input to produce an output that will be consumed by the next stage. This autonomous concept is built on previous contribution of (Krishnan, Eppinger, Whitney, 1997) where they suggest "accelerating a sequential process involves removing the coupling between the activities ..." as shown in the next figure.
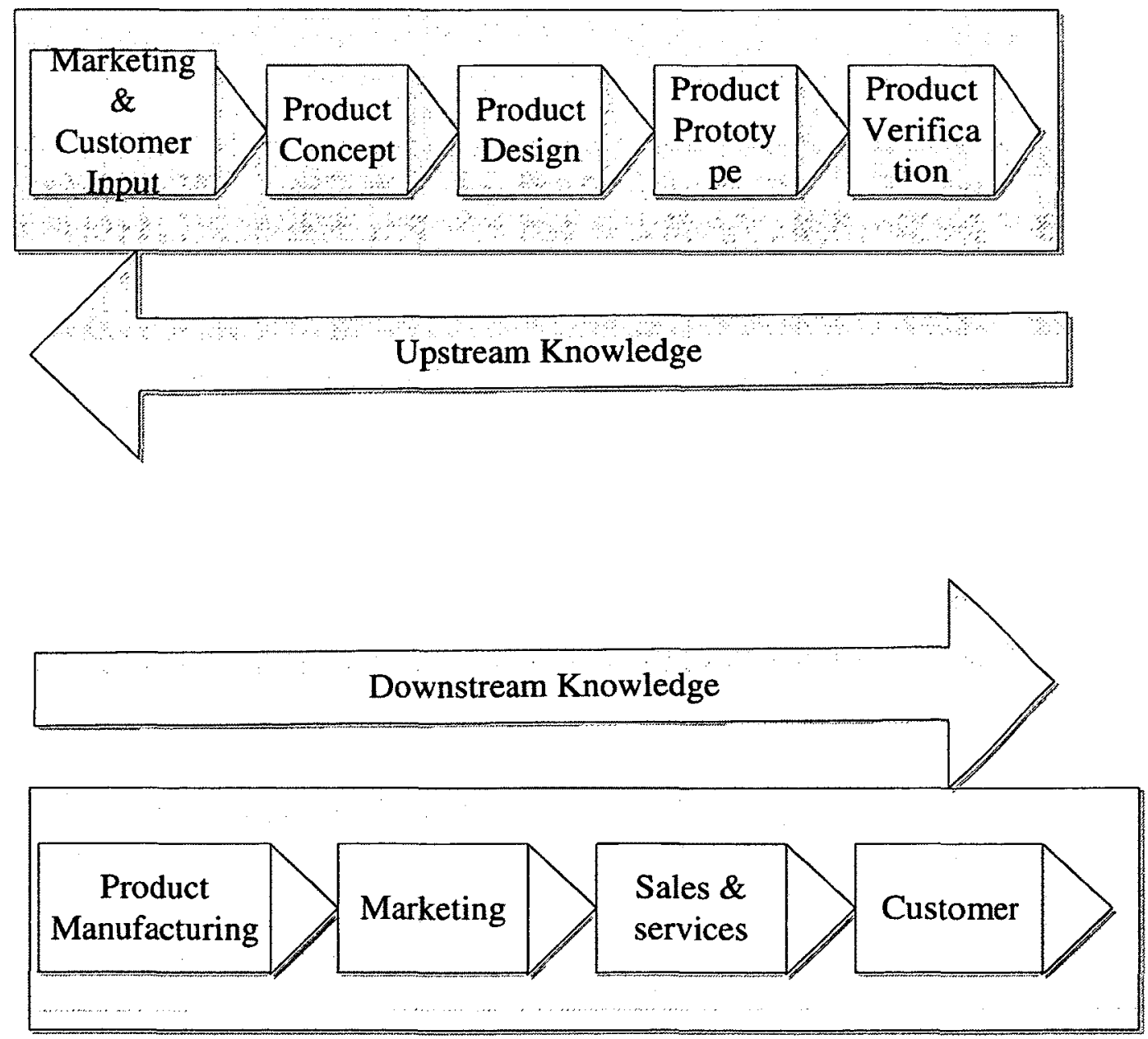
Figure 14 : Parallel Process

However such approach is like borrow acceleration time on credit to run a business unit where the reimbursement is delayed up to the integration time. Even with a great investment in the design of the system architecture this parallel methodology can be "undesirable or difficult at best" (Krishnan, Eppinger, Whitney, 1997). These authors propose also an alternative to overlap the tasks in upstream and downstream through more frequent information between them. In the present study we found that a joint serial and overlapping (Krishnan et al. 1997, Bhattacharya et al. 1998) processes hold the promise of flexibility in NPD that we share with (MacCormack, Verganti, Iansiti, 2001). We illustrate this flexible conjunction approach as follows.

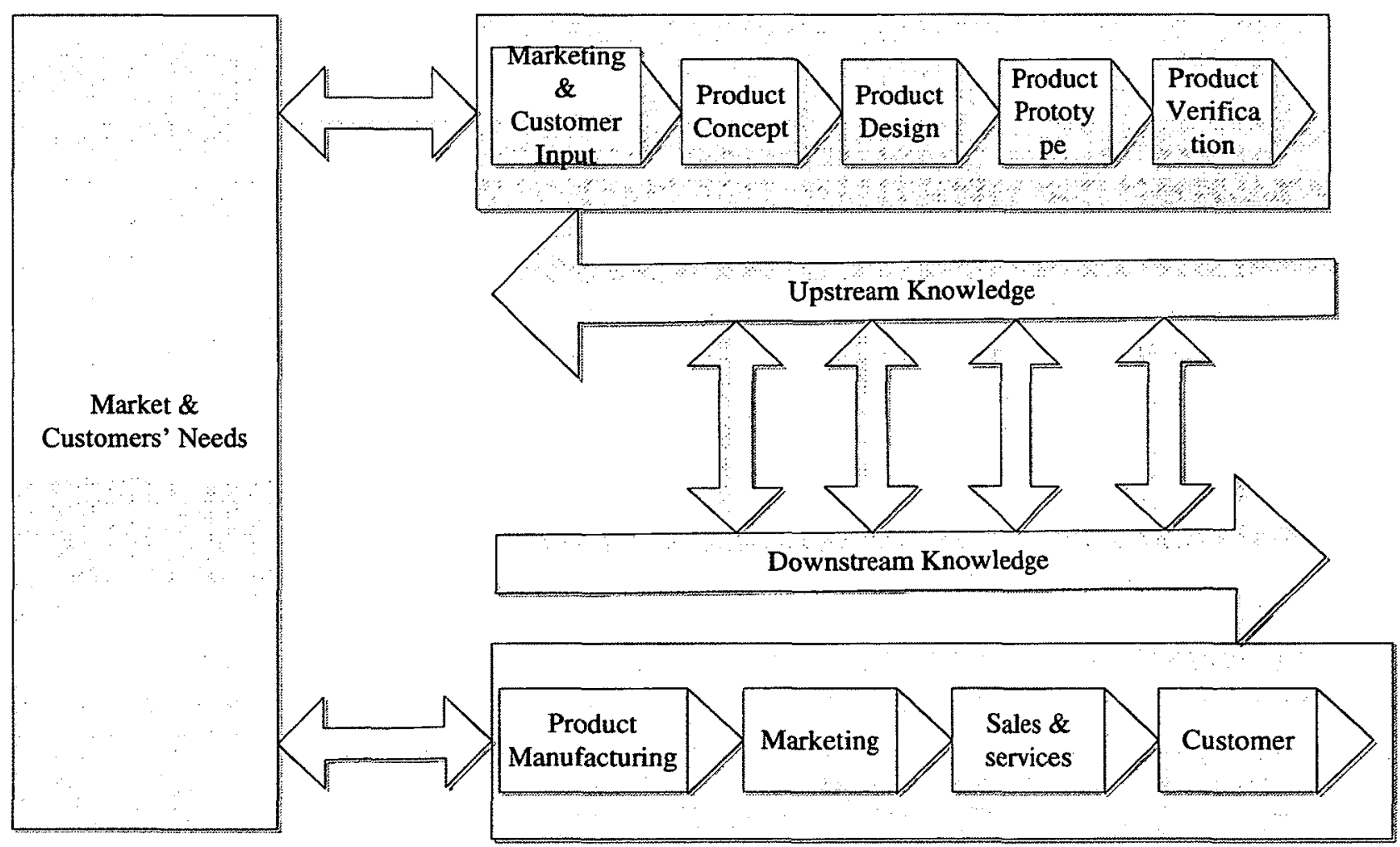

Figure 15 : Flexible Process 
It is now appropriate to build the arguments that justify the results in table 5 and relate the three scenarios with the sequential, parallel and flexible managerial approaches introduced earlier. Starting with scenario one in figure 16 , it uses a standard dedicated microcontroller as its core processor hardware unit. In analogy to the previous management discourse the choice of this fixed hardware microcontroller kit in the present experiment is a strong justification that this NPD scenario indirectly assumed an early definition for the project that leaves little room for change in the processor unit as new information may emerge. Therefore, this product definition and moreover a microcontroller are well adapted, technically, for the sequential management approach. This fixed hardware with its sequential inclination may be a complex managerial task if the control system application is complex or the customer needs deviate significantly from its origin. Inversely to its hardware architecture, in terms of software exploration this scenario gives rise to an open system. 


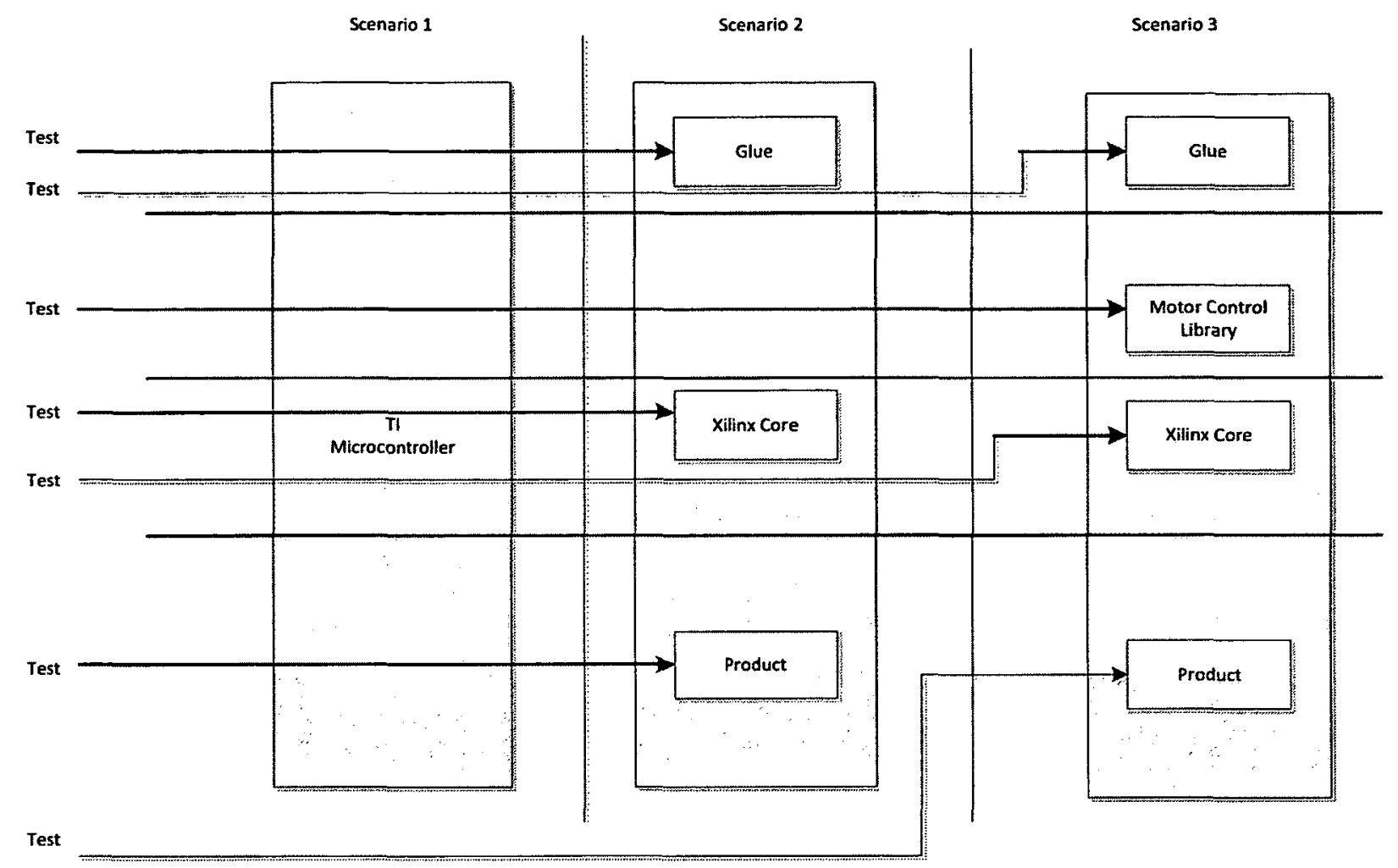

Figure 16 : scenarios

In comparison, scenario two incorporates in the Xilinx FPGA the characteristics that facilitate the parallel NPD management. It alleviates the NPD complexity and the possible difficulty arising from high velocity in customer needs. In effect, the control system application that we want to implement and test here is equivalent to the one in scenario one. It may contain a variety of subsystems that can be fixed, shared and adapted to other subsystems if the design team invests time and resources in early system architecture. The biggest advantage of scenario two in comparison to the previous one is the capability of emulating the ARM processor inside the FPGA while keeping the option of designing volatile and complex dedicated digital subsystems with a flexibility that can accommodate new information as they emerge from customers, technologies and internal teams. The exploration variable is still open because the needed intellectual property components are still all internally developed by the firm. 
Scenarios one and two lean themselves more on the technical side of NPD. However, our vision of successful NPD synchronizes with scenario three. It provides the competitive advantage that requires a firm to close not only the science and technology gap but also the management one. By joining the serial and parallel value proposition offered by the other scenarios through custom motion libraries, scenario three provides a process that allows the development of a NPD that is flexible by hiding its complexity to the end users. This scenario offers a flexibility that invites users to explore various what-if alternatives and helping them to stay the course on their core business. All this has the economic benefit of reducing the NPD time-to-market, diminishing cost, improving quality and facilitating feedback. In terms of software and algorithm this scenario can be qualified as semi-open because sometime some libraries are from third party who may hide the essential knowledge needed to develop them or may require a premium fees to grant full access to the inner knowledge required to understand and develop these libraries.

We expect feedback for scenario one to have a late time response. This is dependent on the upstream tasks which can be high level functions that get the attention of the processor for so long insofar they can starve downstream tasks that can't interrupt the processor and have to wait until the processor get released.

Considering our three scenarios, the literature on the management of new product development and the feedback block diagram developed earlier towards measuring our variables, and the arguments developed in the prototype section; it appears that if the new product is simple and has a very low complexity, the microcontroller kit is an enviable choice and the FPGA-based platform development is an overhead if it had to start from scratch. However, if an internal or third party platforms already exit on the market the second FPGA-based scenario is a better option for customers looking for flexibility, early feedback and exploration. In all other cases 
from medium to very high complexity an FPGA-based platform scenario three is a valuable option and sometime it may well be the best one.

For the management performance evaluation we use the metrics design in chapter two specifically adapted to our study. As it is implied from the management literature and our feedback block diagram, early feedback is the transformation of the information, data and knowledge that we acquire in collaboration with customers into a prototype or a document that customers understand and able to compare it with the solution they are looking for. In that sense, it can be measured as the time it takes to consume information, data and knowledge and produce results understandable by customers. Scenario A doesn't give enough flexibility to do that early and often. Scenario B improves the feedback loop but in our specific case, if we don't have some. specific motion control IP cores the feedback can vary from early to late. In the end, having Xilinx IP, third party IP and custom IP specific to motion control a system engineer can work at very high level and be very productive and provide early feedback to customers. When we say feedback early and often, this is a service to customers that has an incremental cost, however as reported by (Smith, 2007) and others the cost of early feedback and flexibility is smaller than the devastating consequences a late error finding can have on the future of a product. In comparison to an ASIC the cost benefit that we have can be shared for the flexibility that we gain with the FPGA. In comparison to a microcontroller and DSP the cost benefit is in the total cost of ownership when we include obsolescence, peripheral devices and faster time-to-market for medium to very high complex product. Cost can also be measured as the level of IP reusability in a product. In terms of quality, FPGAs have a competitive advantage for the fact that the give complete control of the hardware and software on the same fabric to designers therefore they can design better architecture adaptive to flexibility and feedback. 
As per the previous exploration of the flexible early feedback concept in our project, the explanation of the theoretical results and description our process to feedback understandable by customers, the following table present the measurement that we estimate for each managerial and technical variable of interest in our inquiry. In chapter 9 we also include in annexe the measurements data from the TI microcontroller, the FPGA and the simulation from matlab.

\begin{tabular}{|l|l|l|l|}
\hline Variables & Scenario A & Scenario B & Scenario C \\
\hline Feedback & Late & Early to late & Early \\
\hline Flexibility & Low & Medium & High to Very high \\
\hline Time-to-market & Late & Early to Late & Early \\
\hline Costs & Expensive & Affordable & Cheap \\
\hline Quality & Medium & Low & High \\
\hline Exploration & Close & Open & Semi-open \\
\hline Complexity & High & Medium & Low \\
\hline
\end{tabular}

Table 5: Variables measurements 


\section{Discussions}

Now that we are almost at the end of this mission of showing the effect of early feedback on NPD performance, it is an appropriate time to give a definitive answer to the question before us. We have drawn on (Thomke, 2003) observation and emphasize "no product can be a product without first having been an idea subsequently shaped through experimentation". An NPD is either an invention or an innovation. Whichever be the case, it is the result of individual or team effort where human beings use their gift of intelligence to address and solve human needs for the benefit of the human race. To this purpose we share the point of view presenting in (Corsi et al., 2006) by insisting "innovation never emerges ex nihilo from the electronic brain of a machines ...". In spite of the performance of the controller embedded in high performance computing machine, until now it always needs a bootstrap knowledge that is always embodied in people. The key catalyst to activate and influence the performance of an NPD lies in the integration of soft skills pertaining to social sciences and hard skills connecting natural sciences, applied professions and Technology Information Management (TIM) under a unified tent of interdisciplinary teamwork. Such interdisciplinary environment is a necessary winning condition to seek, promote and generate early feedback from all levels (internal, external and technological) of a business designed for flexibility and openness to co-create NPD with and for satisfied customers. The feedback treated over the course of this work finds its meaning in the context of the integration of people with various background and perspectives to the common good of developing a needed product that should solve a customer's problem by following management processes that: simplify complex systems, amplify the sum of knowledge accumulated from an interdisciplinary team, stimulate the performance of the team, reduce cost and diminish time-to-market. In the following paragraphs of this section we will draw our 
discussions based on what we have learned from the literature and what we have achieved to shed light on two propositions:

Proposition 1: An automatic control system needs to be designed with the focus of taking advantage of feedback and experimentation technologies and firms need to be organized for that.

The advancement in science, technology and internet has changed the landscape of all fields of study and particularly engineering. Systems have become more and more complex in the sense highlighted by (Simon, 1962), the interconnections between their subsystems are non-trivial and the effect of each one on another is such that "the whole is more than the sum of the parts". It is in this context that we propose an automatic control system platform based on FPGA should take advantage of feedback and experimentation technologies. As we have used for instance, these technologies for exploring various what-if scenarios and mathematical models for motion control or energy conversion systems could be simulation tools such as matlab, in the case of electronic design and manufacturing it could be Orcad. Our project is still an academic research and development thus we didn't have a customer relationship management and project management tools, two necessary tools to manage internal and external people that usually shape a successful industrial NPD. These tools have multiplied the capability of scientists and engineers to understand some complex natural laws and thus our capacity to control numerous natural phenomena through early warning and feedback monitoring system. Taking advantage of feedback and experimentation technologies provides a vast competitive business advantage to firms to differentiate their value proposition through multiresolution modeling (Shalf, Quilan, Janssen, 2011) that can vary in a hardware-software codesign from crude guess to exact hardware model by passing from rough idea through very good estimate with cause and effect as a middle point modeling between all of them. This competitive advantage can also manifest itself 
by reducing the rapid prototyping of NPD cycle time. (Shalf, Quilan, Janssen, 2011) provide their research evidence for reducing cycle time from 6 years to days. Our FPGA based platform has the potential to take advantage of the experimentation technologies such as matlab, orcad, Xilinx Extensible Processing Platform and Xilinx ecosystem to reduce time-to-market from about one year to about two months.

The best organization for a firm to take advantage of feedback and experimentation technologies is a strategy that focuses on fighting against social, scientific and technological inertia. This strategy requires a continuous awareness and readiness to move and act on the signals of change that come from society, market, customers, science and technology. The change in question can be customers' feedback in a particular market segment, the penetration and adoption of new technologies and laws, perturbation in a financial market and so on. Therefore, we argue that successful product development is a firm outcome that emerges from the firm's interaction with its environment. In the current context, to examine the effect of early feedback on NPD performance we shall consider the management and the technical sides of this proposition as follows: firms that want to profit from feedback and flexibility need to get organized by integrating their design team as well as their advanced technical tools in an interdisciplinary research and development environment that has the capability to foster feedback and build on the experience of each member in an interdisciplinary network. We also need a management process to evaluate the benefit of feedback and what we get from tapping to the experience of each member in a group and customer because (Thomke, 2003) raises the awareness that new experimentation technologies do not lead to superior performance simply by their introduction into an organization. 
Proposition 2: A flexible product development and organization management designed for feedback reduces cost, complexity and foster learning.

In high technology, computer itself is the tip of the iceberg when it comes to complexity and feedback. This is resumed as, computers help designing complex chips which in turn help designing complex computers and in the current state-of-the-art one can not be designed without the complementarity of the other. In an evolutionary biology perspective, it is accurate to say there is a symbiotic relationship between these technological trends. All this to confirm that the advent of ICT has had a multiplier and accumulator effect on NPD design and management complexity, and at the same time we have gained powerful capability and experimentation technology and business ecosystem to solve complex problem and learned through experimentation.

The computing power of new experimentation technology brings the cost for test very low, therefore firms can do more tests earlier and often which provides enormous database to infer reality reduce complexity and foster learning. The illustration of this assertion can be best understood in discussing the three scenario of our unit of analysis.

In scenario A, if the product is simple the flexibility for codesign of hardware and software is not mandatory thus forcing or investing in a flexible foundation with an FPGA may well be an overhead that could potentially overload the firm's product development process.

The case in scenario 2 is a necessary step to implement flexibility and get prepared for feedback. Starting an FPGA-based platform new product development is not a trivial objective. The system engineer needs to manage the product development with the hardware and software engineers if these tasks are performed by others. Therefore, the customers may well be just internal with 
other engineers and managers or external with end users or problems owners. In the beginning, to foster an early feedback the system engineer have two bridges to customers either through documentation explaining concepts, schematics and bloc diagram or early prototypes which customers can use to see, feel and experiment to better express their needs and shape what they want. With the trends of systems becoming more and more complex, this customer early feedback is possible only by using a variety of surrogates for the applications software as suggested by (Shalf, Quilan, Janssen, 2011) and in our case we need some digital and analog hardware surrogates also such as pulse width modulator (PWM), full bridges, adaptive inputs and outputs to simulate important functions in real time and already tested hardware development kits such as power supplies, motors and applications specifics kits close to our application.

With all these surrogates applications we need now to prepare a custom infrastructure which can be used to integrate complex IP from third party, internal custom design for the specific application and Xilinx IP. Paraphrasing (Smith, 2007), this custom infrastructure is "not one person endeavour" for the fact that one person doesn't have enough depth and breadth in all cross disciplinary of all these IPs. As it always is in science, we need to build on the shoulder of others. With the advanced experimentation tools that we have these days starting small with a bottom up design approach is an important strategy to adopt in scenario B. In figure 17, we adapt the conceptualization of interplay among layers in the application hierarchy from (Shalf, Quilan, Janssen, 2011) to show that the bottom up approach custom infrastructure that we refer to is analog to the vertical integration arrow in this figure. The horizontal up arrows show, at high level, designers run their test early and often until they have a flexible deliverable that they can use to communicate and seek feedback from customers. In this sequence and in our case, a deep 
understanding of interdisciplinary IPs and full workload may not be necessary at this stage of the development. What is important is the closeness with customer reality as we agree with the authors. Once we get a feedback from the customer, the flexible process cycles again to the bottom. In this down trajectory, an increase in the level of understanding is necessary because we need to adapt each layer to solve the customer specific problem and then the cycle continues.

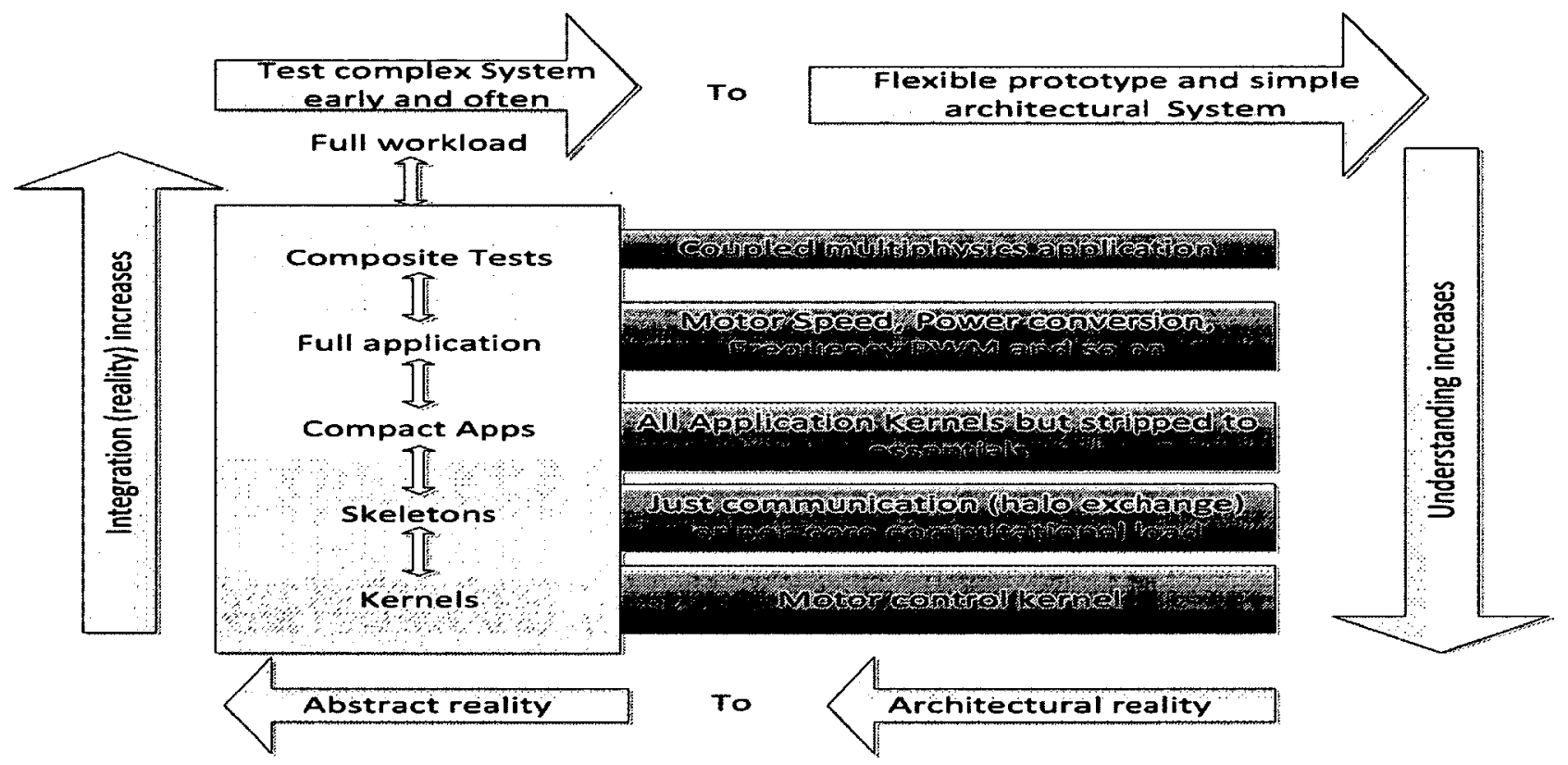

Figure 17 : Interplay among layers of surrogate applications

Adapted from (Shalf, Quilan, Janssen, 2011)

What was presented earlier for scenario $\mathrm{B}$ is also valid for scenario $\mathrm{C}$ because at some degree all systems are modular. In reality, in the bottom up approach we have developed modules that will be integrated for high level representation of customer reality. Scenario $\mathrm{C}$ facilitates a top-down design process where an engineer will get some requirements for a customer need and follow the top-down design process to augment what is available in an experimentation technology tools. 
For the product, the motor control is suitable not only for motion control but also by the nature of its control it is an instrument to reduce energy consumption. For instance, by using the PWM to increase or reduce the motor speed we indirectly reduce its power consumption 


\section{Conclusions, Limitations and Future Research}

\subsection{Conclusions}

Over the course of this interdisciplinary research, aggregated in management science, control of industrial electronic and power systems, automatic and simulation, we have examined the effect of early feedback on new product development performance. We focus on solving the problems related to the reduction of cost and complexity, the acceleration of time-to-market, the increase of quality and flexibility in new product development. We have used three scenarios to illustrate this effect as sequential, parallel and flexible management and science and technology design decisions. We retain that scenario $\mathrm{C}$ is better than $\mathrm{A}$ and $\mathrm{B}$. This comes from the fact that scenario $\mathrm{C}$ presents the flexibility of designing standard systems either by using a firm's own IP assets or by working with other collaborators if the problem is too complex for one firm to master all aspect of it. We have found that experimentation technologies have played an important role in virtual prototyping which in turn facilitates three levels of feedback for a firm: internal, external and technological. All of them concur to better performance in new product development.

In sum, the problems related to NPD are wide and different. The field of NPD in itself among other things is multidisciplinary (Loch and Kavadis, 2008), it is also a transformation of a market opportunity into profitable deliverables (Eppinger, 2004), an adaptive response to uncertain market environments (Eisenhardt, Tabrizi, 1995), a flexible process (Thomke, 1997, 1998, Gerwin, 1993, Eisenhardt, Tabrizi, 1995).

Researchers have drawn similarities between NPD and evolutionary theory (Loch and Kavadis, 2008). Across different product generations flexibility and feedback with customers and technologies help firms develop better products for tests and resilience to obsolescence 
(MacCormack, Verganti, Iansiti. 2001, Thomke, 2003). In summary, the concept of feedback is related to electronic, control system, management marketing, communication and psychology (Eisenhardt 1995, Sterman, 1989, Ashford, Blatt, VandeWalle, 2003, Dellarocas, 2003, Thomke, 2003, Smith, 2007, Dorf, Bishop, 2011).

The insight and implications related to our deliverables is the imperative to manage collaborators and the development of new skills set that are difficult to gain without a "learning and doing often" environment that takes advantage of feedback and experimentation technologies. Early feedback has plenty advantages to improve the performance of NPD. However these performances can be conflicting if we want all of them at the same time. We need to balance trade-offs between advantages and disadvantages. For instance, we may sometime favor less exploration for higher quality and, less flexibility for to lower cost and accelerate time-to-market.

The state of the art experimentation technologies that Xilinx has developed contribute to unleash the feedback capability and capacity of the FPGA chips. They can perform very well in complex high technology environments where time-to-market, cost, complexity, reconfiguration are the required competitive advantage. They can outperform microcontrollers and DSP in emerging technology for traditional industry such as aerospace, automotive, biomedical and energy. They help shifting the locus of feedback experimentation with application specific development kit. The mean advantage of these chips in a platform system is to exploit managerial and technical feedback to put solution early in the hand of a customer at reduced cost.

The flexibility of an FPGA in comparison to a microcontroller, DSP and ASICs is that, it is easier to explore and recycle more modular design architectures to solve a customer problem. Then because of this architectural and hierarchical view, how feedback captures the real essence 
or the performance of a complex system (Simon, 1962) depends on the level of abstraction, what signals response get measured, how system is documented, how history and stories are reported.

\subsection{Limitations}

The amount of data that would allow a full case study or building a theory on the relationship between feedback and performance was limited. We can certainly acquire more data to extend some qualitative results such as complexity and flexibility and measure them quantitatively.

The flexibility of the GUI for this microcontroller was limited. The access to some hardware functions such as analog to digital converter was difficult.

\subsection{Future Research}

In the future, the implementation of the ADC and DAC in FPGA-platform is certainly an improvement to be able to compare measurements of the current with the ones from the simulation and the microcontroller-based system.

Our model for the feedback block diagram is mostly conceived as a linear system, we know that decision in project management would be more accurate with a nonlinear model. Can the nonlinearity be taken in this model with some approximation? Is the deviation significant relative to the insights we can acquire with the present feedback block diagram? Are questions that can be answered with further research.

A delay in the feedback loop can make the system unstable and the comparison with the desired output irrelevant. Therefore, a method to partition the management tasks in way that allow each subsystem to accomplish their work in a timely manner that can optimize the system overall bandwidth. 
We only measure the variables in accordance to our specific scenarios. As more research in the future will provide more data, a research agenda may well aim towards a categorization and generalization in the measurements of these variables. 


\section{References}

Altera.com

Ashford, Susan J., Blatt, Ruth, VandeWalle, Don, 2003. Reflections on the Looking Glass: A Review of Research on Feedback-Seeking Behaviour in Organization, Journal of Management 2003, 29(6), $773-799$

Babbie, Earl, Benaquisto, Lucia, (2002). Fundamental of Social Research.

Bhattacharya, S., V. Krishnan, V. Mahajan. 1998. Managing New Product Definition in Highly dynamic Environnments. Management Science. 44(11 Part 2) S50-S64.

Bennett, Stuart, 1996. A Brief History of Automatic Control, IEEE Control Systems

Betz, Frederick (2003). Managing Technological Innovation.

Boutellier, Roman, Olivier Grassman, Maximilian von Zedtwitz, 2000. Managing Global Innovation, Second Revised Edition.

Brown, S. L., and Eisenhardt, K. M., 1995. Product Development: Past Research, Present Findings, and Future Directions. Academy of Management Review, 20(2) 343-378.

Christensen, Clayton (2004). Seeing What's Next, Harvard Business School Press;

Corsi, Patrick, Simon Richir, Herve Christofol and Henri Samier (2006). Innovation Engineering: The Power of Intangible Networks.

Dellarocas, Chysanthos, 2003. The Digitization of Word of Mouth: Promise and Challenges of 
Online Feedback Mechanisms. Management Sci. Vol. 49(10) 1407-1424

Dorf, Richard C., Bishop, Robert H., 2011. Modern Control Systems, Twelfth ed.

Dorf, Richard C., 2006. The Electrical Engineering Handbook, $3^{\text {rd }}$ ed., Systems, Controls, Embedded Systems, Energy and Machines.

Dubey, Rahul, Argawal, Pramod, Vasantha, M. K., February 2007. Programmable Logic Devices for Motion Control - A Review. IEEE Trans. on Ind. Electronics, 54(1).

Dukkipati, Rao V, 2005. Control Systems

Eisenhardt, K. M., B. N. Tabrizi. 1995. Accelerating Adaptive Process: Product Innovation in the Global Computer Industry. Admin. Sci. Quat 40(1) 84-110.

Fine, Charles H. 2000. Clockspeed-based Strategies for Supply Chain Design. Production and Operation Management, Vol. 9, No. 3, Fall 2000.

Fleming, Lee and Santiago Mingo, 2008. Creativity in new product development: An evolutionary integration. In Loch, Christoph H., Stylianos Kavadis. 2008. Handbook of New Product Development, Elsvier Ltd.

Fuller, S., 1993. The Position: Interdisciplinary as Interpretation. In Philosophy, rethoric, and the end of knowledge: The coming of science and technology studies (pp. 29-65). Madisson: University of Wisconsin Press.

Gerwin, Donald. 1987. An agenda for research on the flexibility of manufacturing process. 
International Journal of Operations and Production Management Vol. 7(1) 38-49.

Gerwin, Donald. 1993. Managing Flexibility: A Strategic Perspective.

Management Sci. 39(4) 395-410.

Gerwin, Donald, Nicholas J. Barrowman. 2002. An Evaluation of Research on Integrated Product Development. Management Sci. 48(7) 938 - 953.

Gerwin, Donald. 2004. Coordinating New Product Development In Strategic Alliances. Academy of Management Review 29(2) 24-257.

Getov, Vladimir, Adolfy Hoisie, Harvey J. Wasserman. 2011. Codesign for Systems and Applications: Charting the Path to Exascale Computing. IEEE Innovative Technology for Computer Professionals, 44(11) $19-21$.

Gieras, Jacek F., Zbigniew J. Piech, 2000, Linear Synchronous Motors, Transportation and Automation Systems

Golnaraghi, F., Kuo, B. C., 2010. Automatic Control System, $9^{\text {th }}$ ed.

Griffin, A. and J. R. Hauser. 1993. The Voice of the Customer. Marketing Science 12 (1): 1-27.

Hanselman, Duane C., 1994. Brushless Permanent-Magnet Motor Design

Hirotaka Takeuchi and Ikujiro Nonaka, 1986. The New Product Development Game. Harvard Business Review, January - February 1986

Hillbarand, Bas, Biemans, Wim G., 2003. The relationship between internal and external 
Cooperation: literature review and propositions. Journal of Business Research, 56(2003), $735-743$

Keyhani, Ali, 2011. Design of Smart Power Grid Renewable Energy Systems.

Krishnan, V. and K. Ulrich, "Product Development Decisions: A Review of the Literature", Management Science, 47(1), 1-21, 2001.

Krishnan, V., S. D. Eppinger, D. E. Whitney, 1997. A model based framework to overlap product development activities. Management Science, 43(4), 437-451.

Kuon, Ian, Russell Tessier and Jonathan Rose, 2007. FPGA Architecture : Survey and Challenges. Foundations and Trends in Electronic Design Automation. Vol. 2, No. 2 (2007) $153-253$

Lam, Fu Chak, DeRue, D. Scott, Karam, Elizabeth P., Hollenbeck, John R., 2011. Organizational Behaviour and Human Decision Processes, 116 (2011) 217 - 228

Le-Huy, H., August 1994. Microprocessors and Digital ICs for Motion Control, Proc. IEEE, Vol. 82, No. 8, pp. $1140-1163$, August 1994.

Loch, Christoph H., Stylianos Kavadis. 2008. Handbook of New Product Development, Elsvier Ltd.

Loch, Christoph H., Christian Terwiesch. 2008. Coordination and information exchange. In Loch, Christoph H., Stylianos Kavadis. 2008. Handbook of New Product Development, 
Elsvier Ltd.

MacCormack, Alan, Roberto Verganti, Marco Iansiti. 2001. Developing Products on "Internet

Time": The Anatomy of Flexible Development Process.

Management Sci. 48(7) 938 - 953.

Mohan, Ned, Tore M. Undeland, William P. Robins, 2003, $3^{\text {rd }}$ ed.. Power Electronics

Monmason, Eric and Cirstea, Marcian N., August 2007. FPGA Design Methodology for

Industrial Control System - A Review. IEEE Transactions on Industrial Electronics, Vol.

54. No. 4

NASA, http://www.nasa.gov/mission pages/shuttle/behindscenes/rms anniversary.html

Palm III, W. J., 2010. System Dynamics, $2^{\text {nd }} \mathrm{ed}$.

Parnel, Karen, Roger Bryner, 2004. Comparing and Contrasting FPGA and Microprocessor

System Design and Development. Xilinx, White Paper, WP213 (V1.1).

Patterson, David, July 2010. The Trouble with Multicore. IEEE Spectrum

Ramdas, K., "Managing Product Variety: An Integrative Review and Research Directions",

Productions and operations Management, 12(1), 79 - 101, Spring 2003.

Repko, Allen F., 2008. Interdisciplinary Research. Sage Publications, Inc.

Robertson, D. and K. T. Ulrich, Planning for Product Platforms:, Sloan Management Review, 39, 


$$
19-31,1998
$$

Roberts, Edward B., 2002. Innovation: Driving Product, Process, and Market Change, MITSloan Management Review.

Saleh, Joseph H., Gregory Mark and Nicole C. Jordan. 2009. Flexibility: a multi-disciplinary review and a research agenda for designing flexible engineering systems. Journal of Engineering Design Vol. 20(3), 307-323.

Shalf, John, Dan Quilan, Curtis Janssen, 2011. Rethinking Hardware-Software Codesign for Exascale Systems. IEEE Innovative Technology for Computer Professionals, Vol. 44(11) $22-30$.

Simon, Hebert A., December, 1962. The Architecture of Complexity. Proceedings of the American Philosophical Society, vol. 106(6)

Smith, Preston G., 2007. Flexible Product Development

Sosa, Manuel E., Jurgen Mihn, 2008. Organization design for new product development. In Loch, Christoph H., Stylianos Kavadis. 2008. Handbook of New Product Development, Elsvier Ltd.

Sterman, John D., 1989. Modeling Managerial Behaviour: Misperceptions of Feedback in a Dynamic Decision Making Experiment. Management Science, Vol. 35(3) 321-339.

Thomke, Stefan H., 1997. The role of flexibility in the development of new product: an empirical 
study. Research Policy 26(1997) 105-119

Thomke, Stefan H., 1998. Agile Product Development: Managing Development Flexibility in Uncertain Environments. California Management Review. Vol. 41 (1)

Thomke, Stefan H. and Eric von Hippel, 2002. Customers as Innovators: A New Way to Create Value. Harvard Business Business Review.

Thomke, Stefan H., 2003. Experimentation Matters. Harvard Business School Press.

Toliyat, H. A., Cambell, S. G., 2004. DSP-Based Electromechanical Motion Control

Toliyat, Hamid A., Mehdi Abolhassani, Peyman Niazi, Lei Hao, 2001. DSP-based Control of variable Speed Drives. In Rachid, Muhammad H., 2011. Power Electronics Handbook: Devices, Circuits, And Applications, Third Edition.

Ulrich, K. T., and Eppinger S. D. (2004). Product Design and Development $3^{\text {rd }}$ edition, NY: McGraw Hill.

Ulrich, K. T., 2008. Users experts, and institution in design. In Loch, Christoph H., Stylianos Kavadis. 2008. Handbook of New Product Development, Elsvier Ltd.

Von Hippel, E., 1986. Lead Users: A Source of Novel Product Concepts. Management Science 32(7): 791-805

Von Hippel, E., 2005. Democratizing Innovation. MTT Press Cambridge, Massachusetts Wheelwright S. C. and Clark K. B. (1992). Revolutionizing Product Development, Maxwell- 
Macmillan, New-York, NY.

\section{Xilinx Xilinx.com}

Yazdani, Amienaser, Reza Iravani, 2010. Voltage Source Converters in Power Systems:

Modeling, Control and Applications. 


\section{$9 \quad$ Annexe}

\subsection{Annexe 1, Measurements from TI Microcontroller-based System}

The following results contain measurement data for the speed and torque transient from testing related to the TI microcontroller-based system

\section{GENERAL FUNCTIONING}




\begin{tabular}{|l|l|l|l|l|l|}
\hline Variables & Speed & Load & Vdc & Torque & Current \\
\hline Hall A, VAB, IA & 3000 & 0 & 20.3 & & \\
\hline
\end{tabular}

General functioning

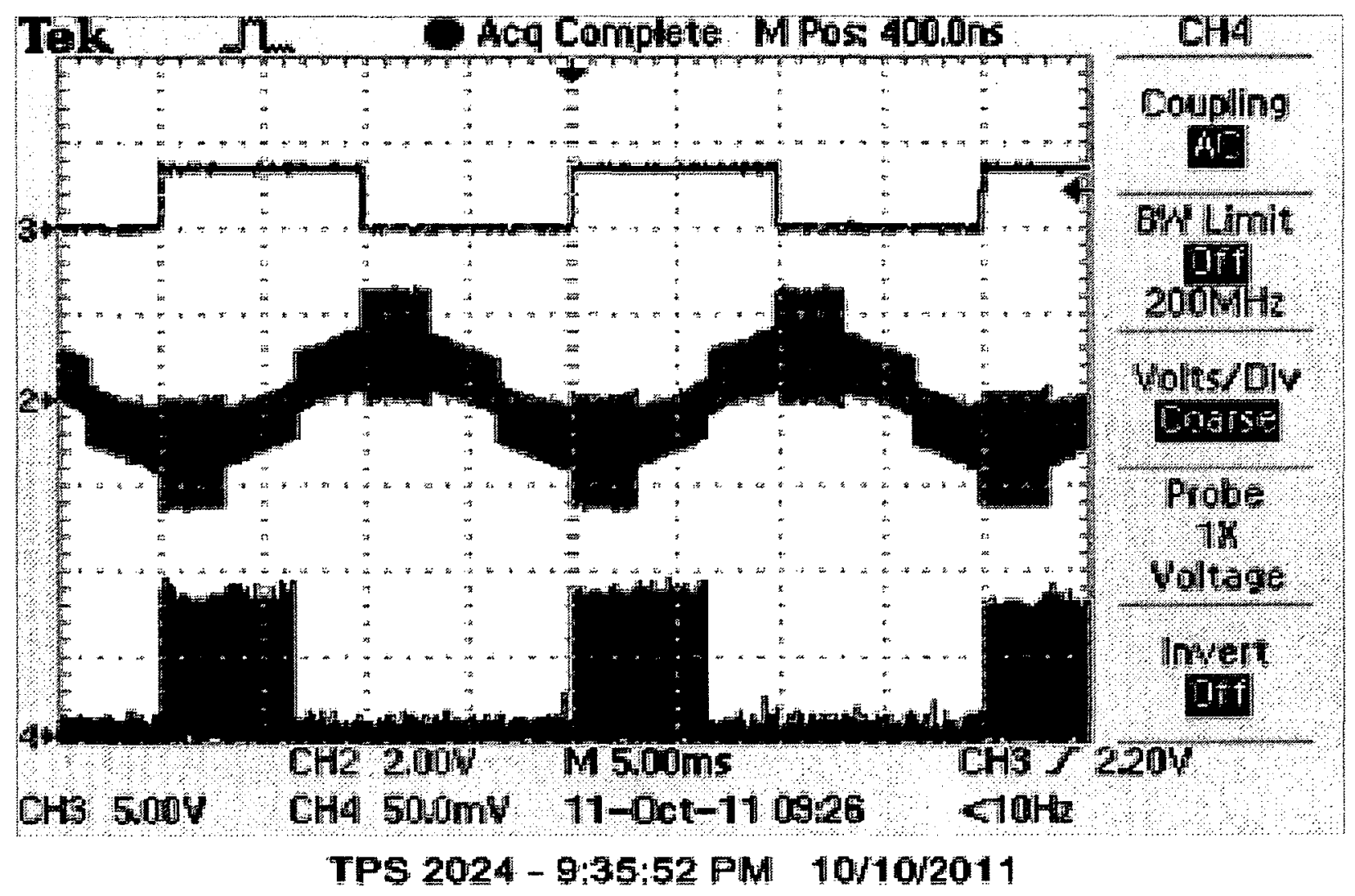


SPEED TRANSIENT

$(1000$ RPM $\rightarrow 2000$ RPM $\rightarrow 1000$ RPM) 


\begin{tabular}{|l|l|l|l|l|l|}
\hline Variables & Speed & Load & Vdc & Torque & Current \\
\hline Hall A, VAB, IA & 1000 to 2000 & 0 & 20.3 & & \\
\hline
\end{tabular}

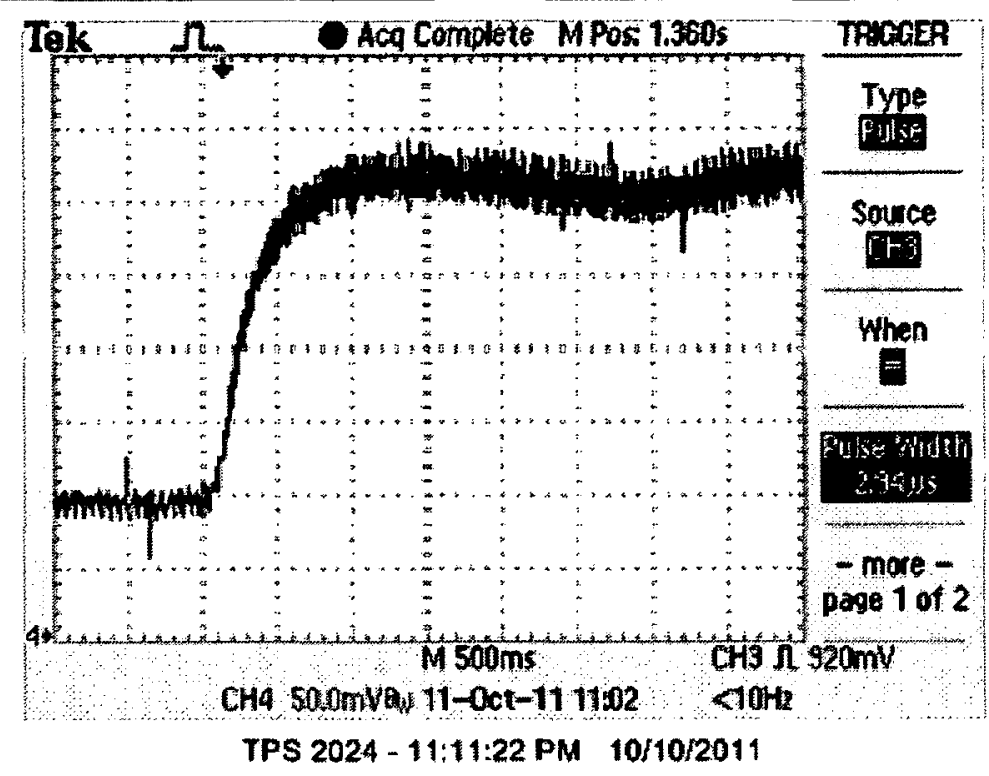

\begin{tabular}{|l|l|l|l|l|l|}
\hline Variables & Speed & Load & Vdc & Torque & Current \\
\hline Hall A, VAB, IA & 2000 to 1000 & 0 & 20.3 & & \\
\hline
\end{tabular}

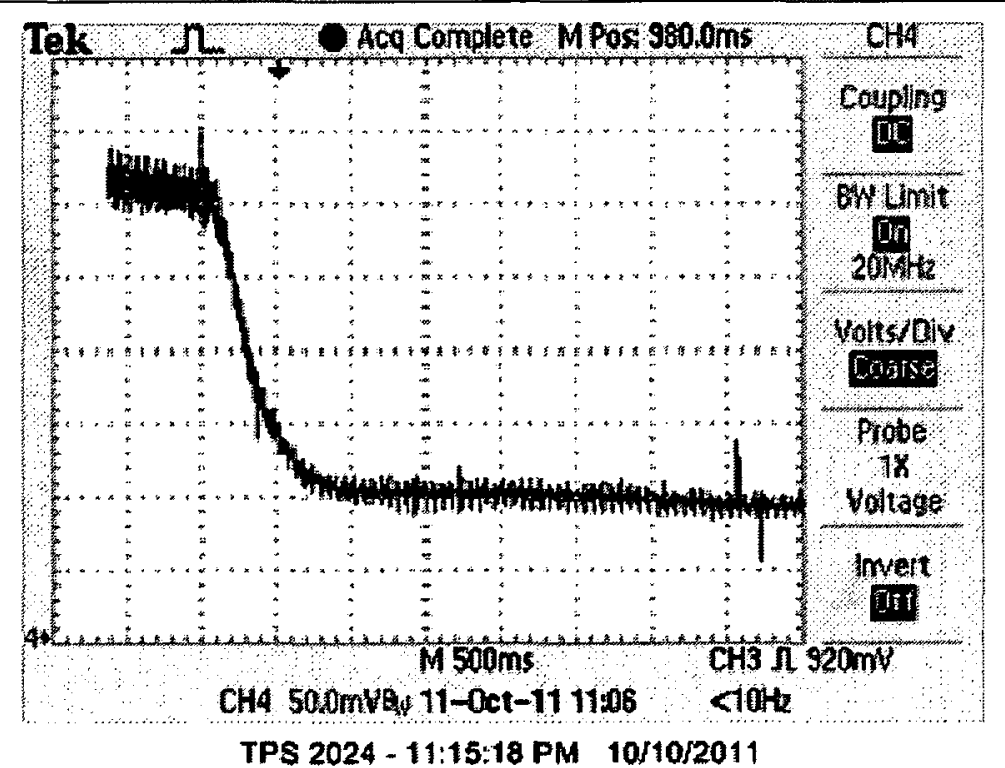




\begin{tabular}{|l|l|l|l|l|l|}
\hline Variables & Speed & Load & Vdc & Torque & Current \\
\hline Hall A, VAB, IA & 1000 to 2000 & 51 & 20.3 & & \\
\hline
\end{tabular}

Speed transient

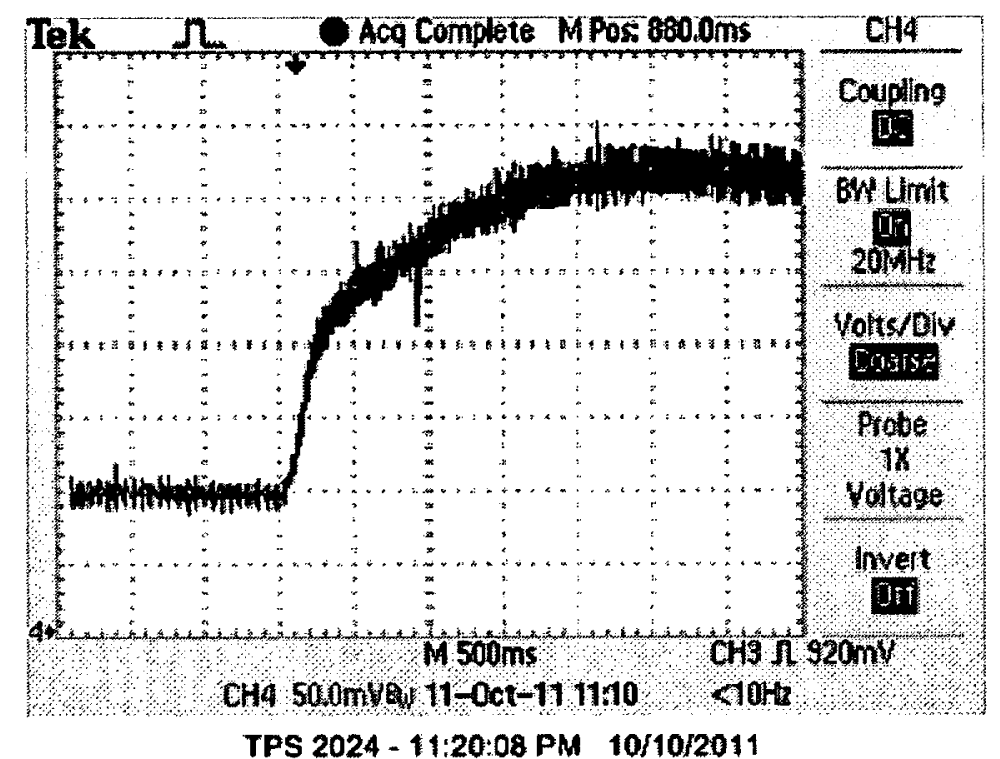

\begin{tabular}{|l|l|l|l|l|l|}
\hline Variables & Speed & Load & Vdc & Torque & Current \\
\hline Hall A, VAB, IA & 2000 to 1000 & 51 & 20.3 & & \\
\hline
\end{tabular}

Speed transient

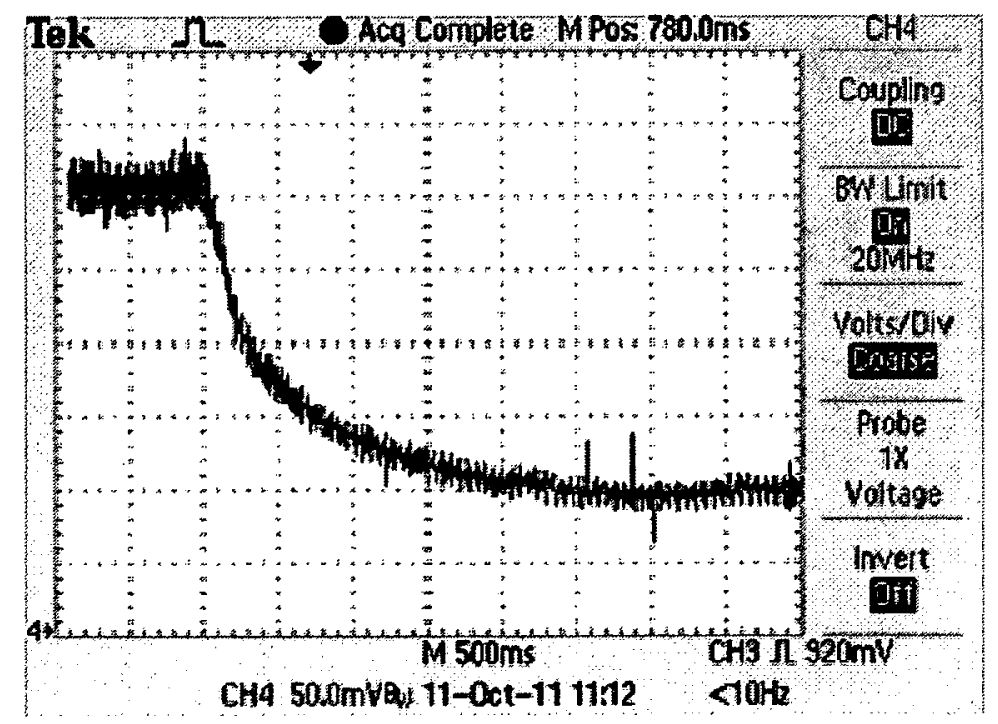

TPS 2024-11:21:37 PM 10/10/2011 


\section{SPEED TRANSIENT}

\section{$(1000 R P M->6000 R P M \rightarrow 1000 R P M)$}




\begin{tabular}{|l|l|l|l|l|l|}
\hline Variables & Speed & Load & Vdc & Torque & Current \\
\hline Hall A, VAB, IA & 1000 to 6000 & 0 & 20.3 & & \\
\hline
\end{tabular}

Speed transient

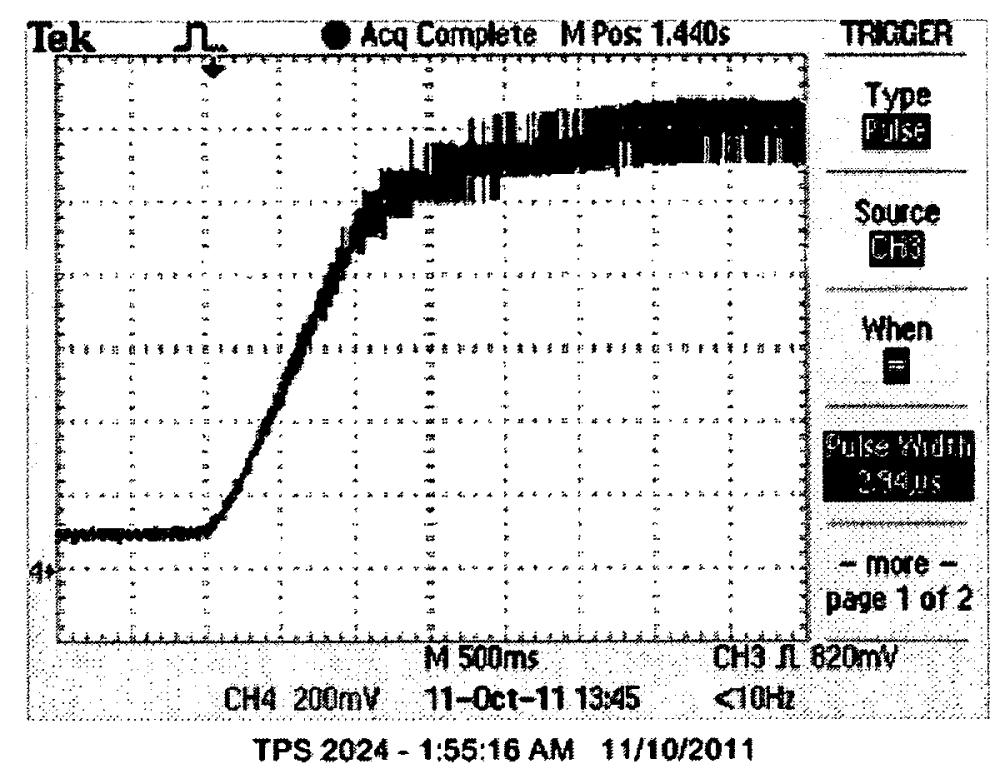

\begin{tabular}{|l|l|l|l|l|l|}
\hline Variables & Speed & Load & Vdc & Torque & Current \\
\hline Hall A, VAB, IA & 6000 to 1000 & 0 & 20.3 & & \\
\hline
\end{tabular}

Speed transient

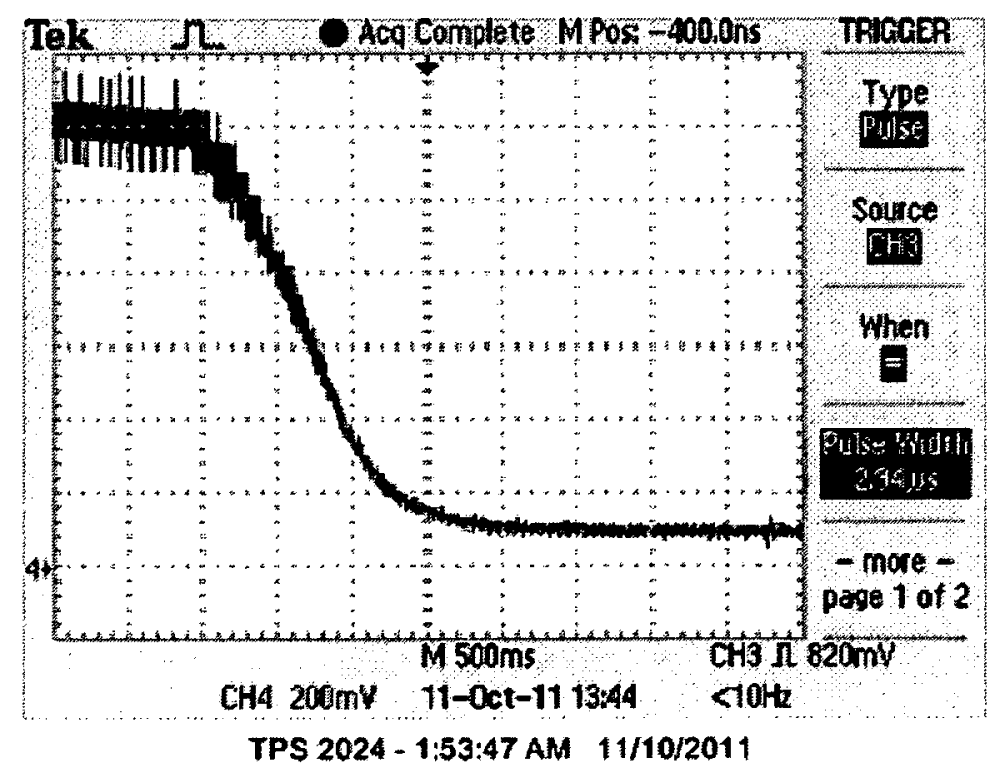




\begin{tabular}{|l|l|l|l|l|l|}
\hline Variables & Speed & Load & Vdc & Torque & Current \\
\hline Hall A, VAB, IA & 1000 to 6000 & $0->51$ & 10.0 & & \\
\hline
\end{tabular}

Speed transient

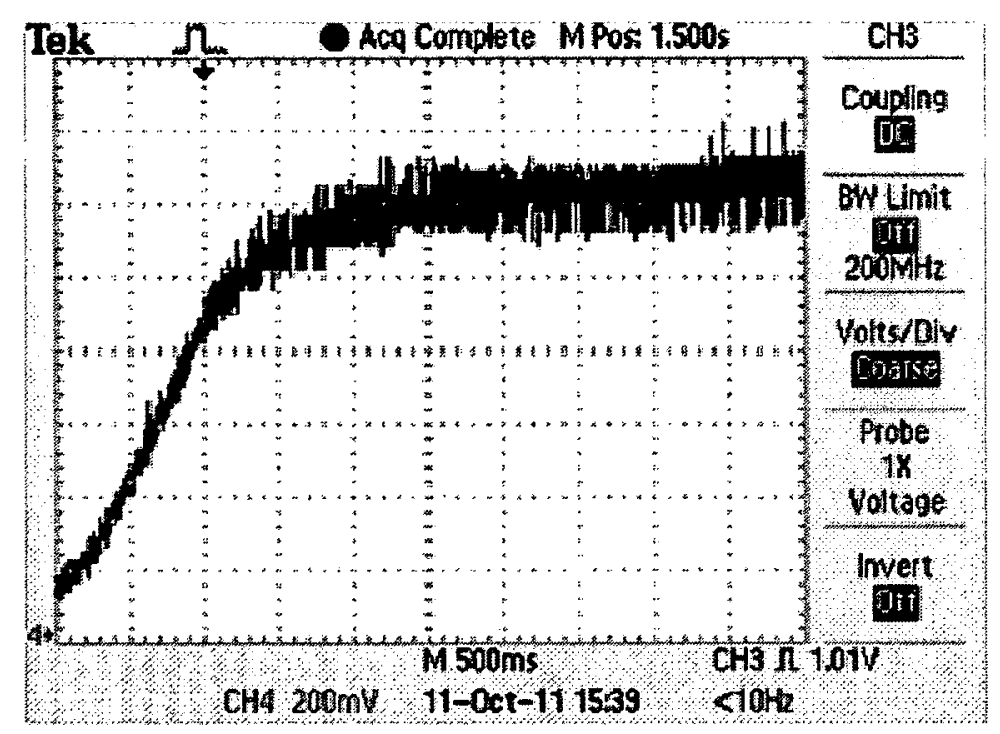

TPS 2024-3;48:29 AM 11/10/2011

\begin{tabular}{|l|l|l|l|l|l|}
\hline Variables & Speed & Load & Vdc & Torque & Current \\
\hline Hall A, VAB, IA & 6000 to 1000 & $51>0$ & 10.0 & & \\
\hline
\end{tabular}

Speed transient

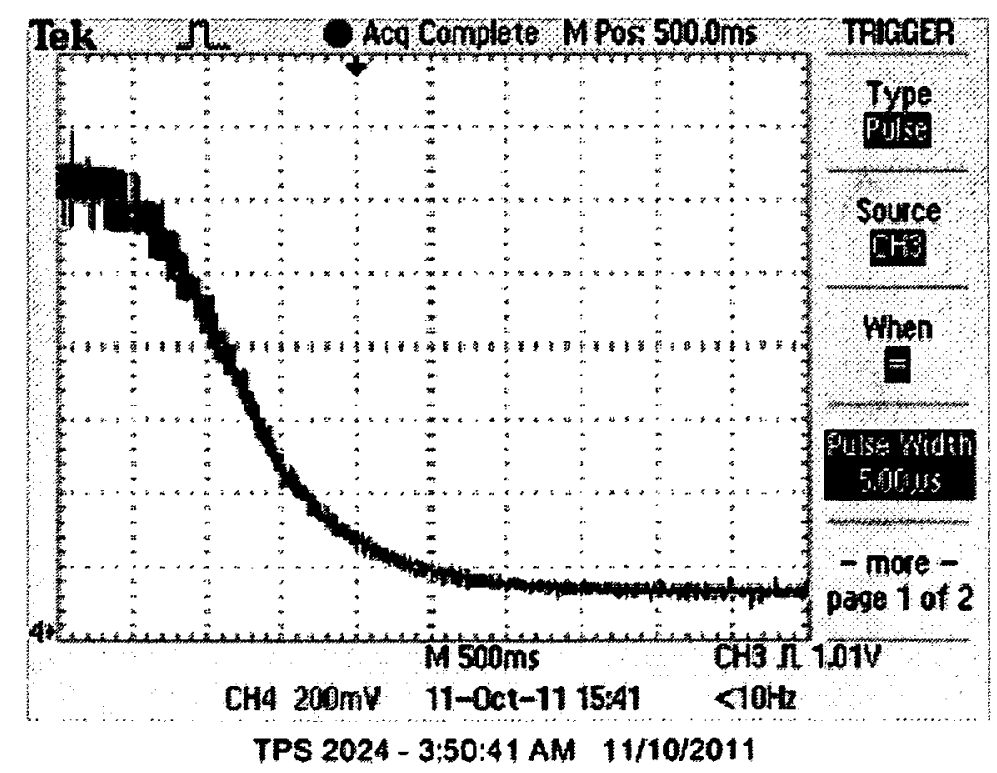




\section{TORQUE TRANSIENT}




\begin{tabular}{|l|l|l|l|l|l|}
\hline Variables & Speed & Load & Vdc & Torque & Current \\
\hline Hall A, VAB, IA & 3000 & $0->51$ & 20.3 & & \\
\hline
\end{tabular}

Speed transient
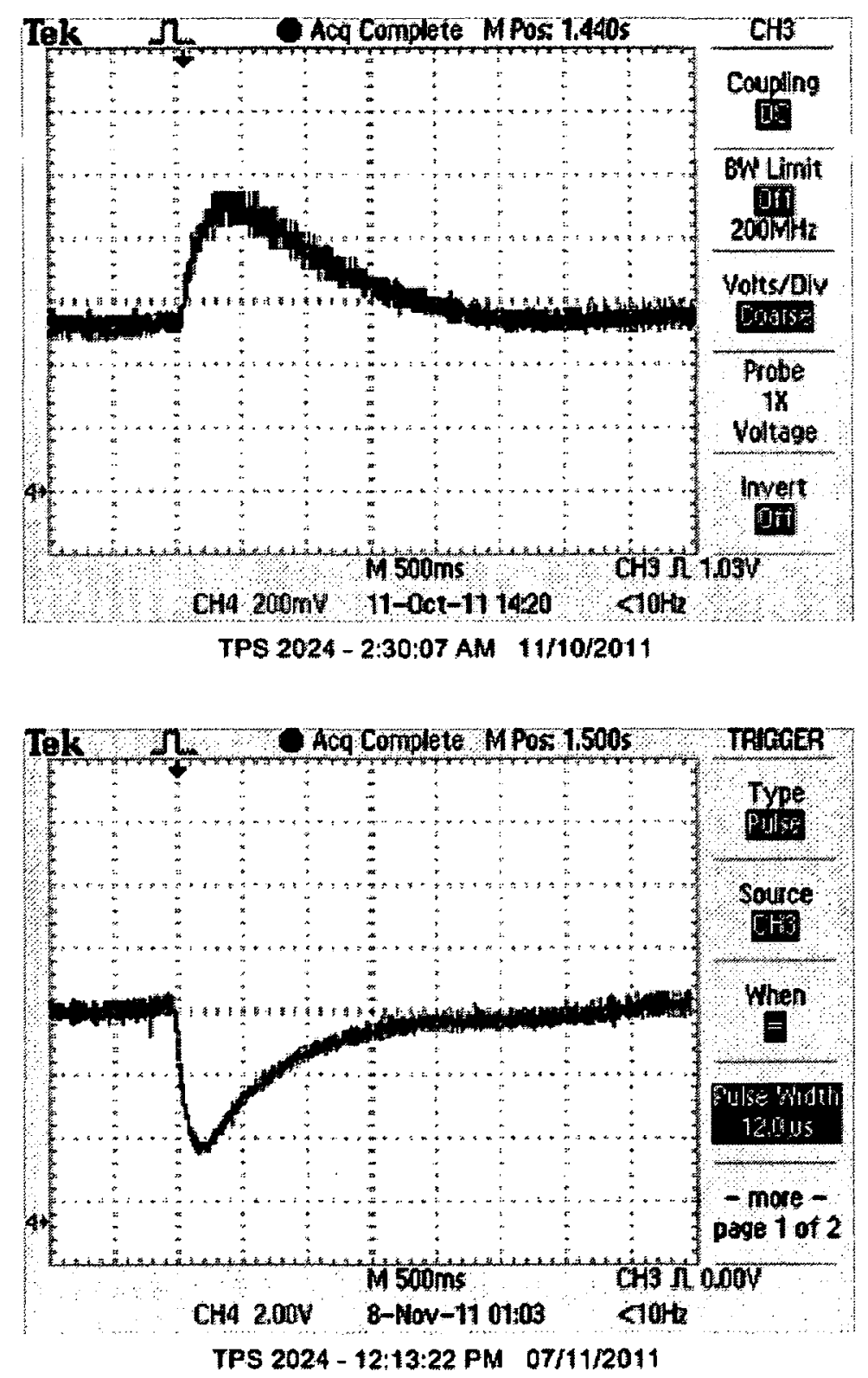

\begin{tabular}{|l|l|l|l|l|l|}
\hline Variables & Speed & Load & Vdc & Torque & Current \\
\hline Hall A, VAB, IA & 3000 & $51 \rightarrow 0$ & 20.3 & & \\
\hline
\end{tabular}

Speed transient 

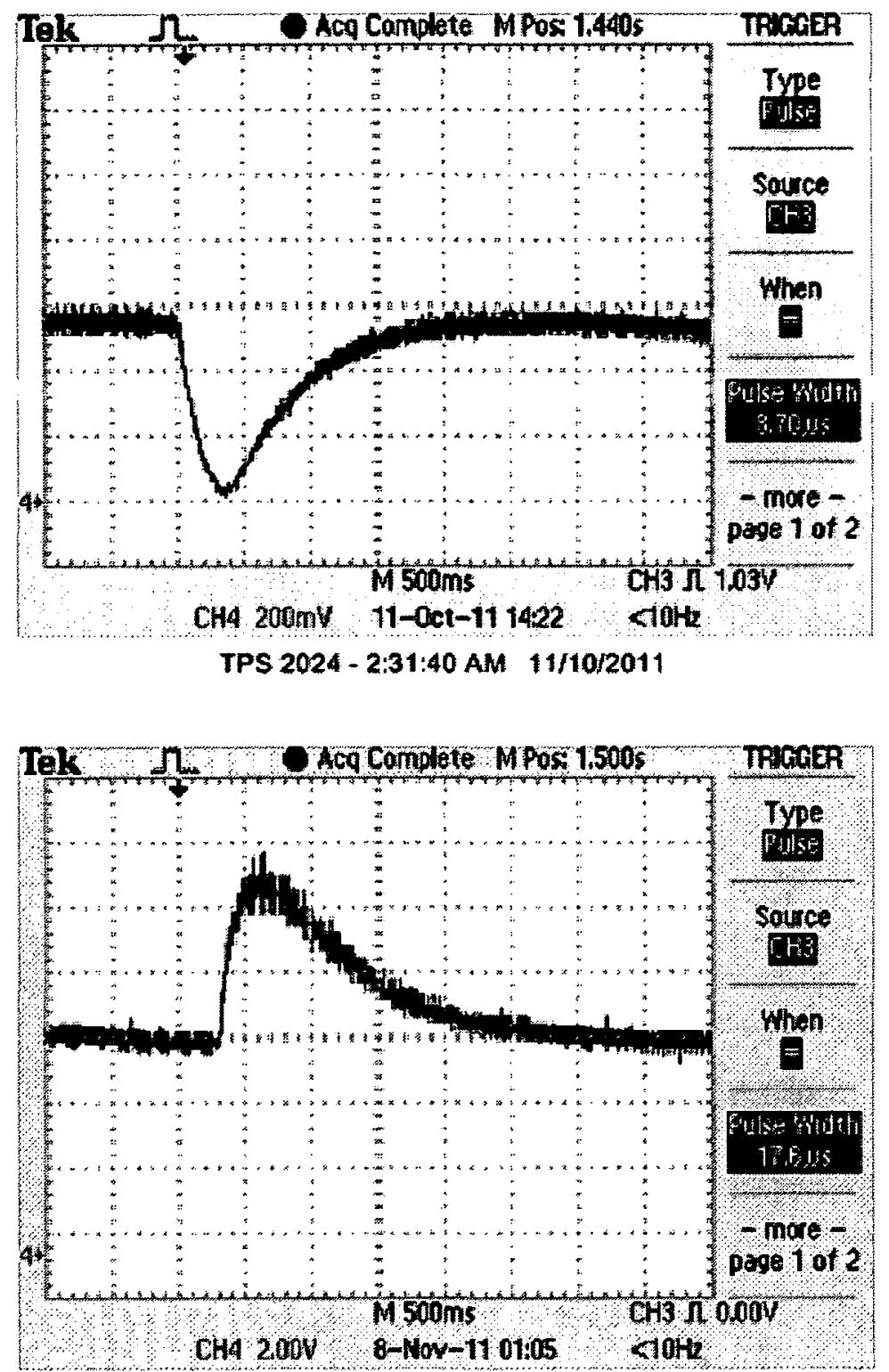

TPS 2024 - 12:15:01 PM 07/11/2011

\begin{tabular}{|l|l|l|l|l|l|}
\hline Variables & Speed & Load & Vdc & Torque & Current \\
\hline Hall A, VAB, IA & 3000 & $0 \rightarrow 22.5$ & 20.3 & & \\
\hline
\end{tabular}

Speed transient 


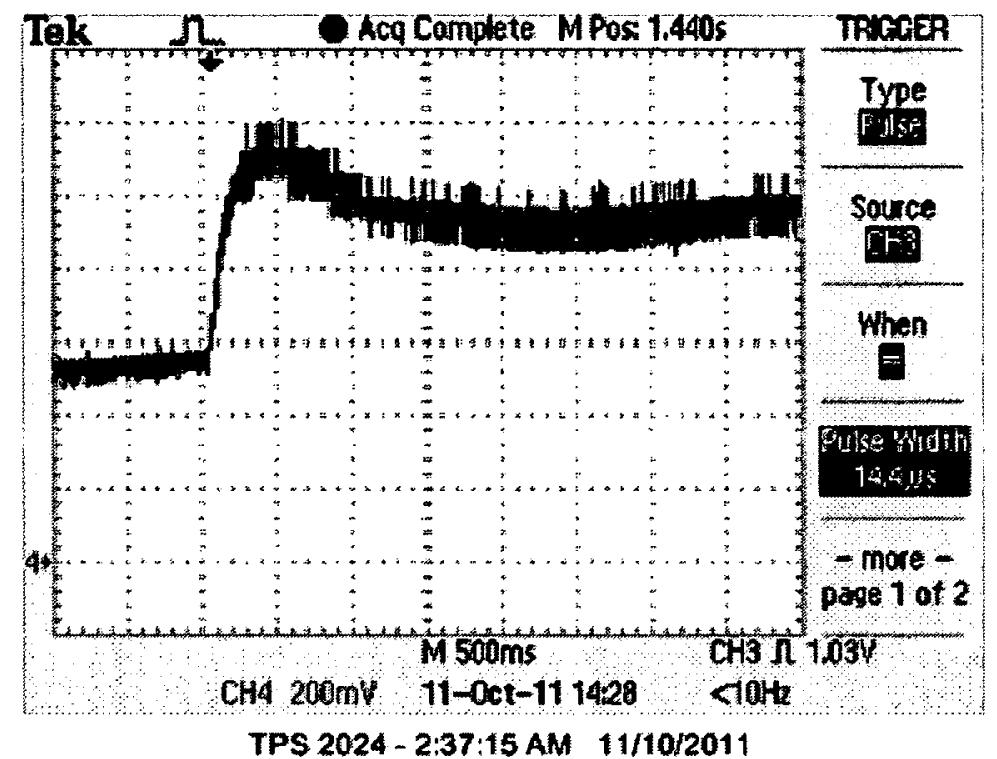

NOTE: TI lost control and could not bring the speed back to 3000 RPM

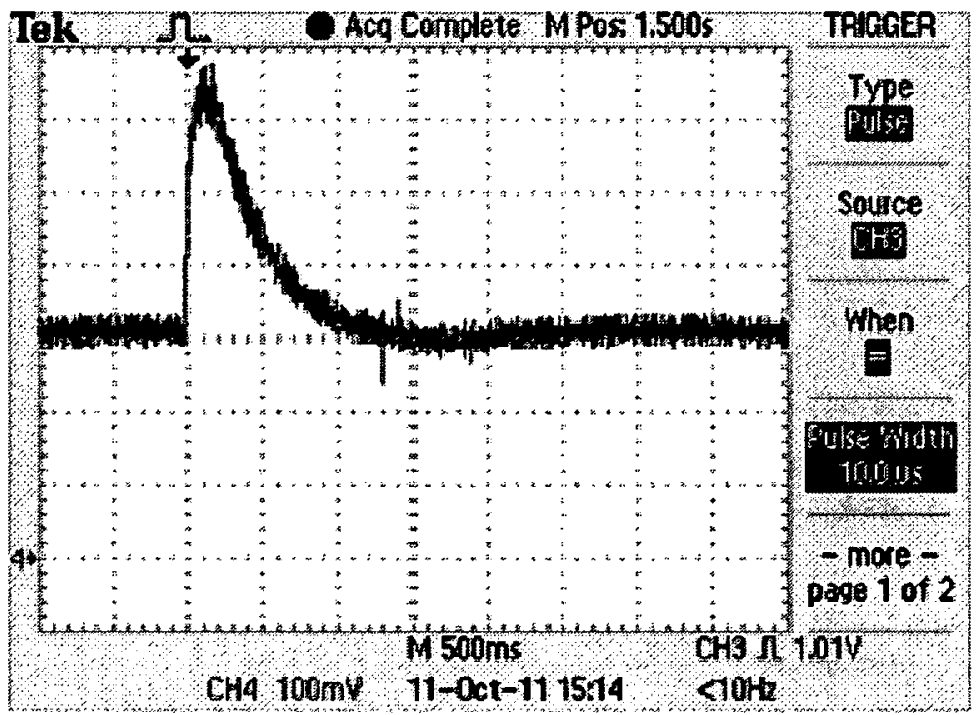

TPS 2024-3:24:02 AM 11/10/2011

NOTE: The value above is for the FPGA controller

\begin{tabular}{|l|l|l|l|l|l|}
\hline Variables & Speed & Load & Vdc & Torque & Current \\
\hline Hall A, VAB, IA & 3000 & $22.5 \rightarrow 0$ & 20.3 & & \\
\hline
\end{tabular}

Speed transient

NOTE: TI lost control completely and stopped 


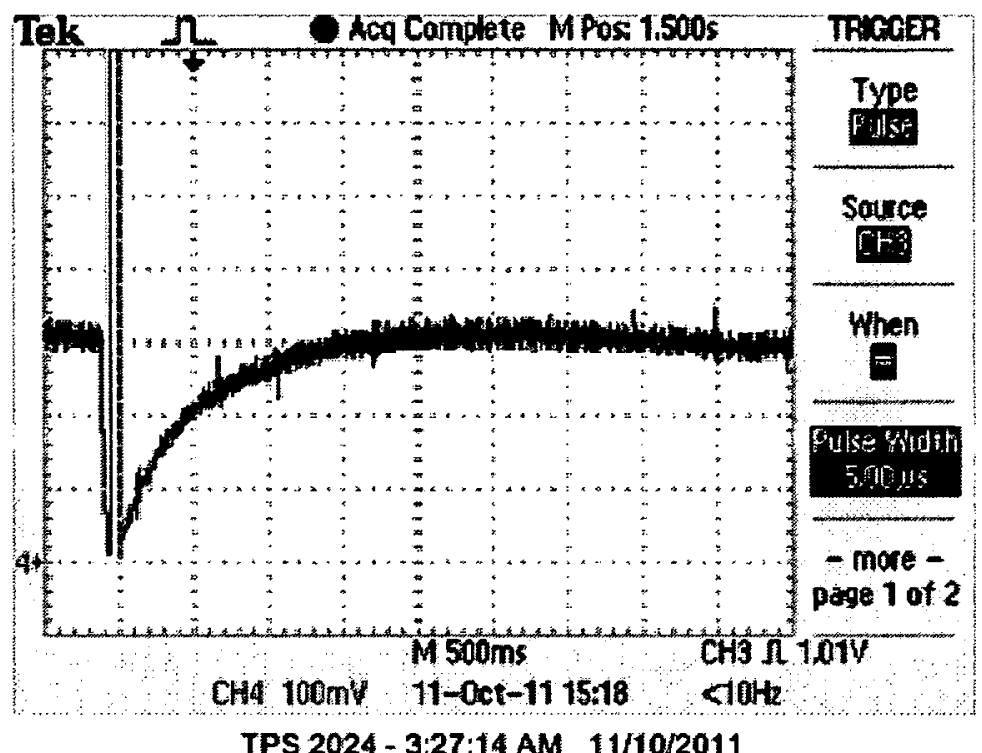

NOTE: The value above is for the FPGA controller

\begin{tabular}{|l|l|l|l|l|l|}
\hline Variables & Speed & Load & Vdc & Torque & Current \\
\hline Hall A, VAB, IA & 3000 & $0 \rightarrow 22.5$ & 10.0 & & \\
\hline
\end{tabular}

Speed transient

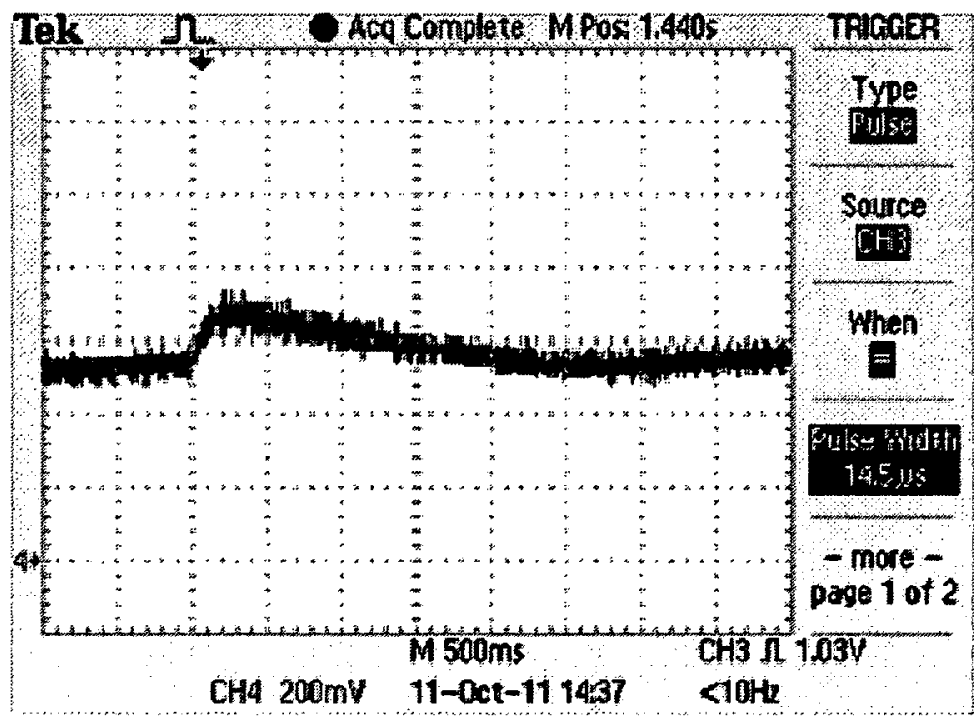

TPS 2024 - 2:46:58 AM 11/10/2011

\begin{tabular}{|l|l|l|l|l|l|}
\hline Variables & Speed & Load & Vdc & Torque & Current \\
\hline Hall A, VAB, IA & 3000 & $22.5->0$ & 10.0 & & \\
\hline
\end{tabular}

Speed transient 


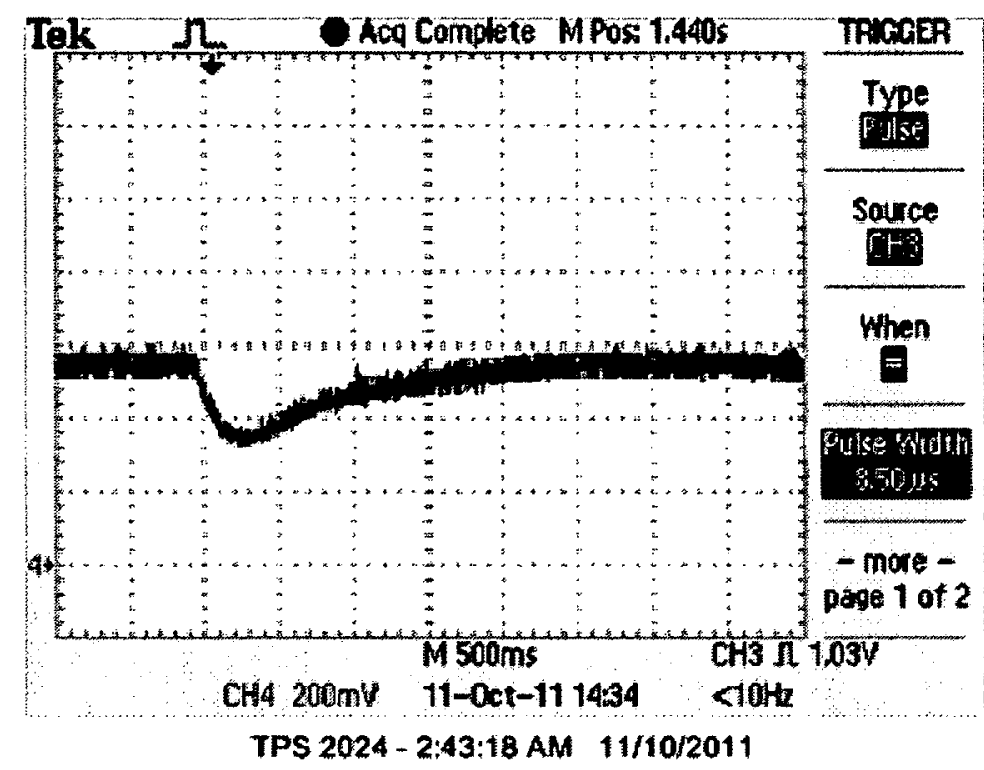

\begin{tabular}{|l|l|l|l|l|l|}
\hline Variables & Speed & Load & Vdc & Torque & Current \\
\hline Hall A, VAB, IA & 2000 & $0 \rightarrow 51$ & 20.3 & & \\
\hline
\end{tabular}

Speed transient

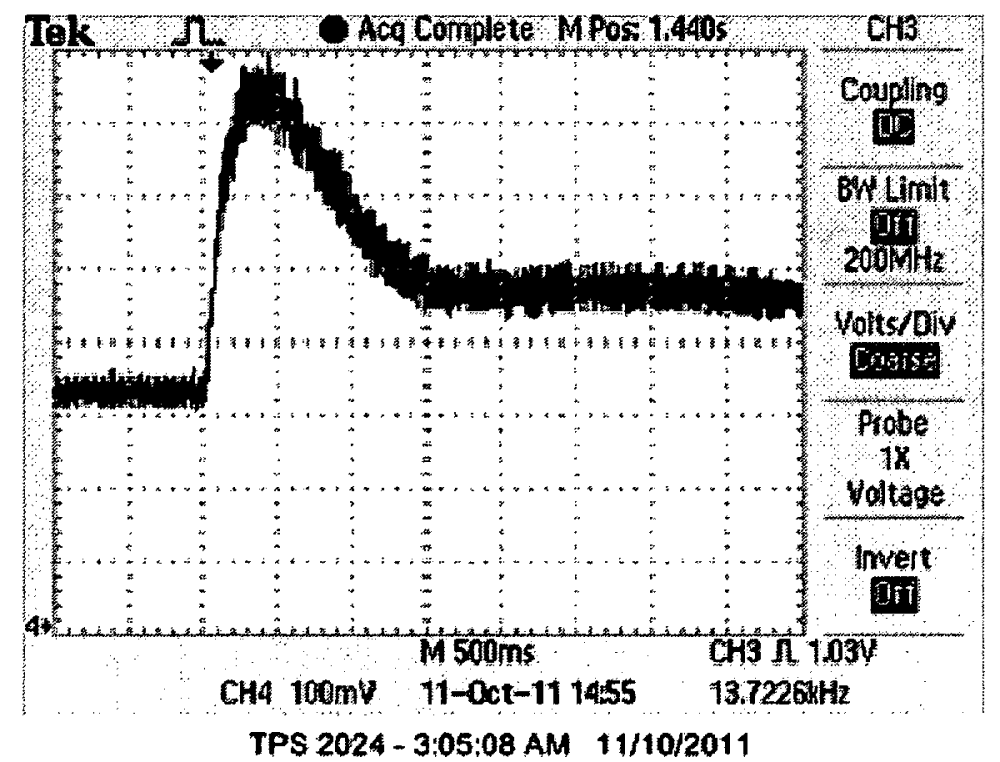

NOTE: $T I$ lost control and could not bring the speed back to 3000 RPM 


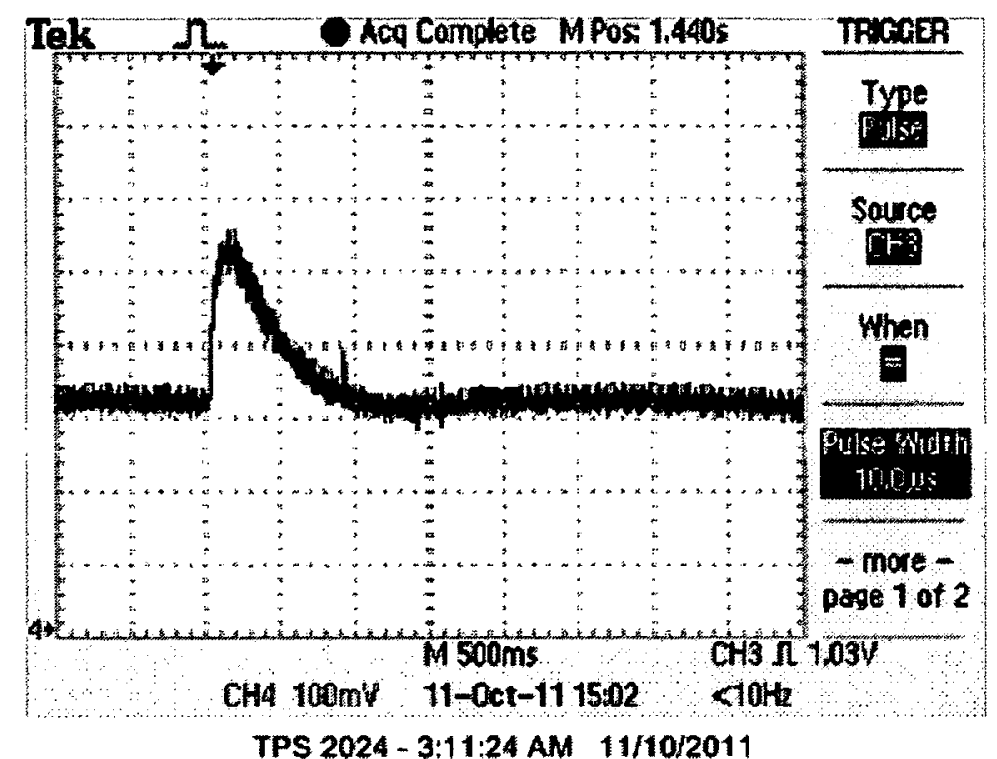

NOTE: The value above is for the FPGA controller

\begin{tabular}{|l|l|l|l|l|l|}
\hline Variables & Speed & Load & Vdc & Torque & Current \\
\hline Hall A, VAB, IA & 2000 & $51 \rightarrow 0$ & 20.3 & & \\
\hline
\end{tabular}

Speed transient

NOTE: TI lost control completely and stopped

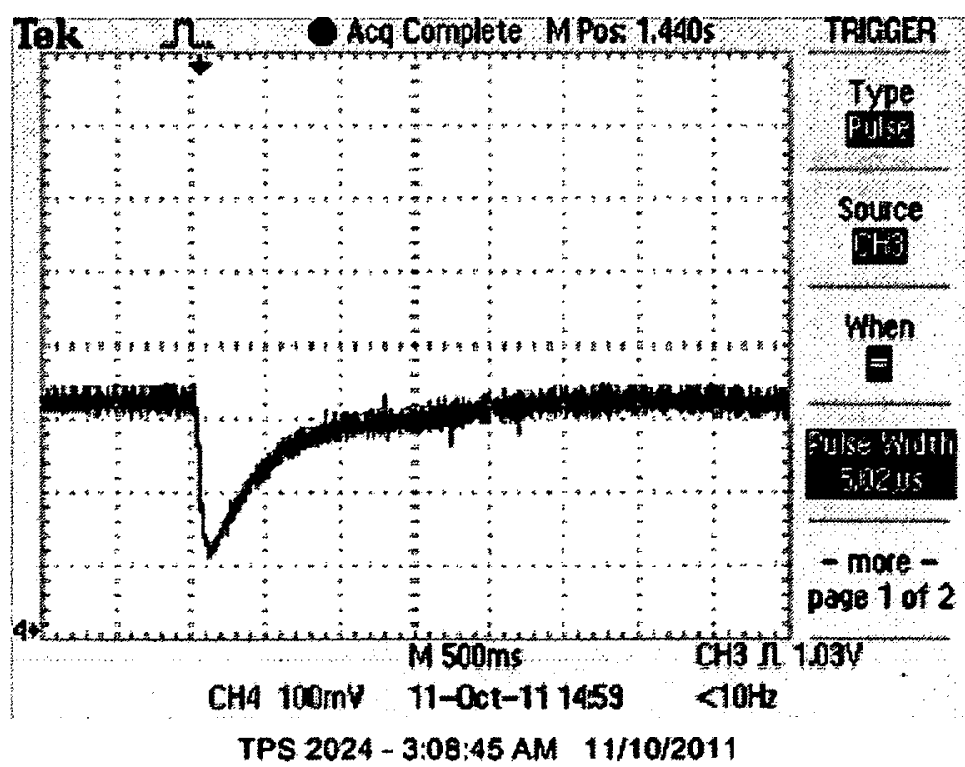


NOTE: The value above is for the FPGA controller

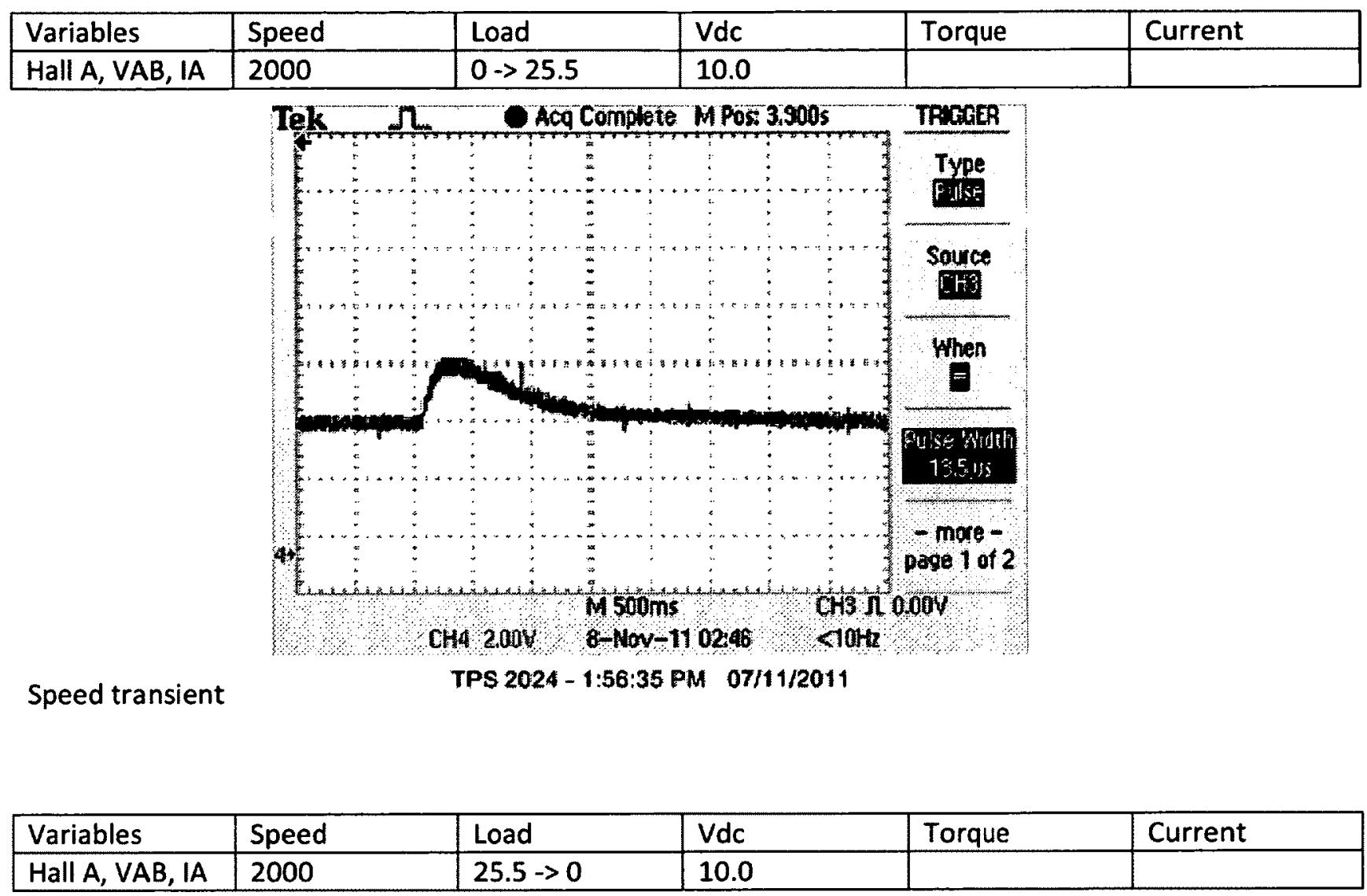

Speed transient

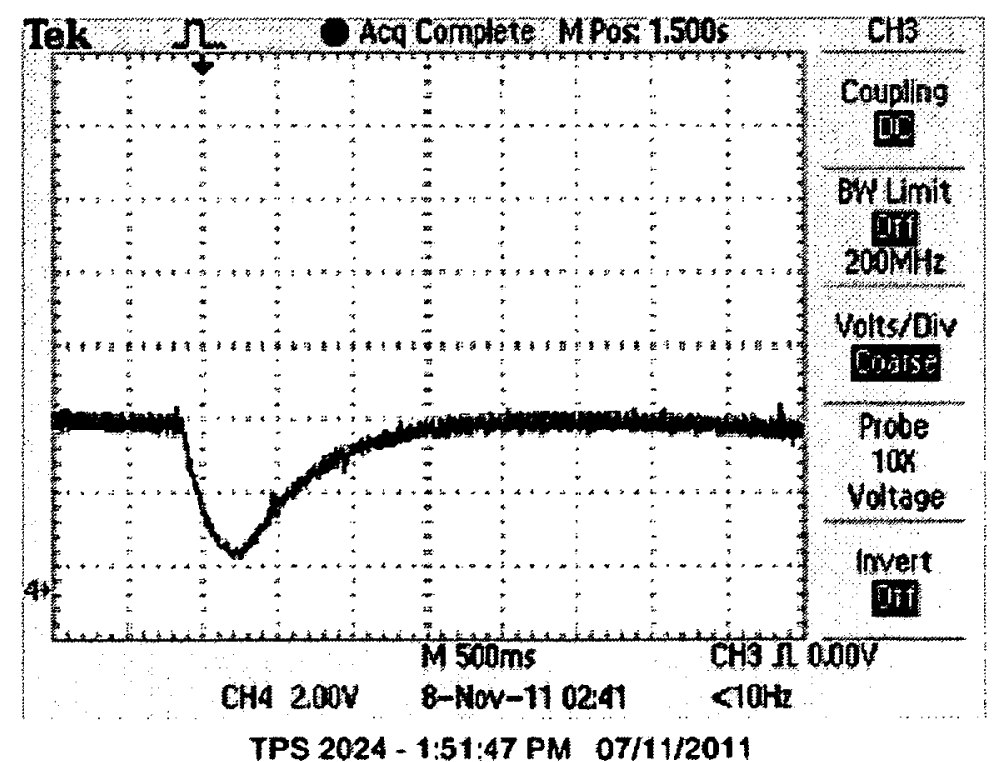




\begin{tabular}{|l|l|l|l|l|l|}
\hline Variables & Speed & Load & Vdc & Torque & Current \\
\hline Hall A, VAB, IA & 2000 & $0->25.5$ & 20.3 & & \\
\hline
\end{tabular}

Speed transient

NOTE: result total torque is beyond the stall torque

\begin{tabular}{|l|l|l|l|l|l|}
\hline Variables & Speed & Load & Vdc & Torque & Current \\
\hline Hall A, VAB, IA & 2000 & $25.5 \rightarrow 0$ & 20.3 & & \\
\hline
\end{tabular}

Speed transient

NOTE: result total torque is beyond the stall torque

\begin{tabular}{|l|l|l|l|l|l|}
\hline Variables & Speed & Load & Vdc & Torque & Current \\
\hline Hall A, VAB, IA & 4000 & $0->51$ & 20.2 & & \\
\hline
\end{tabular}

Speed transient

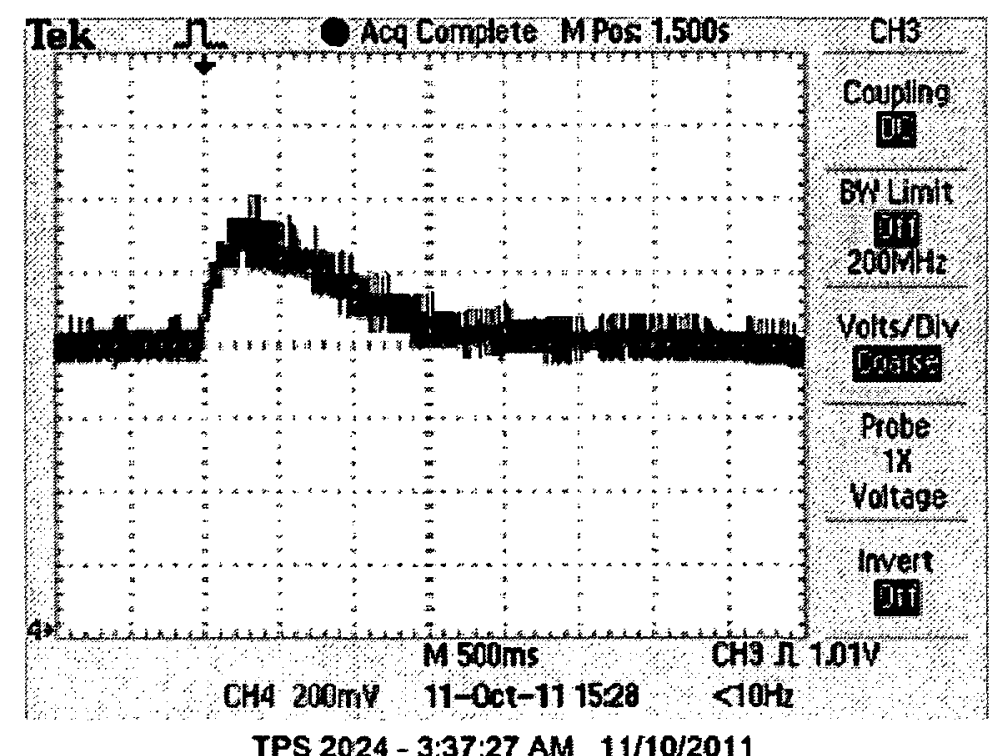

TPS 2024 - 3:37:27 AM 11/10/2011

\begin{tabular}{|l|l|l|l|l|l|}
\hline Variables & Speed & Load & Vdc & Torque & Current \\
\hline Hall A, VAB, IA & 4000 & $51 \rightarrow 0$ & 20.2 & & \\
\hline
\end{tabular}

Speed transient 

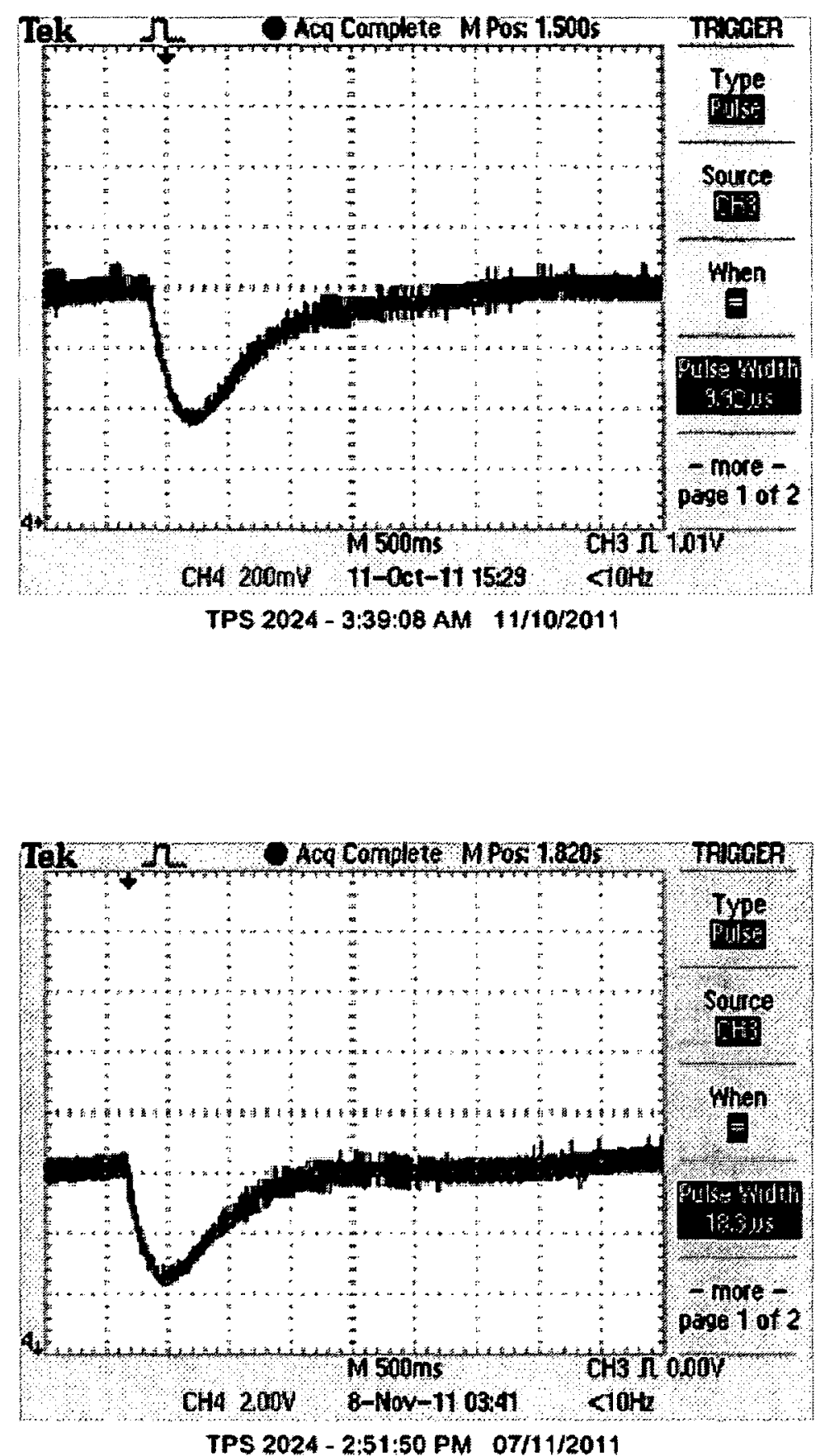

\begin{tabular}{|l|l|l|l|l|l|}
\hline Variables & Speed & Load & Vdc & Torque & Current \\
\hline Hall A, VAB, IA & 4000 & $0 \rightarrow 22.5$ & 10.0 & & \\
\hline
\end{tabular}

Speed transient 


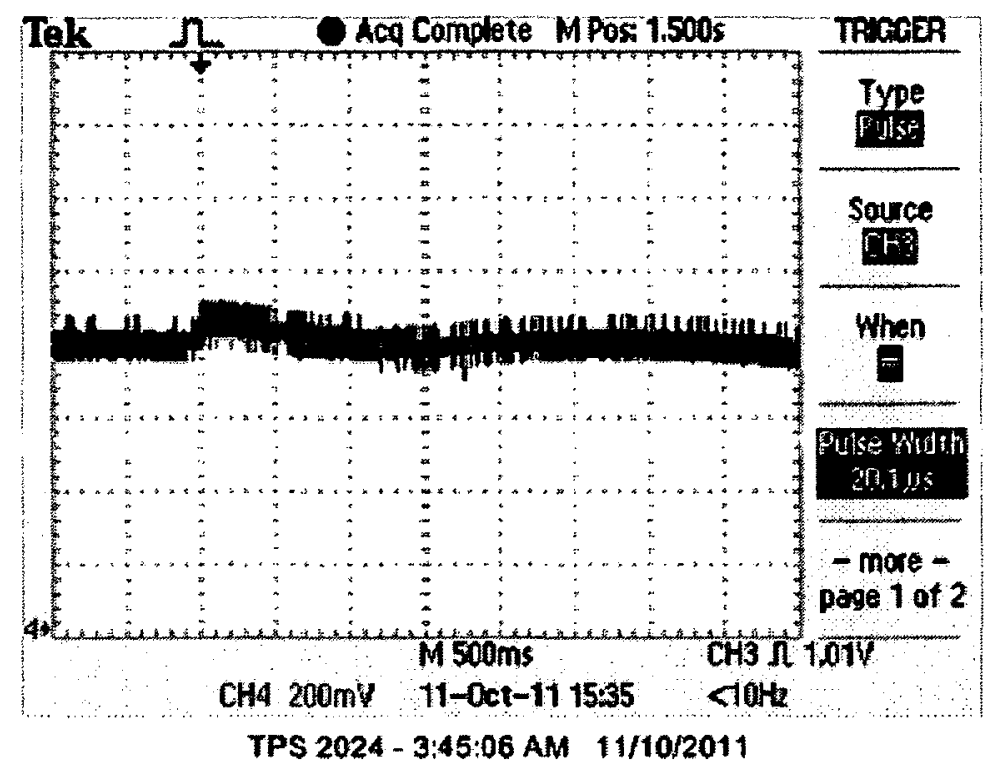

\begin{tabular}{|l|l|l|l|l|l|}
\hline Variables & Speed & Load & Vdc & Torque & Current \\
\hline Hall A, VAB, IA & 4000 & $22.5->0$ & 10.0 & & \\
\hline
\end{tabular}

Speed transient

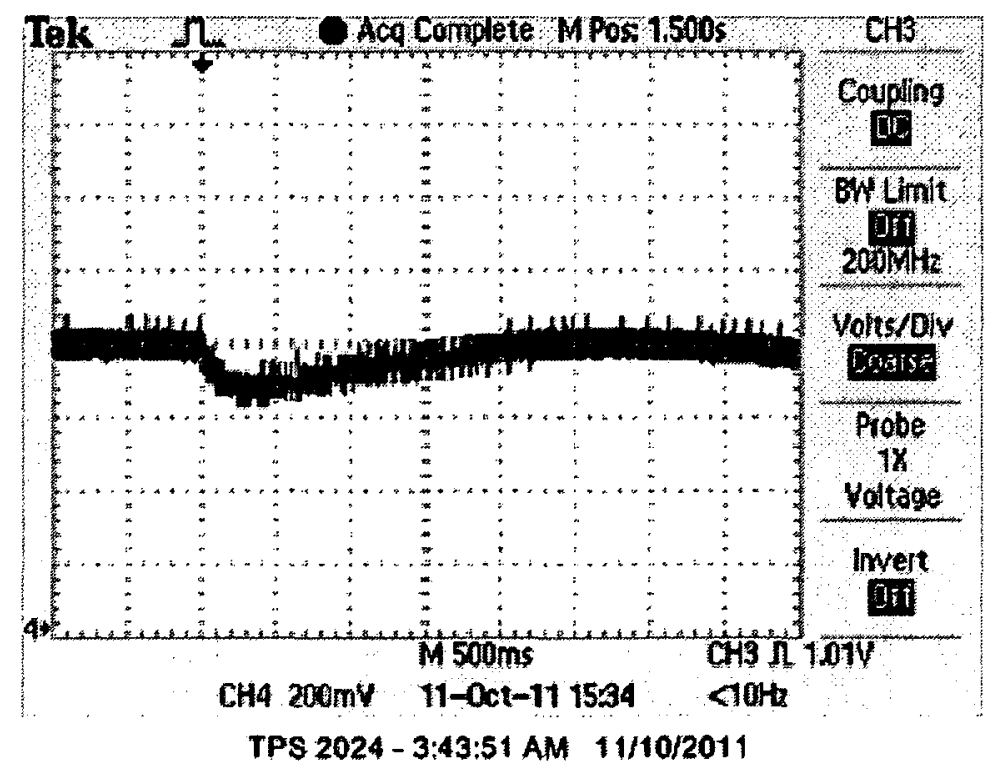




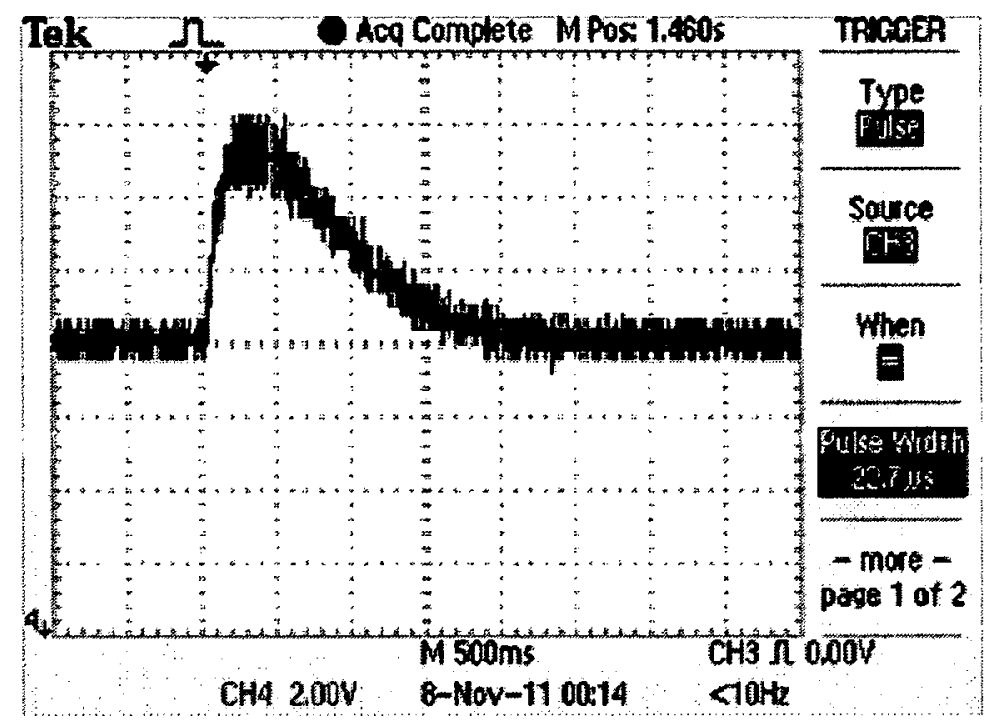

TPS 2024 - 11:24:39 AM 07/11/2011

\begin{tabular}{|l|l|l|l|l|l|}
\hline Variables & Speed & Load & Vdc & Torque & Current \\
\hline Hall A, VAB, IA & 6000 & $0->51$ & 20.3 & & \\
\hline
\end{tabular}

Speed transient

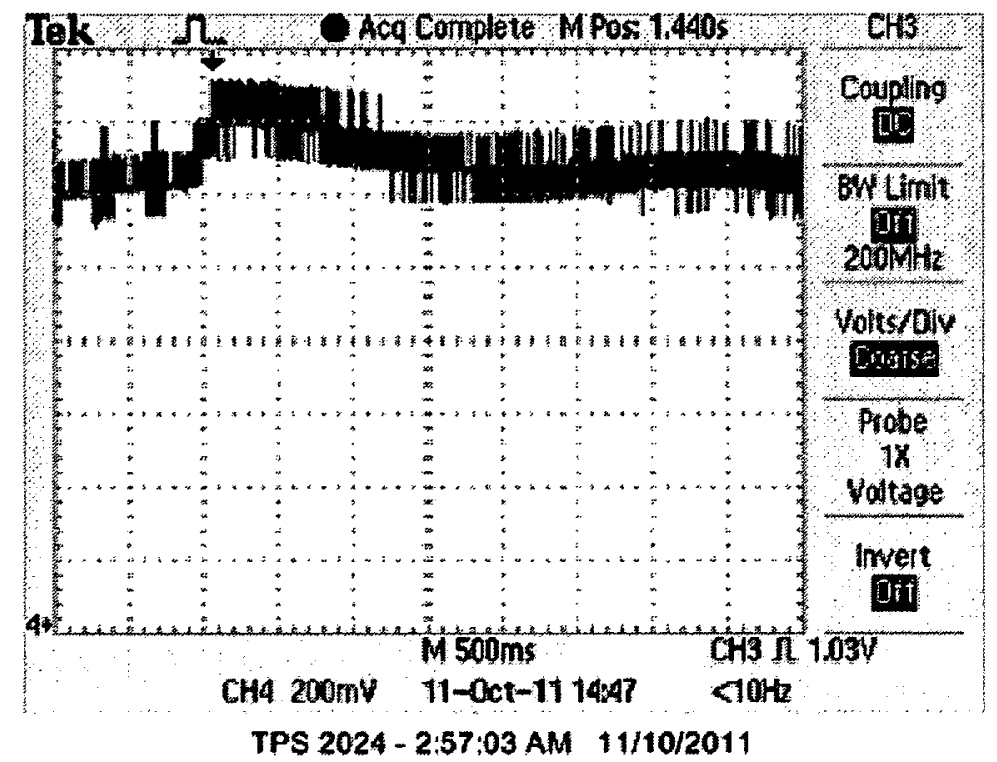

\begin{tabular}{|l|l|l|l|l|l|}
\hline Variables & Speed & Load & Vdc & Torque & Current \\
\hline Hall A, VAB, IA & 6000 & $51->0$ & 20.3 & & \\
\hline
\end{tabular}

Speed transient 

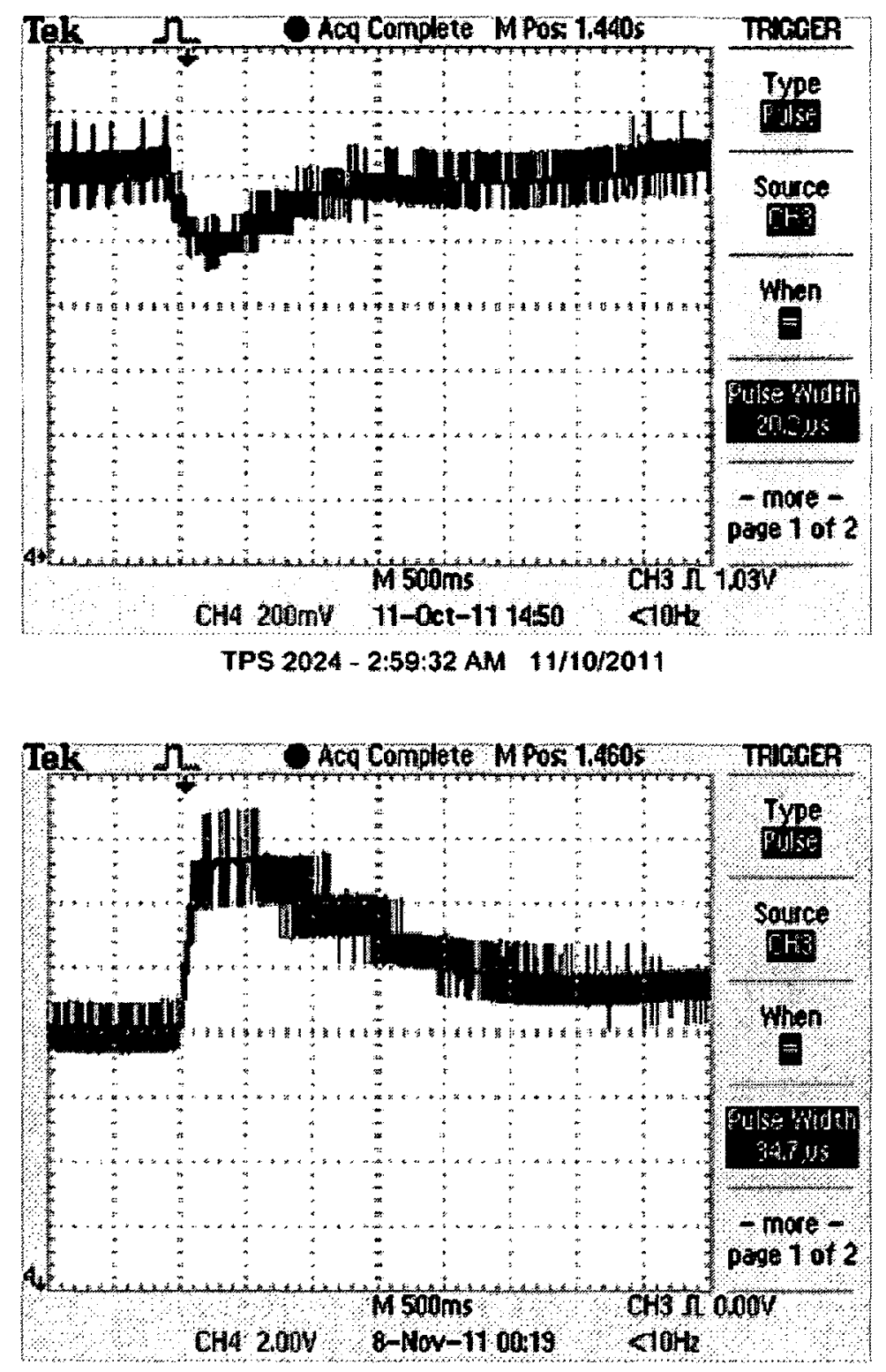

TPS 2024-11:29:56 AM 07/11/2011 


\subsection{Annexe 2, Measurements from the FPGA-based System}

Next we include results the measurement data for the speed and torque transient from testing related to the FPGA-based system

\section{SPEED TRANSIENT}

\section{(1000 RPM $\rightarrow 2000$ RPM $\rightarrow 1000$ RPM)}




\begin{tabular}{|l|l|l|l|l|l|}
\hline Variables & Speed & Load & Vdc & Torque & Current \\
\hline Hall A, VAB, IA & 1000 to 2000 & 0 & 0 & & \\
\hline
\end{tabular}

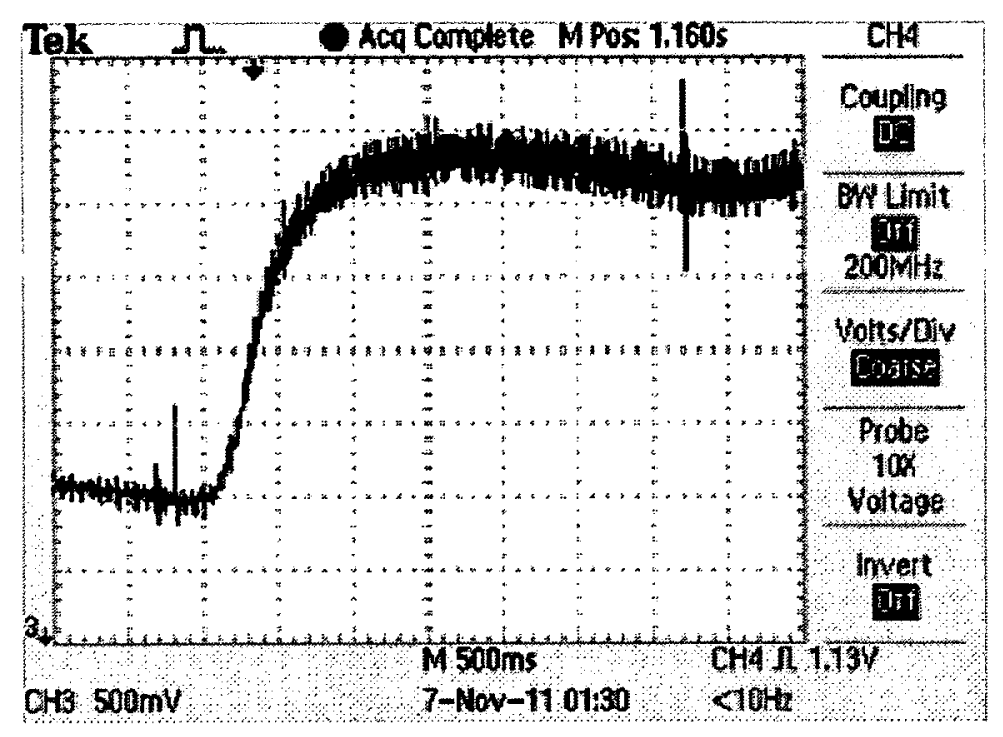

TPS 2024 - 12:40:09 PM 06/11/2011

\begin{tabular}{|l|l|l|l|l|l|}
\hline Variables & Speed & Load & Vdc & Torque & Current \\
\hline Hall A, VAB, IA & 2000 to 1000 & 0 & 0 & & \\
\hline
\end{tabular}

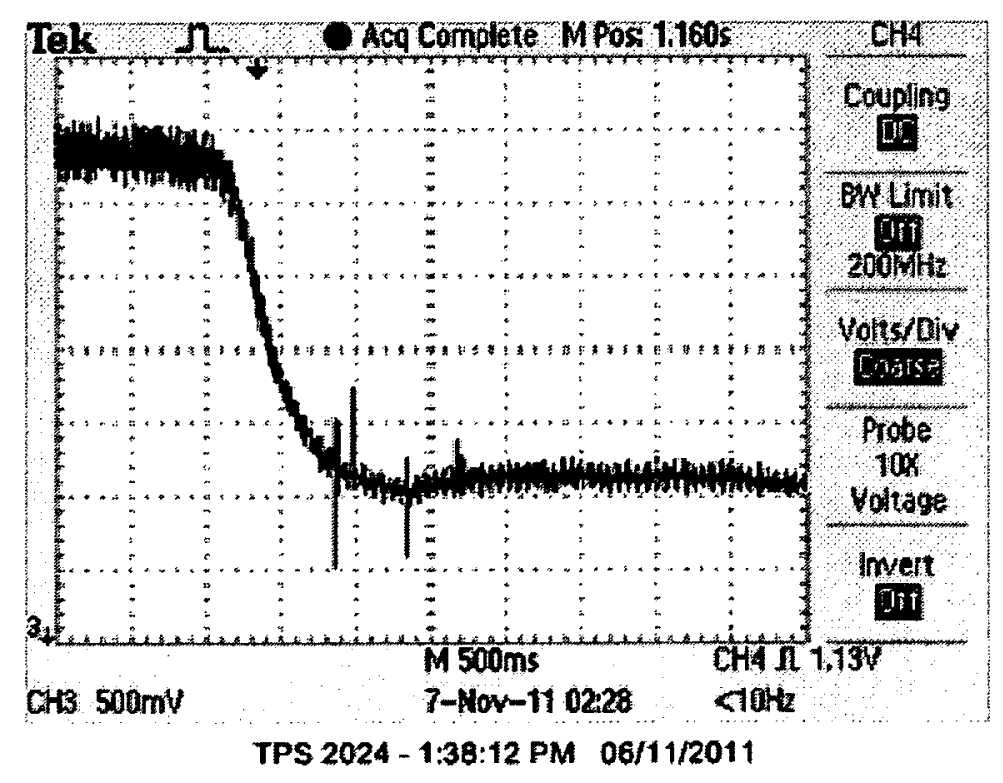




\begin{tabular}{|l|l|l|l|l|l|}
\hline Variables & Speed & Load & Vdc & Torque & Current \\
\hline Hall A, VAB, IA & 1000 to 2000 & 51 & 20.3 & & \\
\hline
\end{tabular}

Speed transient

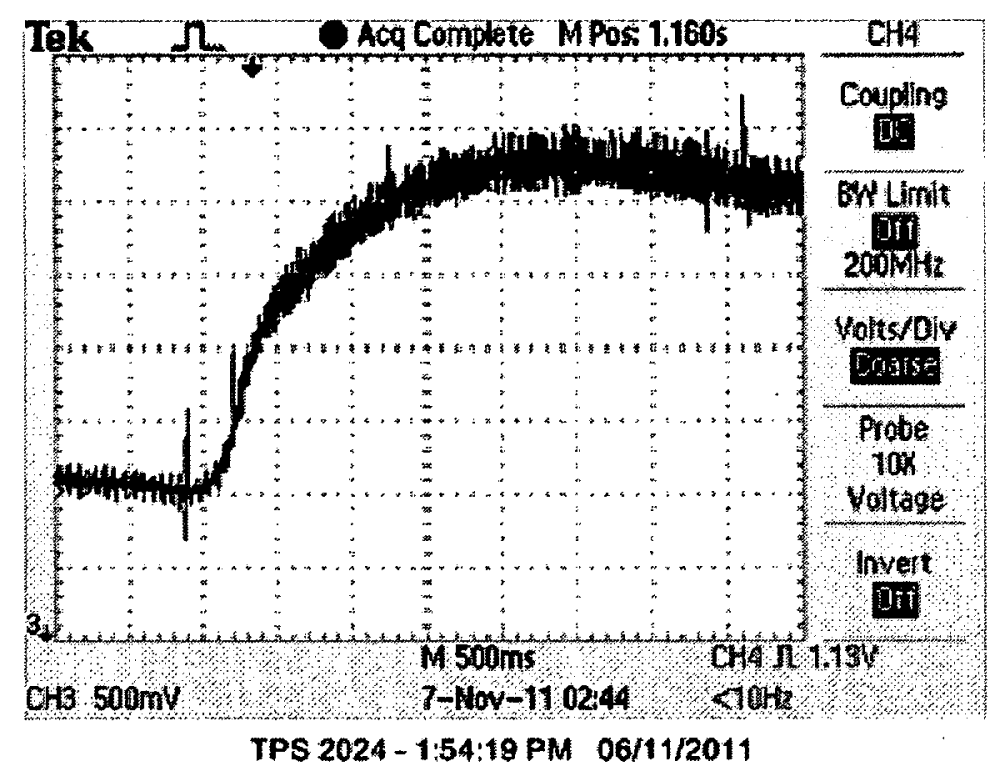




\begin{tabular}{|l|l|l|l|l|l|}
\hline Variables & Speed & Load & Vdc & Torque & Current \\
\hline Hall A, VAB, IA & 2000 to 1000 & 51 & 20.3 & & \\
\hline
\end{tabular}

Speed transient

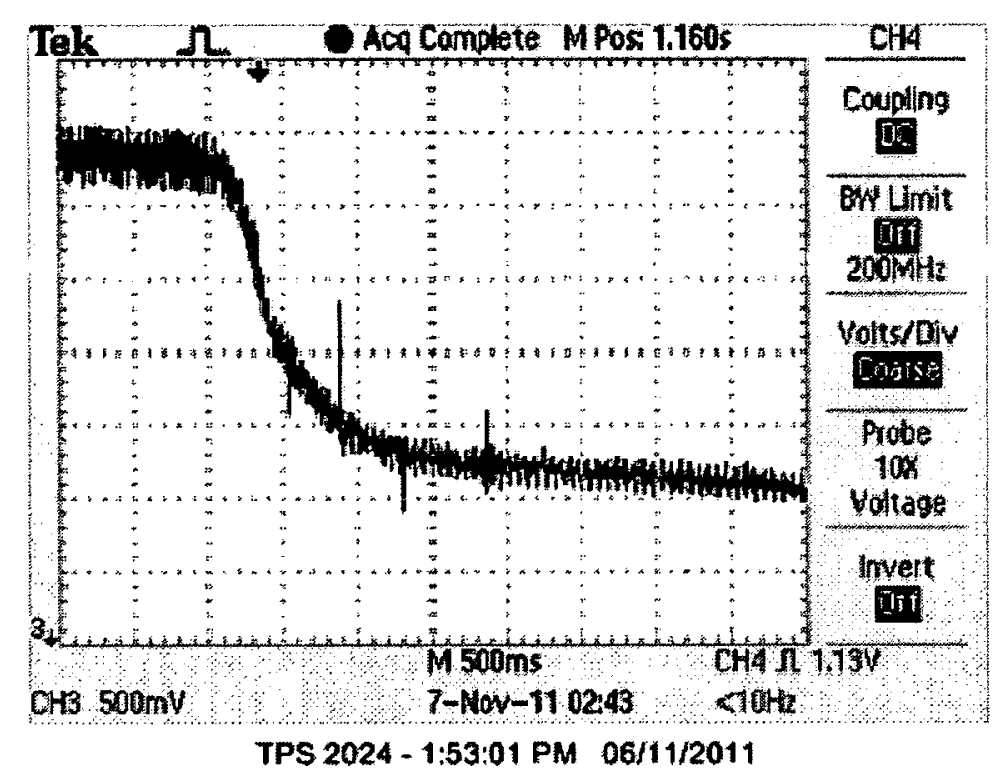




\section{SPEED TRANSIENT}

\section{$(1000 R P M \rightarrow 6000 R P M \rightarrow 1000 R P M)$}




\begin{tabular}{|l|l|l|l|l|l|}
\hline Variables & Speed & Load & Vdc & Torque & Current \\
\hline Hall A, VAB, IA & 1000 to 6000 & 0 & 20.3 & & \\
\hline
\end{tabular}

Speed transient

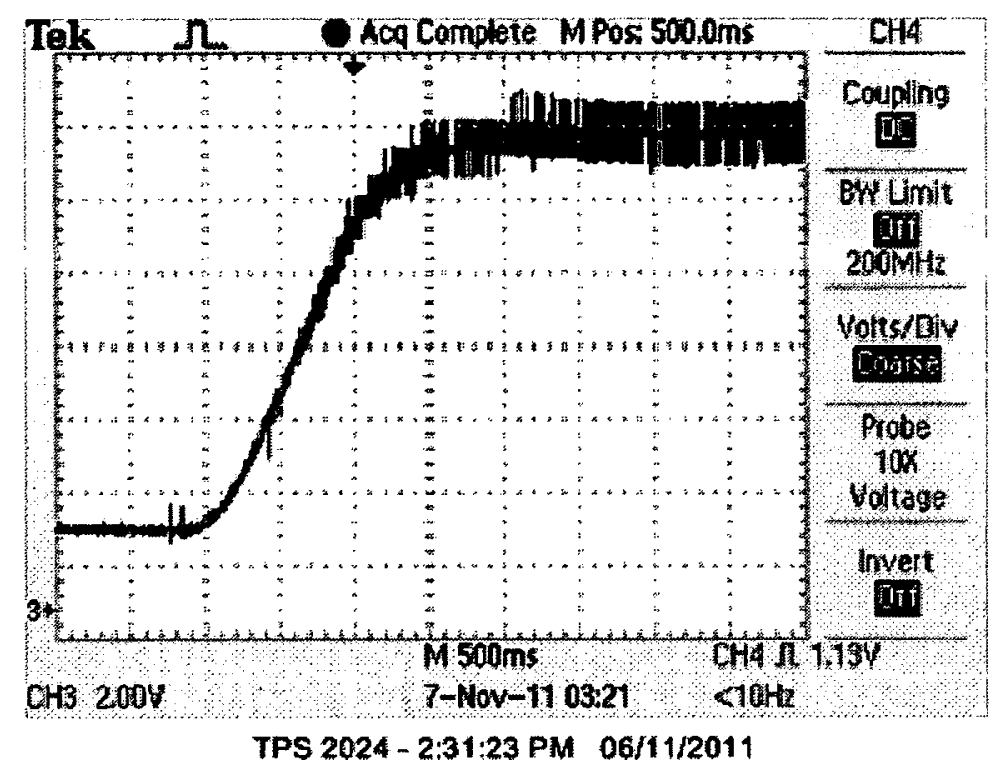




\begin{tabular}{|l|l|l|l|l|l|}
\hline Variables & Speed & Load & Vdc & Torque & Current \\
\hline Hall A, VAB, IA & 6000 to 1000 & 0 & 20.3 & & \\
\hline
\end{tabular}

Speed transient

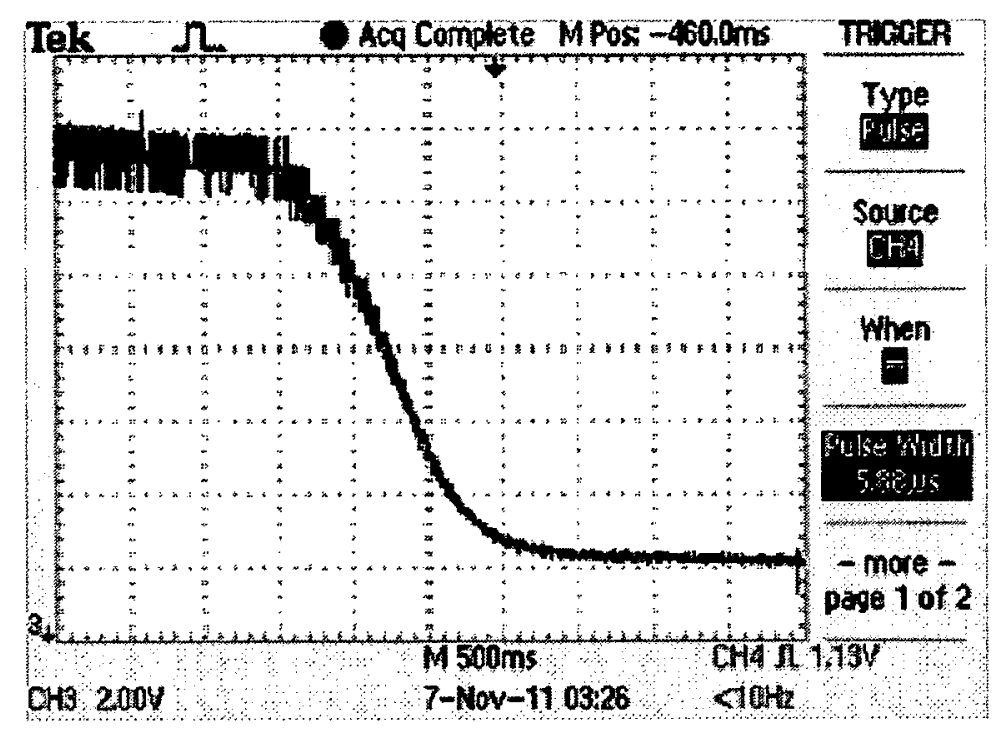

TPS 2024 - 2:36:57 PM 06/11/2011

\begin{tabular}{|l|l|l|l|l|l|}
\hline Variables & Speed & Load & Vdc & Torque & Current \\
\hline Hall A, VAB, IA & 1000 to 6000 & $0->51$ & 10.0 & & \\
\hline
\end{tabular}

Speed transient

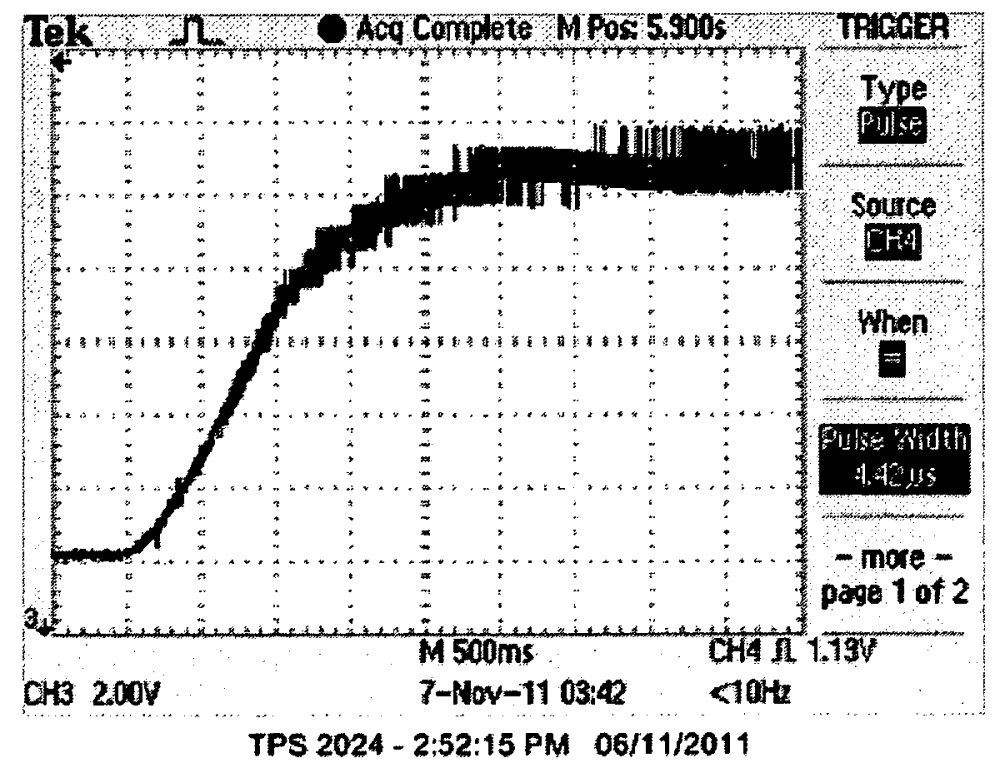




\begin{tabular}{|l|l|l|l|l|l|}
\hline Variables & Speed & Load & Vdc & Torque & Current \\
\hline Hall A, VAB, IA & 6000 to 1000 & $51-0$ & 10.0 & & \\
\hline
\end{tabular}

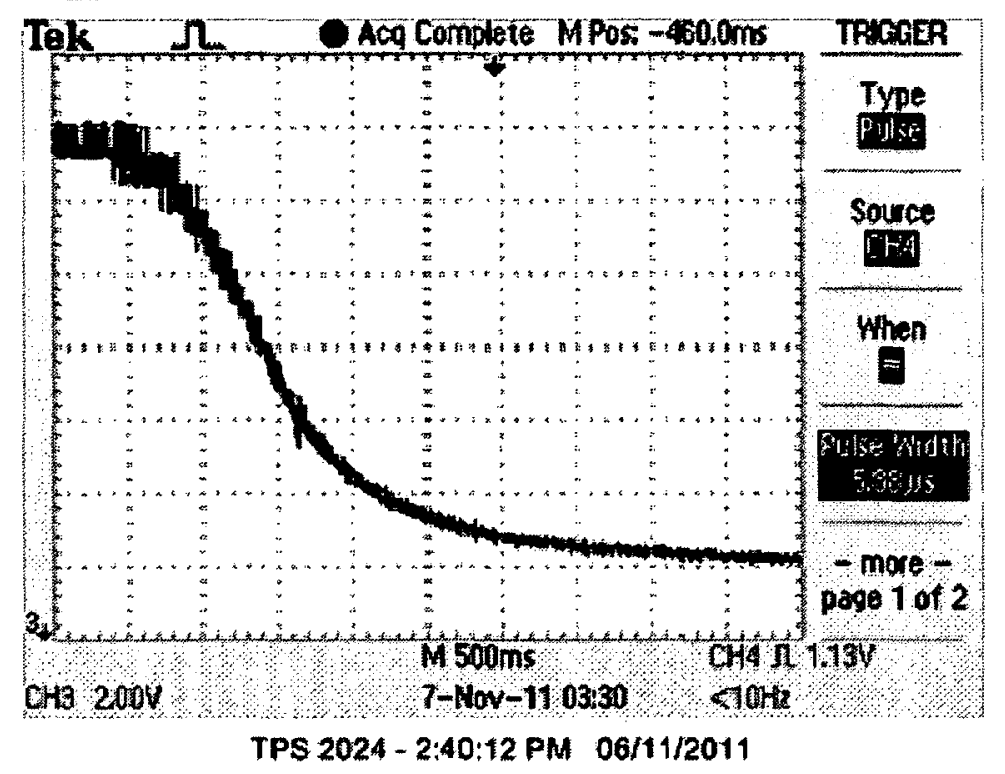


TORQUE TRANSIENT 


\begin{tabular}{|l|l|l|l|l|l|}
\hline Variables & Speed & Load & Vdc & Torque & Current \\
\hline Hall A, VAB, IA & 3000 & $0 \rightarrow 51$ & 20.3 & & \\
\hline
\end{tabular}

Speed transient

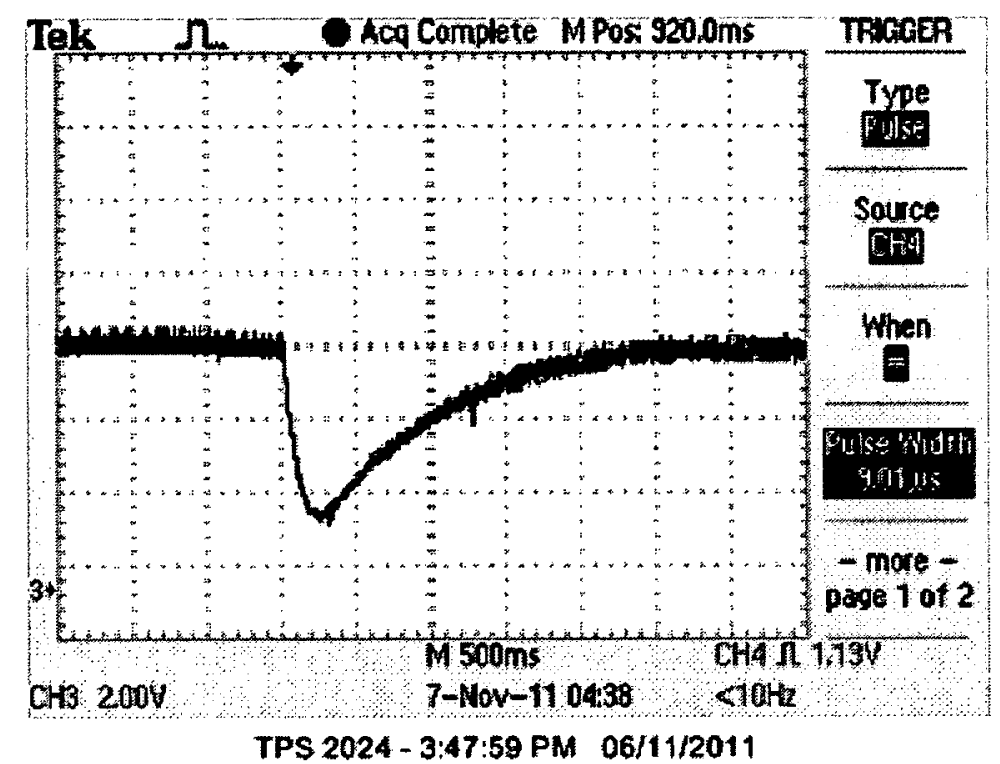

\begin{tabular}{|l|l|l|l|l|l|}
\hline Variables & Speed & Load & Vdc & Torque & Current \\
\hline Hall A, VAB, IA & 3000 & $51-0$ & 20.3 & & \\
\hline
\end{tabular}

Speed transient

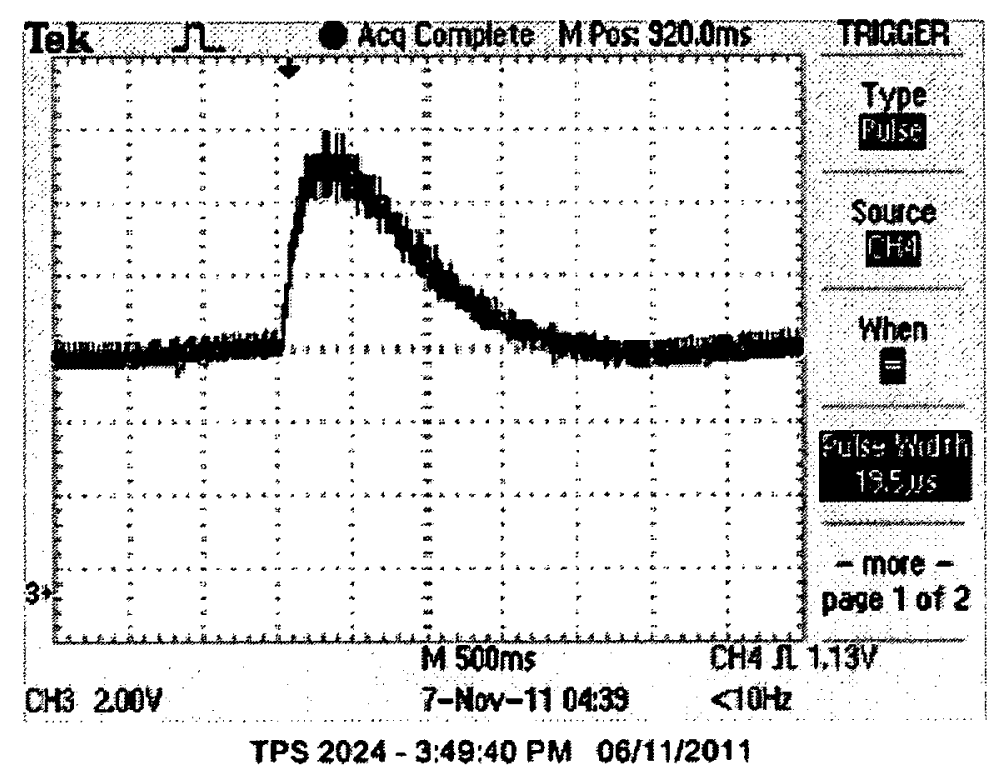

\begin{tabular}{|l|l|l|l|l|l|}
\hline Variables & Speed & Load & Vdc & Torque & Current \\
\hline Hall A, VAB, IA & 3000 & $0-722.5$ & 20.3 & & \\
\hline
\end{tabular}


Speed transient

NOTE: $T$ I lost control and could not bring the speed back to 3000 RPM

NOTE: The value above is for the FPGA controller

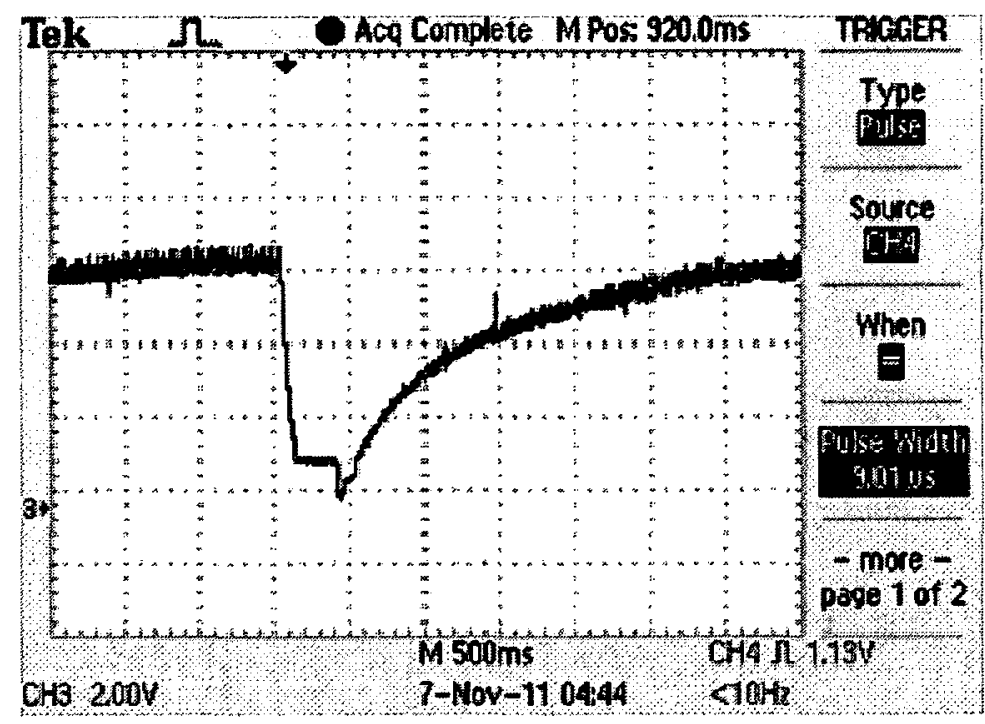

TPS 2024 - 3:54:27 PM 06/11/2011

\begin{tabular}{|l|l|l|l|l|l|}
\hline Variables & Speed & Load & Vdc & Torque & Current \\
\hline Hall A, VAB, IA & 3000 & $22.5-0$ & 20.3 & & \\
\hline
\end{tabular}

Speed transient

NOTE: TI lost control completely and stopped

NOTE: The value above is for the FPGA controller 


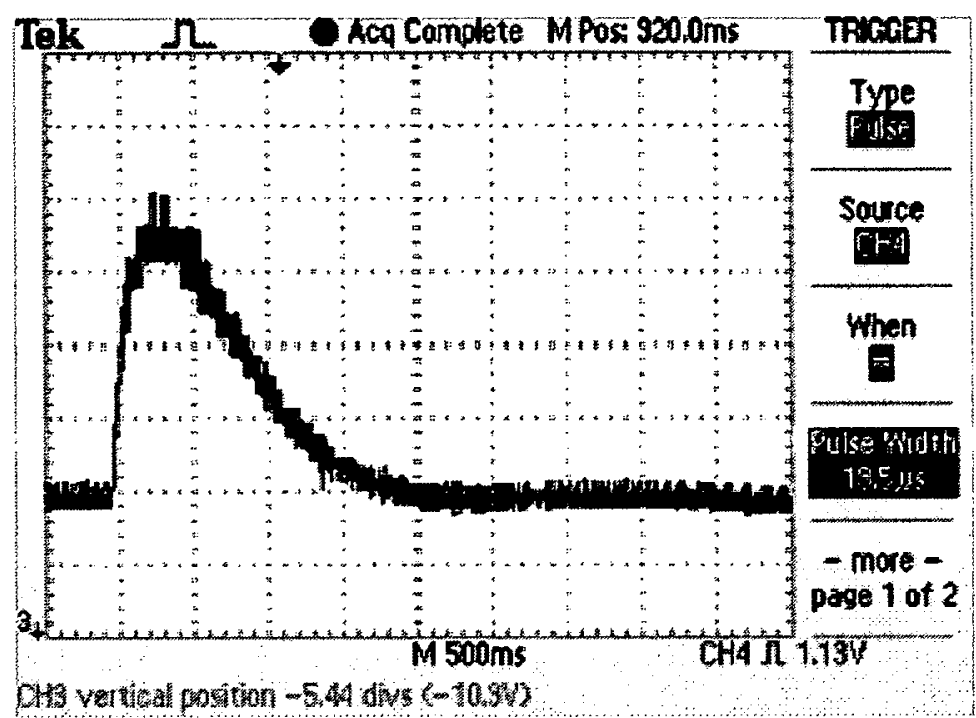

TPS 2024 - 3:52:18 PM 06/11/2011

\begin{tabular}{|l|l|l|l|l|l|}
\hline Variables & Speed & Load & Vdc & Torque & Current \\
\hline Hall A, VAB, IA & 3000 & $0->22.5$ & 10.0 & & \\
\hline
\end{tabular}

Speed transient

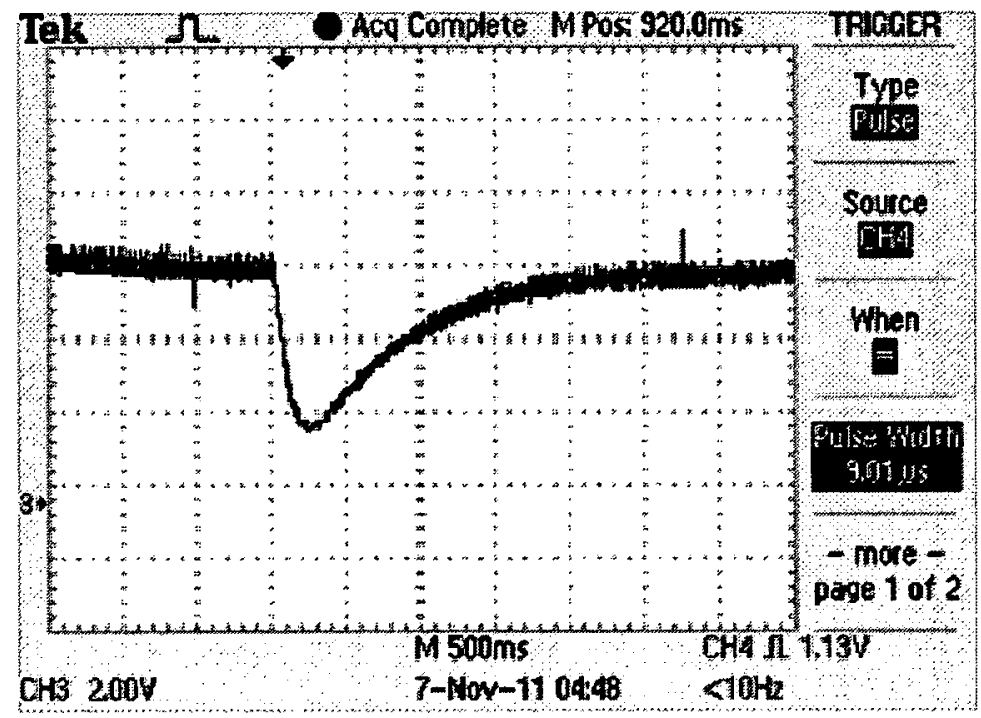

TPS 2024 - 3:58:58 PM 06/11/2011

\begin{tabular}{|l|l|l|l|l|l|}
\hline Variables & Speed & Load & Vdc & Torque & Current \\
\hline Hall A, VAB, IA & 3000 & $22.5 \rightarrow 0$ & 10.0 & & \\
\hline
\end{tabular}

\footnotetext{
Speed transient
} 


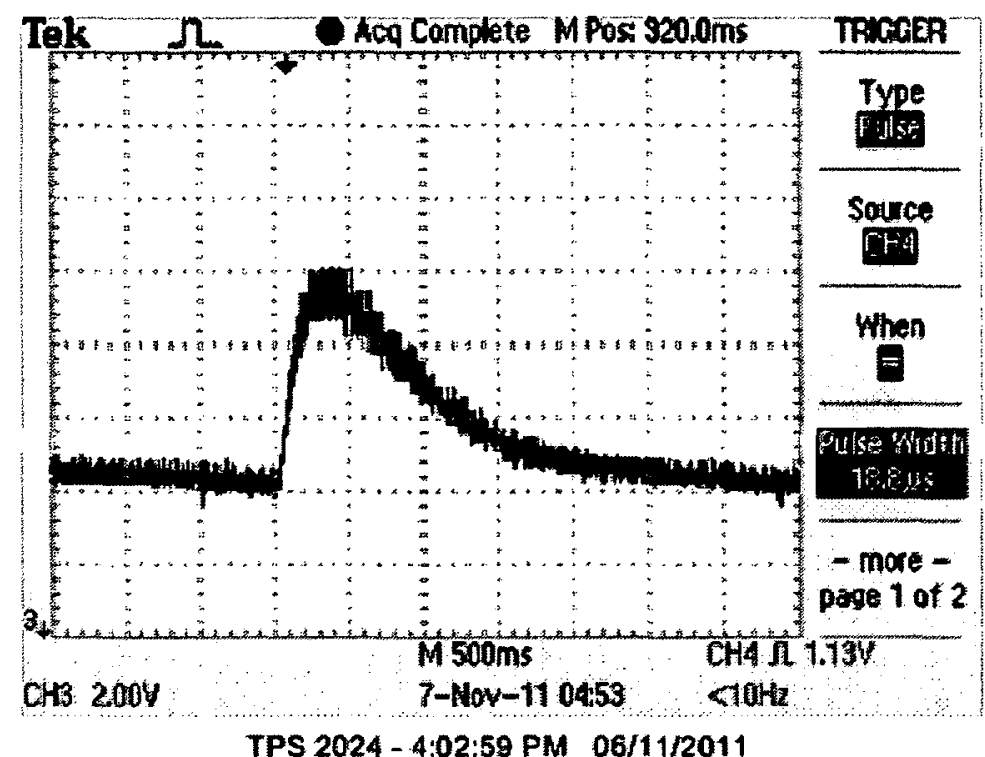

\begin{tabular}{|l|l|l|l|l|l|}
\hline Variables & Speed & Load & Vdc & Torque & Current \\
\hline Hall A, VAB, IA & 2000 & $0->51$ & 10.0 & & \\
\hline
\end{tabular}

Speed transient

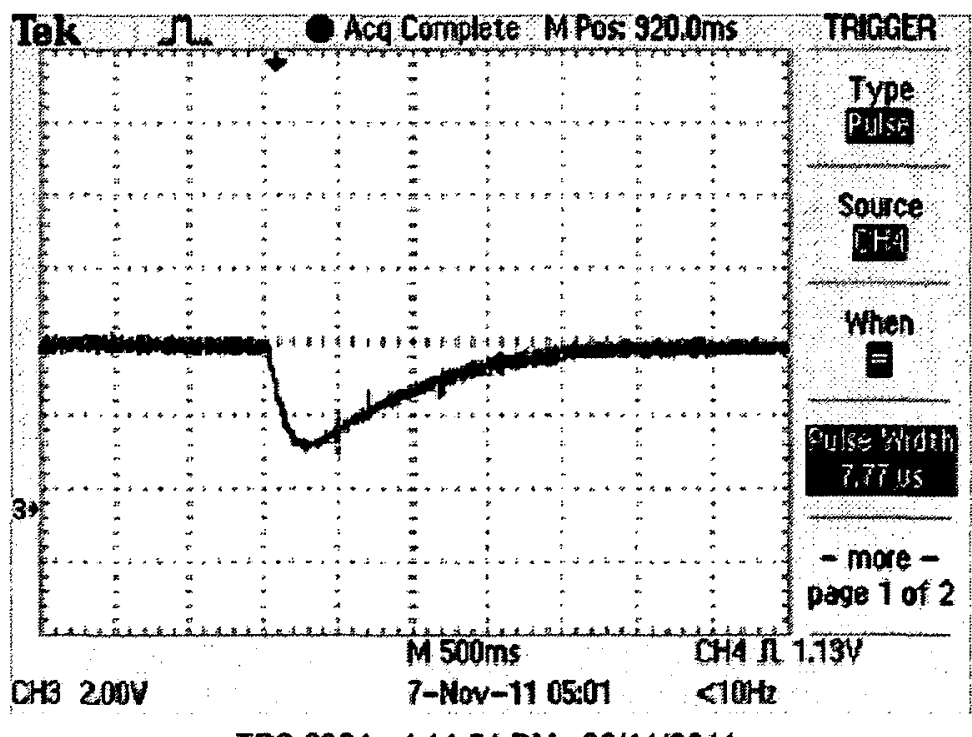

TPS 2024-4:11:54 PM 06/11/2011

\begin{tabular}{|l|l|l|l|l|l|}
\hline Variables & Speed & Load & Vdc & Torque & Current \\
\hline
\end{tabular}




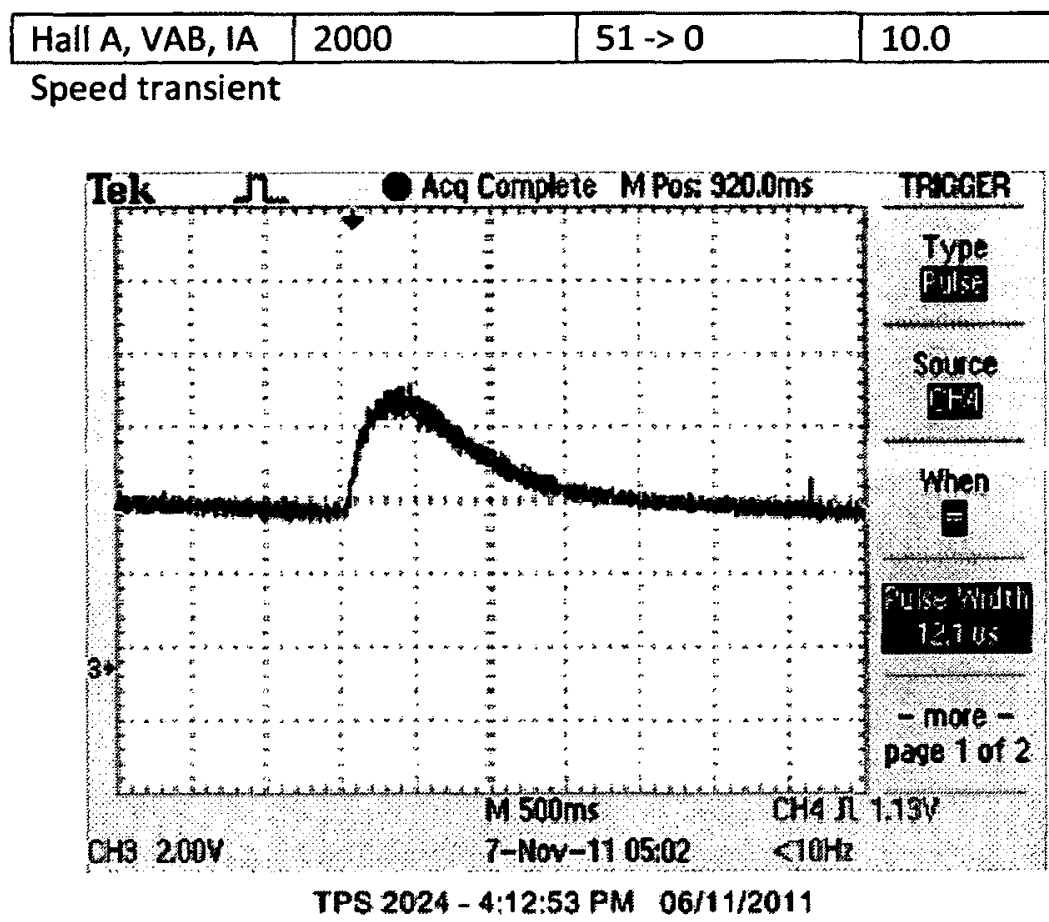

\begin{tabular}{|l|l|l|l|l|l|}
\hline Variables & Speed & Load & Vdc & Torque & Current \\
\hline Hall A, VAB, IA & 2000 & $0 \rightarrow 51$ & 20.3 & & \\
\hline
\end{tabular}

Speed transient

NOTE: TI lost control and could not bring the speed back to 3000 RPM

NOTE: The value above is for the FPGA controller 


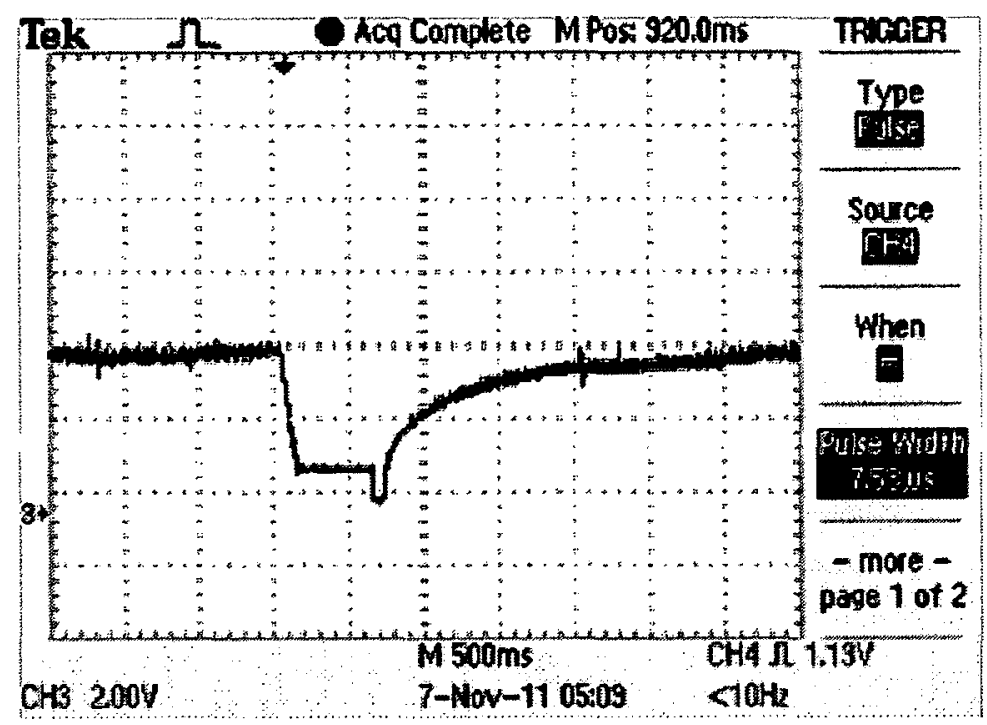

TPS 2024-4:19:54 PM 06/11/2011

\begin{tabular}{|l|l|l|l|l|l|}
\hline Variables & Speed & Load & Vdc & Torque & Current \\
\hline Hall A, VAB, IA & 2000 & $51>0$ & 20.3 & & \\
\hline
\end{tabular}

Speed transient

NOTE: TI lost control completely and stopped

NOTE: The value above is for the FPGA controller

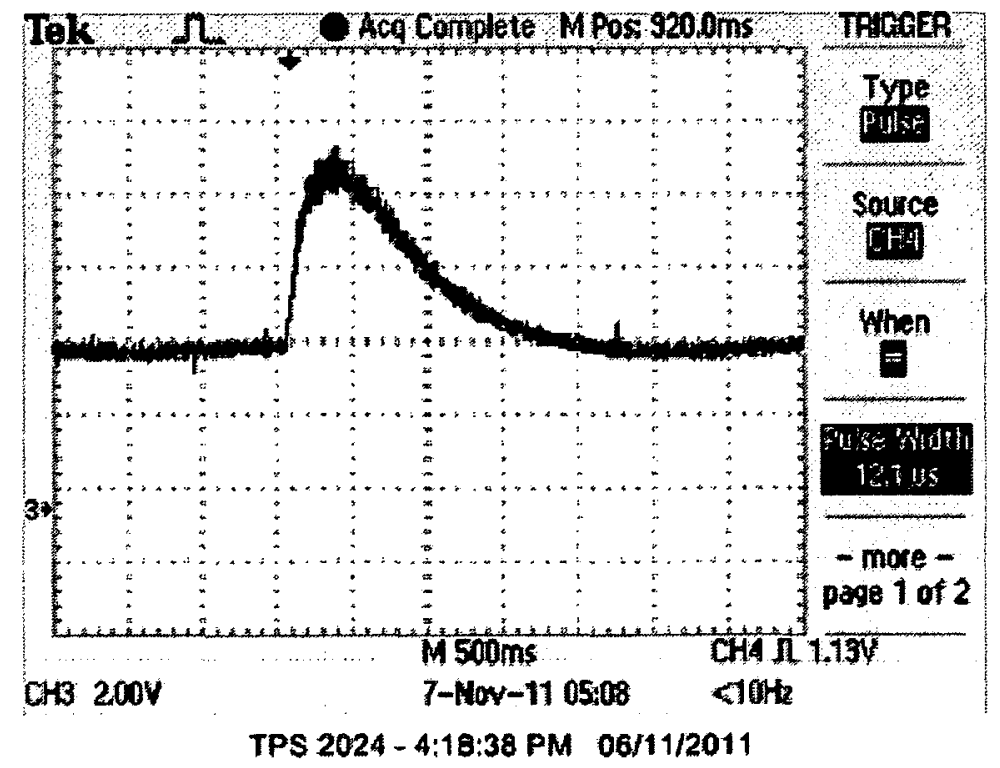




\begin{tabular}{|l|l|l|l|l|l|}
\hline Variables & Speed & Load & Vdc & Torque & Current \\
\hline Hall A, VAB, IA & 2000 & $0 \rightarrow 25.5$ & 20.3 & & \\
\hline
\end{tabular}

Speed transient

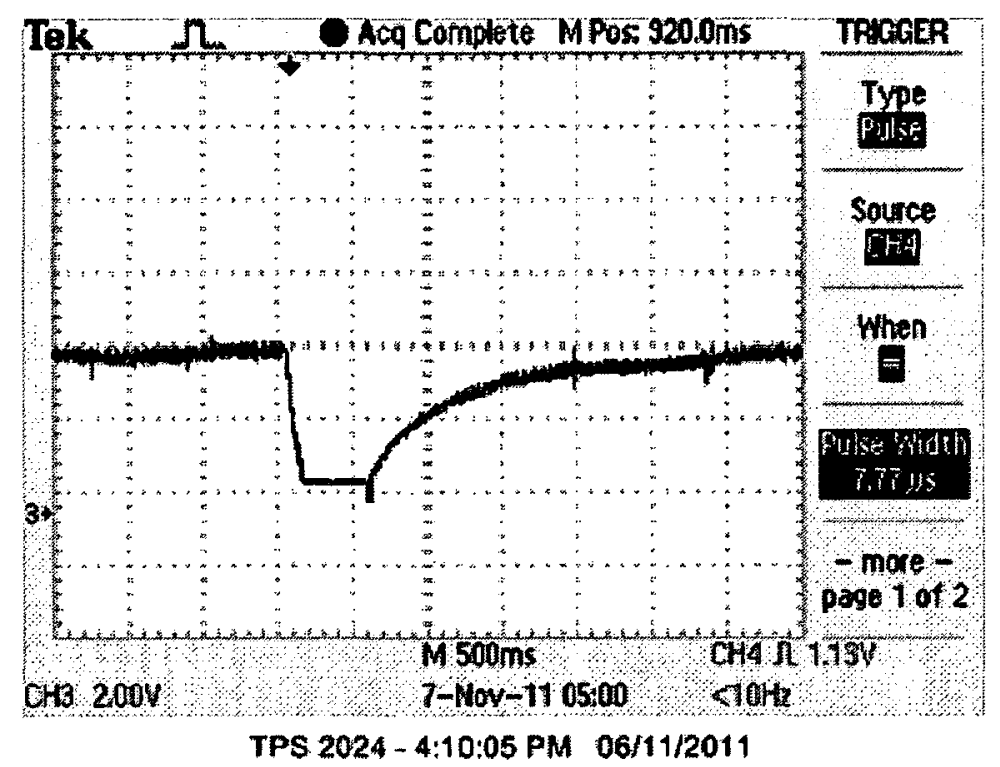

NOTE: result total torque is beyond the stall torque

\begin{tabular}{|l|l|l|l|l|l|}
\hline Variables & Speed & Load & Vdc & Torque & Current \\
\hline Hall A, VAB, IA & 2000 & $25.5->0$ & 20.3 & & \\
\hline
\end{tabular}

Speed transient 


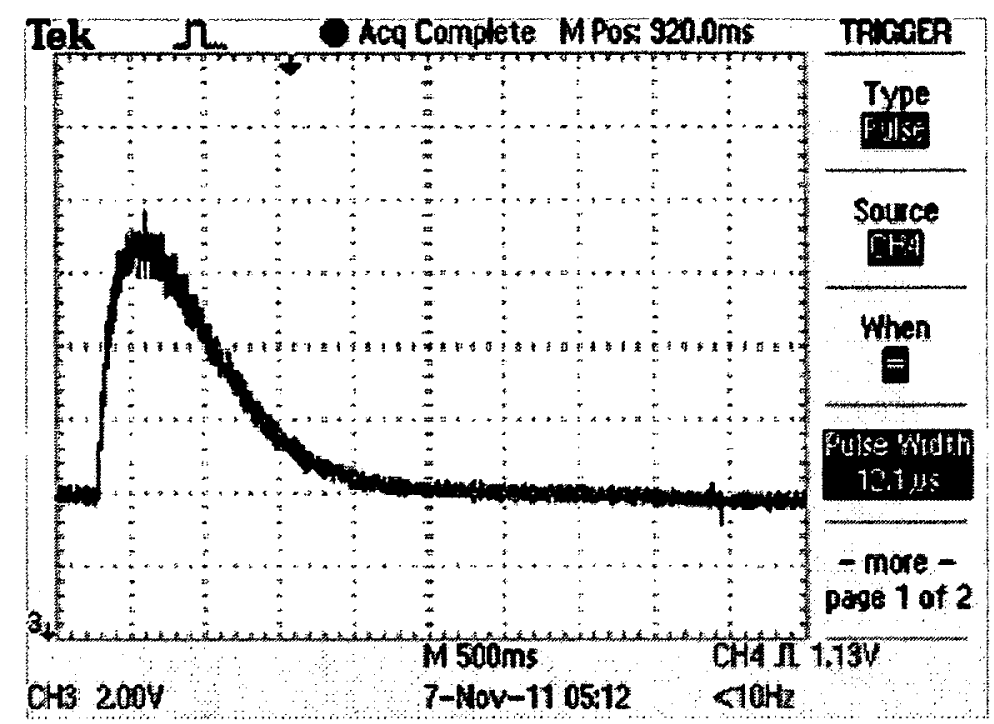

TPS 2024-4:22:31 PM 06/11/2011

NOTE: result total torque is beyond the stall torque

\begin{tabular}{|l|l|l|l|l|l|}
\hline Variables & Speed & Load & Vdc & Torque & Current \\
\hline Hall A, VAB, IA & 4000 & $0->51$ & 20.2 & & \\
\hline
\end{tabular}

Speed transient

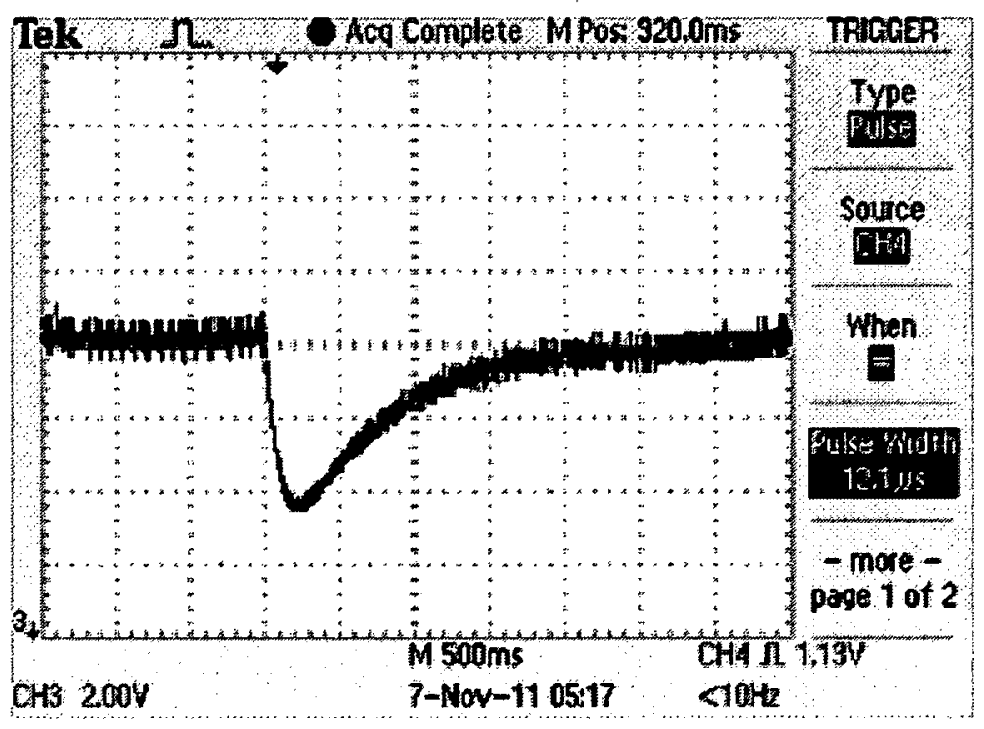

TPS 2024 - 4:27:09 PM 06/11/2011

\begin{tabular}{|l|l|l|l|l|l|}
\hline Variables & Speed & Load & Vdc & Torque & Current \\
\hline Hall A, VAB, IA & 4000 & $51>0$ & 20.2 & & \\
\hline
\end{tabular}




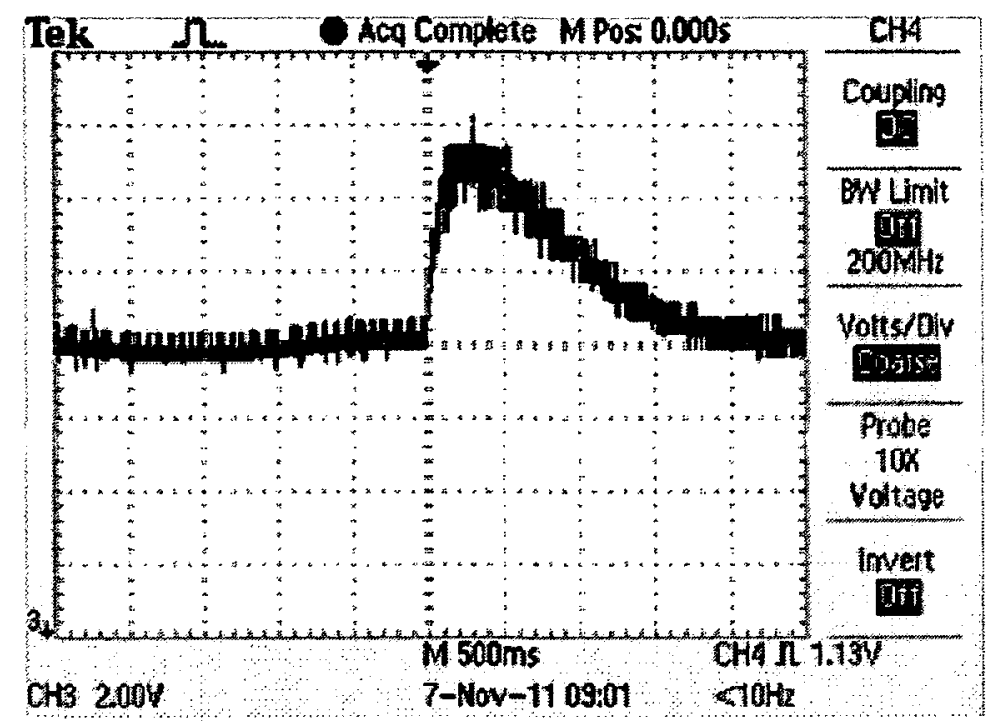

Speed transient

TPS 2024-8:11:49 PM 06/11/2011

\begin{tabular}{|l|l|l|l|l|l|}
\hline Variables & Speed & Load & Vdc & Torque & Current \\
\hline Hall A, VAB, IA & 4000 & $0->22.5$ & 10.0 & & \\
\hline
\end{tabular}

Speed transient

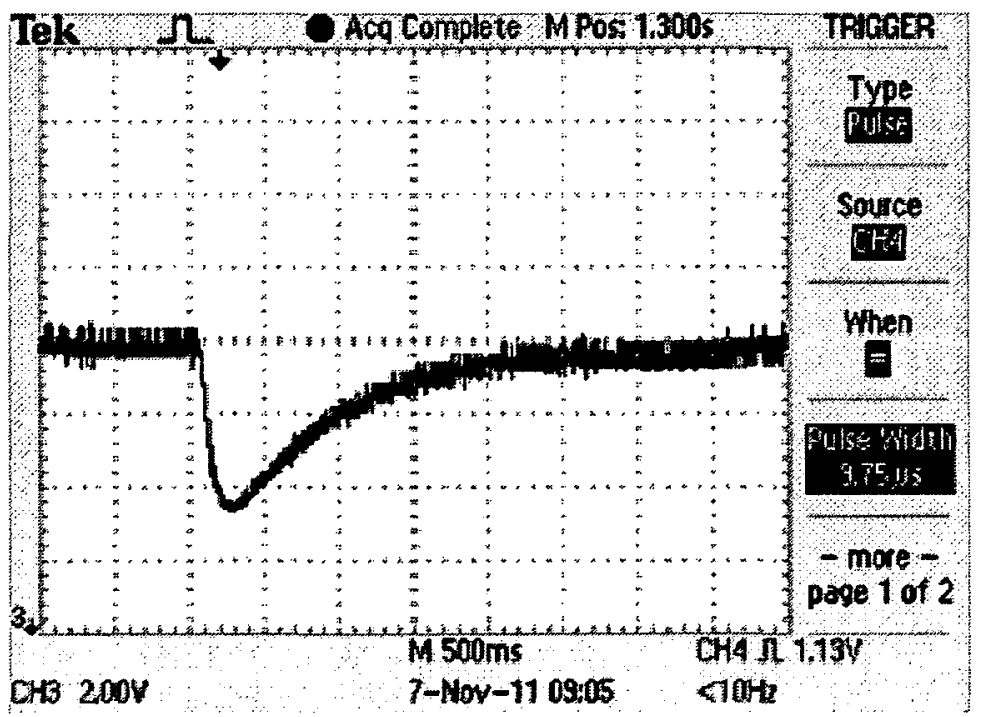

TPS 2024-8:15:26 PM 06/11/2011

\begin{tabular}{|l|l|l|l|l|l|}
\hline Variables & Speed & Load & Vdc & Torque & Current \\
\hline Hall A, VAB, IA & 4000 & $22.5 \rightarrow 0$ & 10.0 & & \\
\hline
\end{tabular}




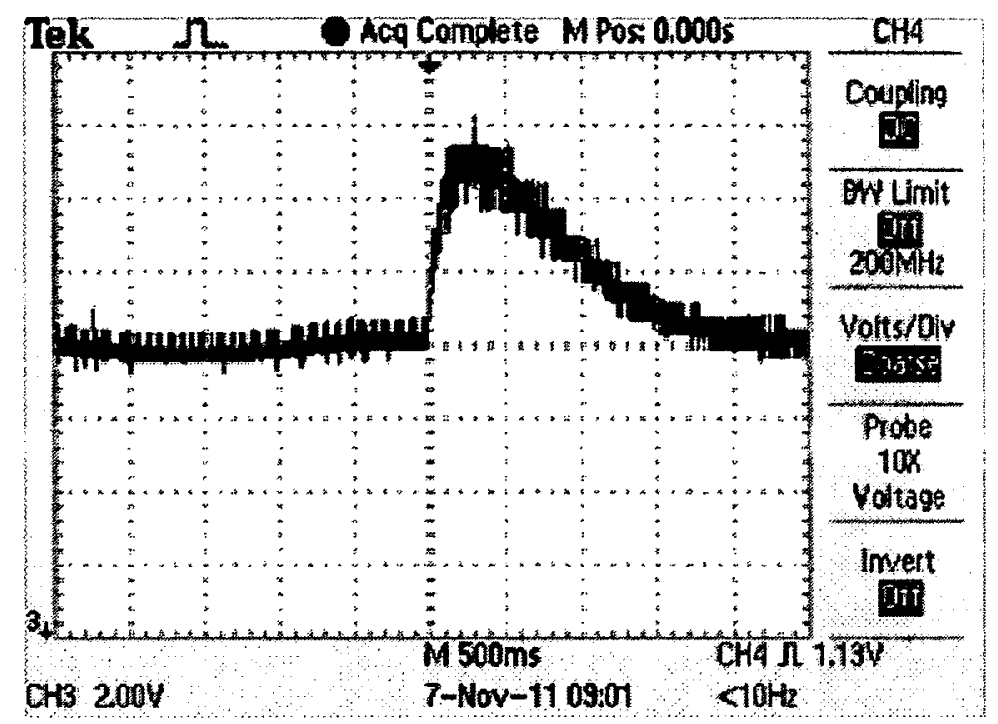

Speed transient

TPS 2024-8:11:49 PM 06/11/2011

\begin{tabular}{|l|l|l|l|l|l|}
\hline Variables & Speed & Load & Vdc & Torque & Current \\
\hline Hall A, VAB, IA & 6000 & $0 \rightarrow 51$ & 20.3 & & \\
\hline
\end{tabular}

Speed transient

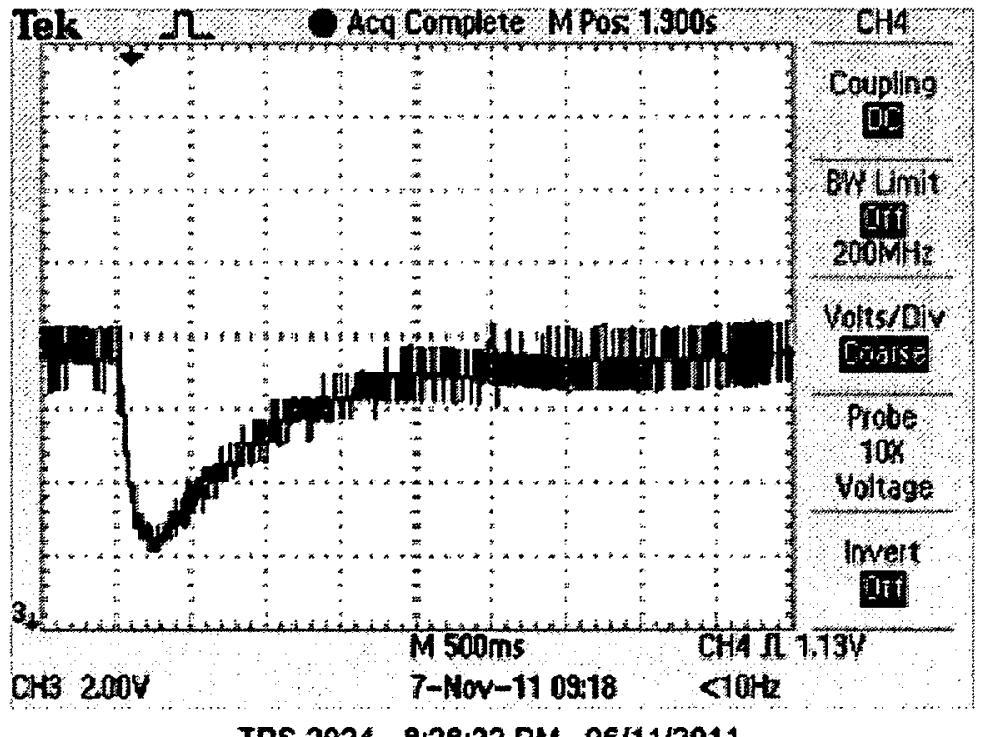

TPS 2024 - 8:28:22 PM 06/11/2011 


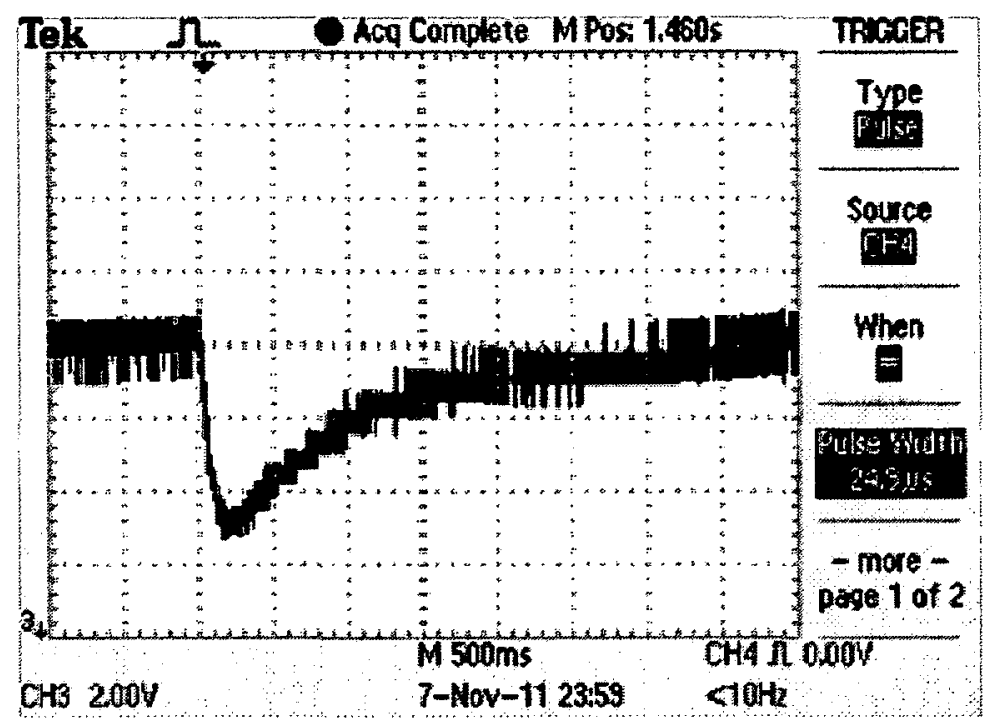

TPS 2024-11:09:43 AM 07/11/2011

\begin{tabular}{|l|l|l|l|l|l|}
\hline Variables & Speed & Load & Vdc & Torque & Current \\
\hline Hall A, VAB, IA & 6000 & $51->0$ & 20.3 & & \\
\hline
\end{tabular}

Speed transient

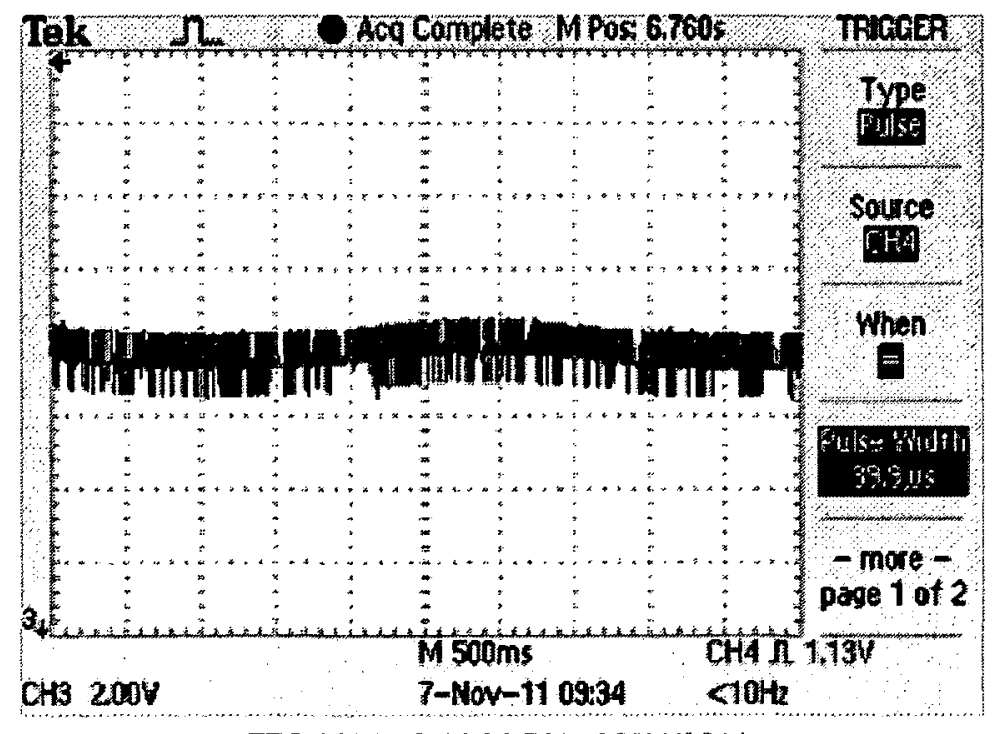

TPS 2024-8:44:06 PM 06/11/2011 


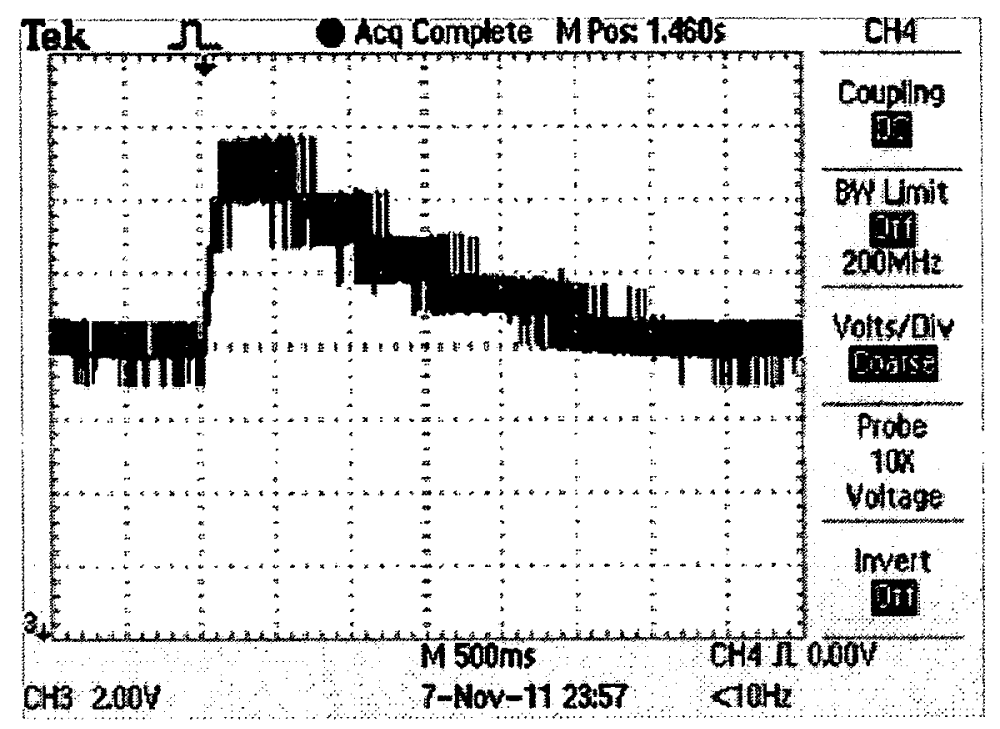

TPS 2024 - 11:07:37 AM 07/11/2011

\begin{tabular}{|l|l|l|l|l|l|}
\hline Variables & Speed & Load & Vdc & Torque & Current \\
\hline Hall A, VAB, IA & 6000 & $0->25.5$ & 20.3 & & \\
\hline
\end{tabular}

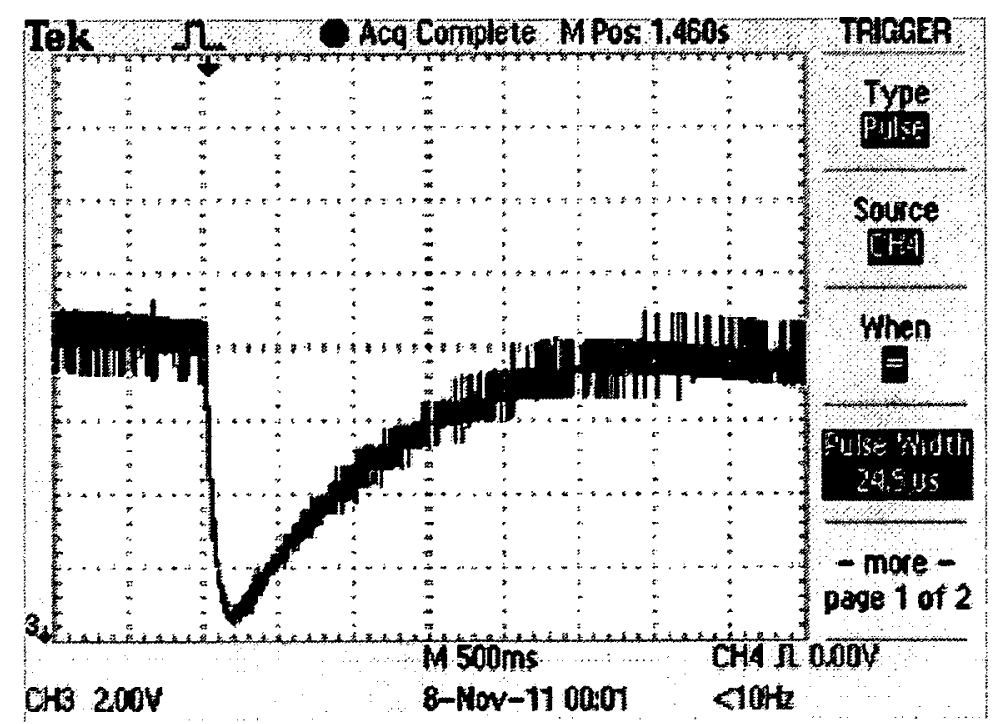

TPS 2024-11:11:46 AM 07/11/2011 


\begin{tabular}{|l|l|l|l|l|l|}
\hline Variables & Speed & Load & Vdc & Torque & Current \\
\hline Hall A, VAB, IA & 6000 & $25.5>0$ & 20.3 & & \\
\hline
\end{tabular}

Speed transient

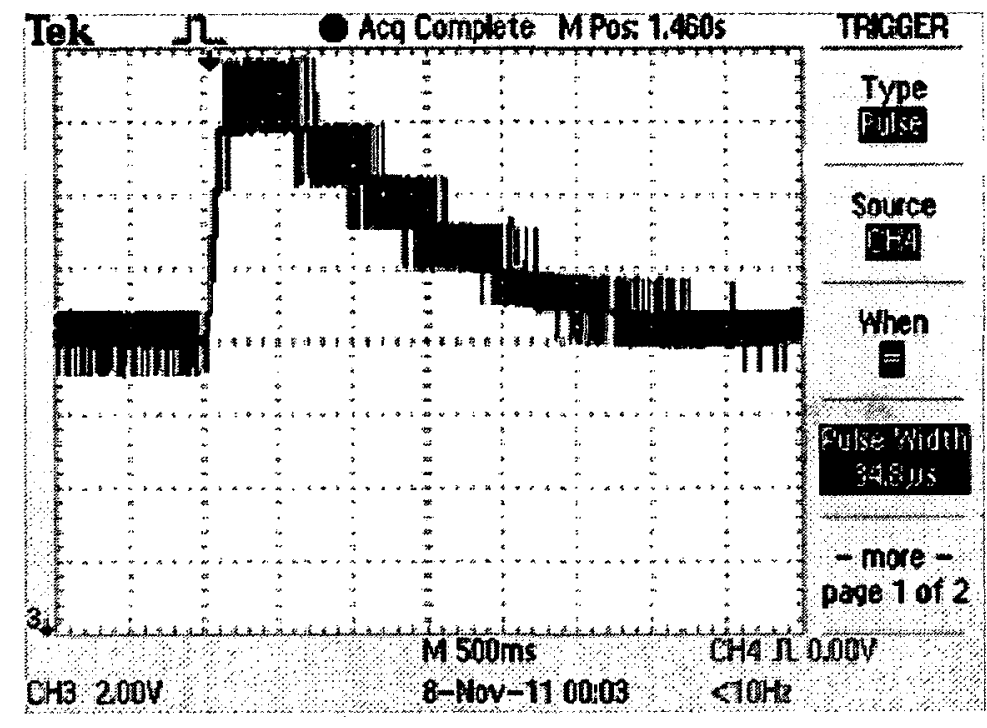

TPS 2024-11:13:09 AM 07/11/2011 


\subsection{Annexe 3, Models used for Measurements from Matlab Simulation}

In figure 18,19 and 20 we capture the matlab model we have developed to show one modeling approach that we have used for experimentation and prototyping for scenarios comparison. It includes the PI controller and a speed profiler.

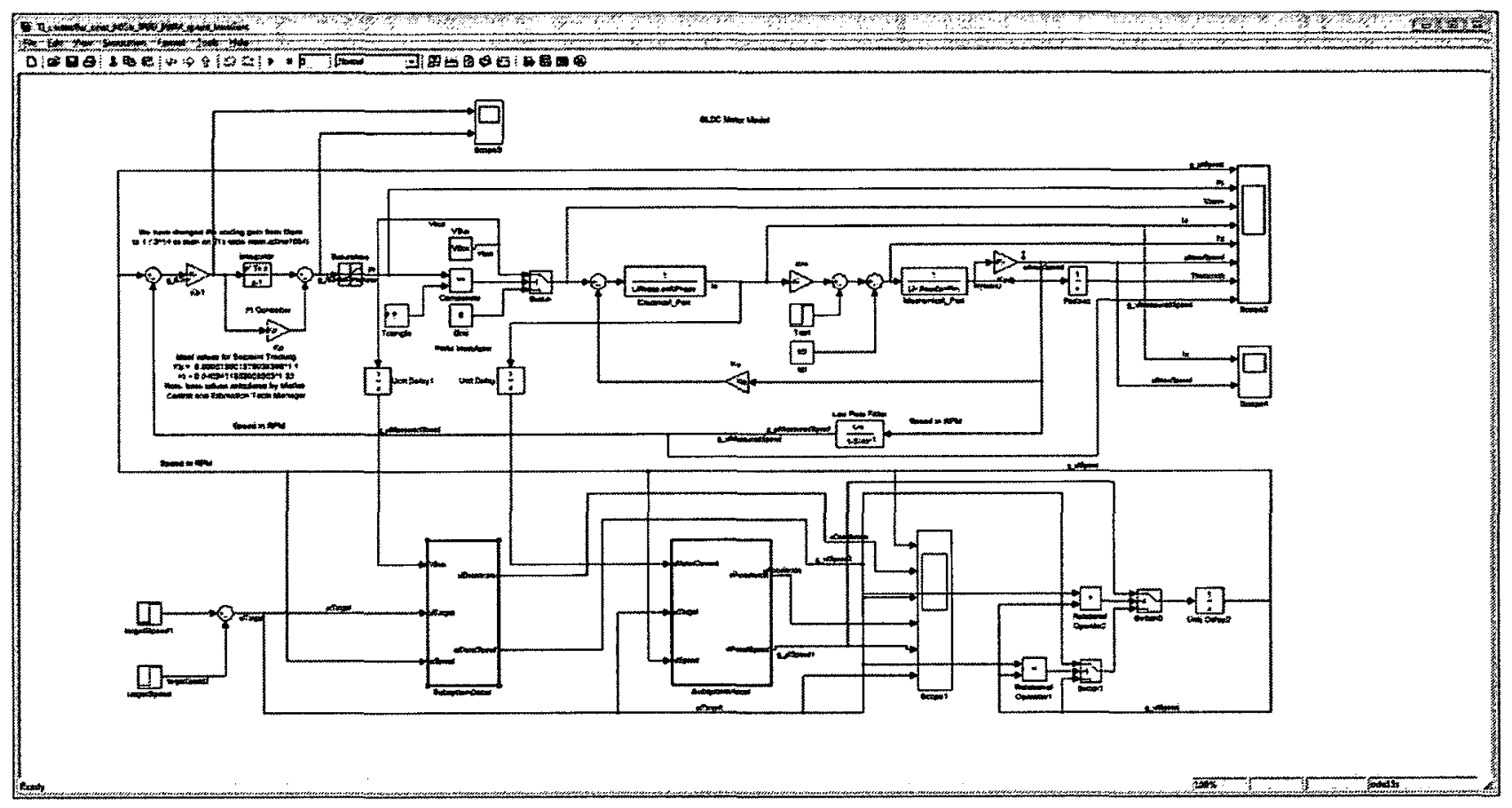

Figure 18 : Matlab model of the motor 


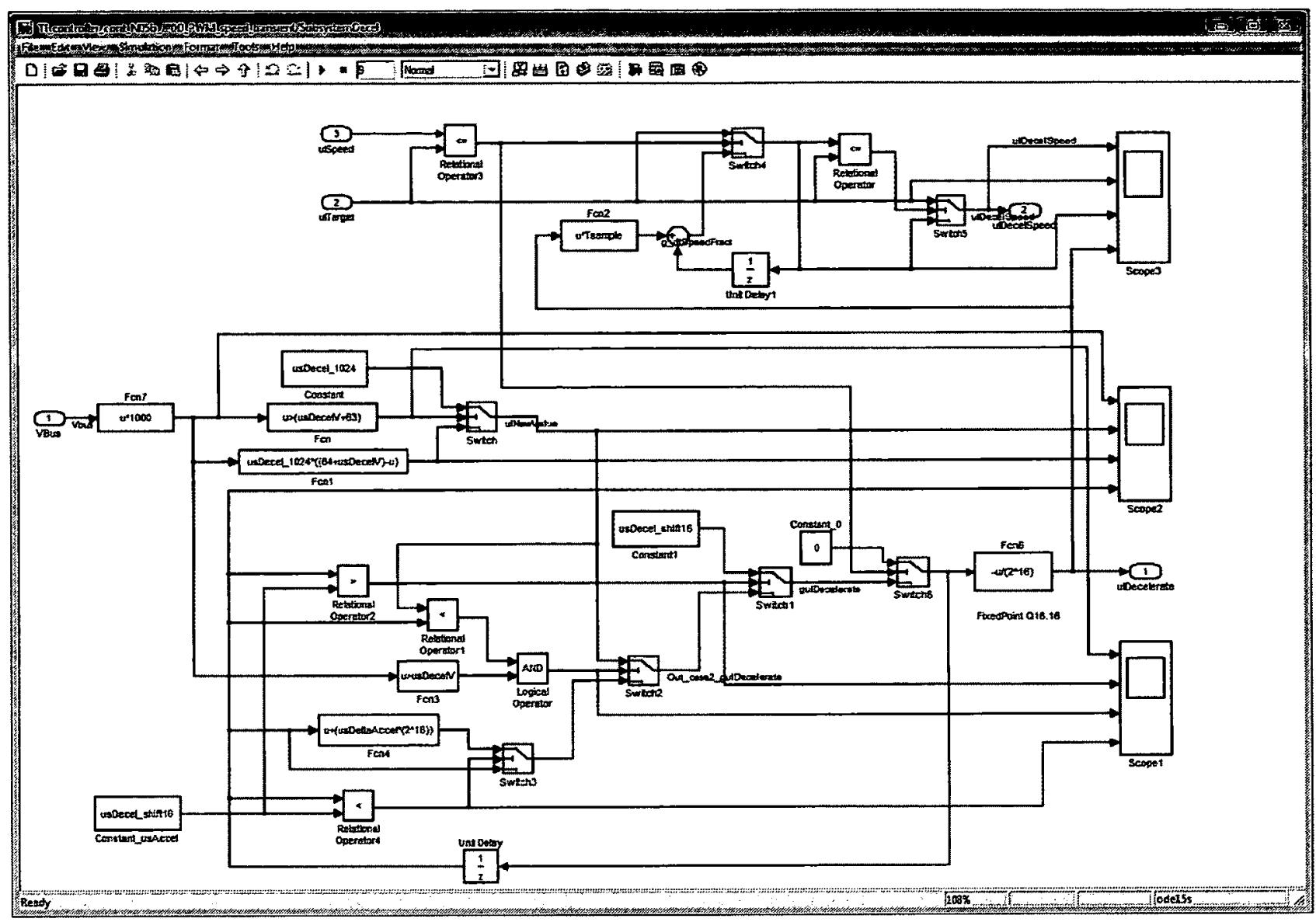

Figure 19 : Matlab model of the deceleration block 


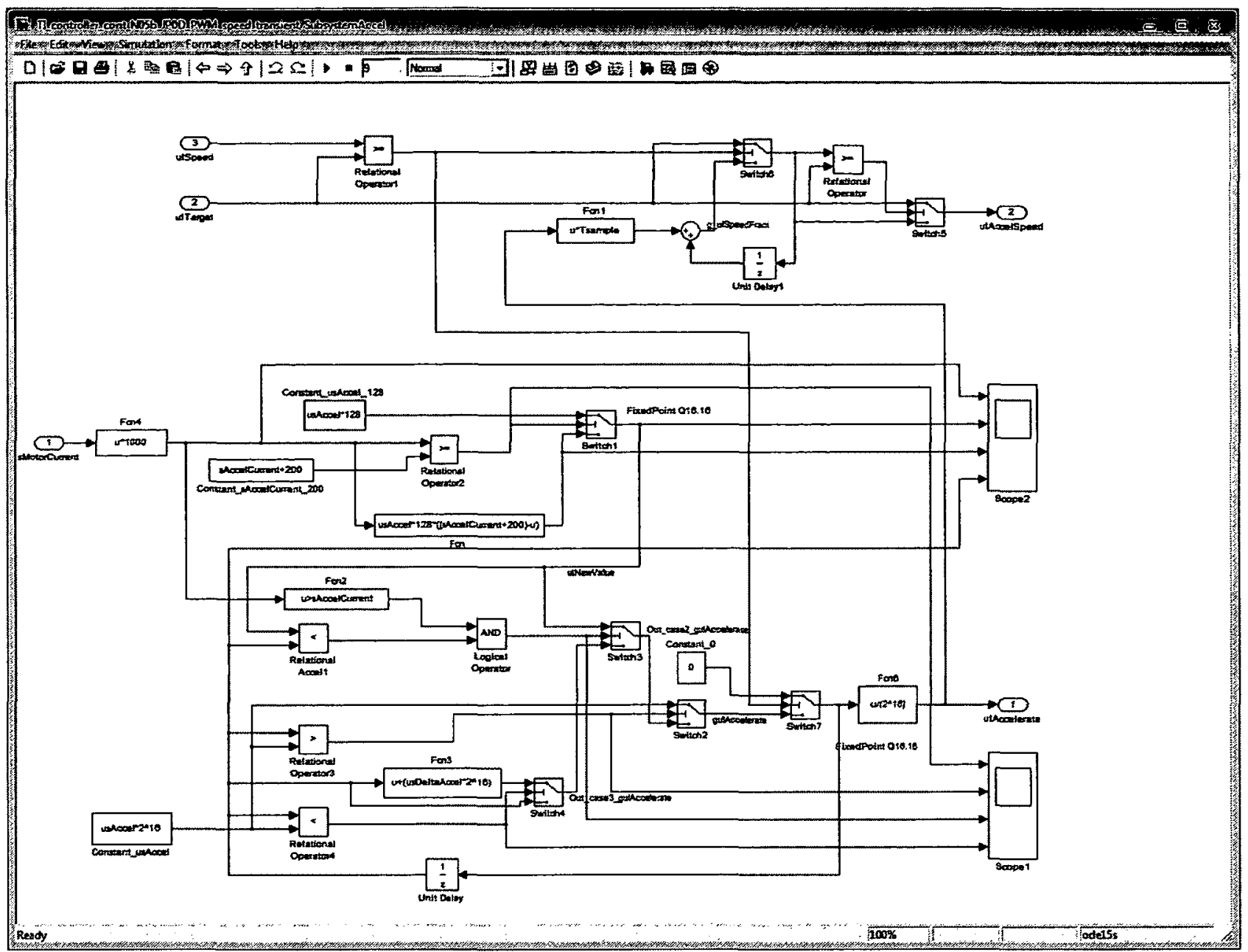

Figure 20 : Matlab Model of the acceleration block 


\subsection{Annexe 4, Selected History of Control and Motor}

\begin{tabular}{|l|l|}
\hline 270 B.C. & Ktesibios: earliest examples of water clocks \\
\hline $1572-1633$ & $\begin{array}{l}\text { Cornelius Drebbel: Temperature measurement by the expansion of a } \\
\text { liquid element. }\end{array}$ \\
\hline $1642-1727$ & Brook Taylor: Taylor's series in mathematical analysis \\
\hline $1642-1727$ & $\begin{array}{l}\text { Isaac Newton: Newton's mechanical laws, mathematical modeling and } \\
\text { analysis }\end{array}$ \\
\hline $1736-1819$ & James Watt: Steam engine governor \\
\hline $1749-1827$ & Pierre Simon Laplace: The Laplace transform method \\
\hline $1831-1879$ & James Clerk Maxwell: mathematical model for various governor \\
& mechanisms \\
\hline 1877 & Routh-Hurwitz: Stability of motion criterion \\
\hline 1913 & Henry Ford: mechanized assembly machine introduced for automobile \\
\hline 1927 & H. S. Black: conception of the negative feedback amplifier \\
\hline 1952 & Creation of first anticraft gun with active control. \\
\hline
\end{tabular}




\begin{tabular}{|c|c|}
\hline 1970 & State-variables models and optimal control developed. \\
\hline Nov. 1981 & $\begin{array}{l}\text { On Space Shuttle mission STS-2, Canadarm is flown in space for the first } \\
\text { time }\end{array}$ \\
\hline 1983 & $\begin{array}{l}\text { Introduction of the personal computer and control design software soon } \\
\text { thereafter) brought the tools of design to engineer's desktop }\end{array}$ \\
\hline 1994 & $\begin{array}{l}\text { Feedback control widely used in automobiles. Reliable, robust system } \\
\text { demanded in manufacturing. }\end{array}$ \\
\hline 1995 & $\begin{array}{l}\text { The Global Positioning system (GPS) was operational providing } \\
\text { positioning, navigation and timing services world wide. }\end{array}$ \\
\hline 1997 & $\begin{array}{l}\text { First ever rover autonomous vehicle, known as sojourner, explores the } \\
\text { Martian surface. }\end{array}$ \\
\hline $1998-2003$ & $\begin{array}{l}\text { Advances in micro- and nanotechnology. First intelligent machines are } \\
\text { developed and functioning nanomachines are created. }\end{array}$ \\
\hline 2007 & $\begin{array}{l}\text { The Orbital Express mission performed the first autonomous space } \\
\text { rendez-vous and docking. }\end{array}$ \\
\hline
\end{tabular}

Table 6 : Selected history of control and motor 


\subsection{Annexe 5, Mathematical Model}

Equivalent circuit of the power stage

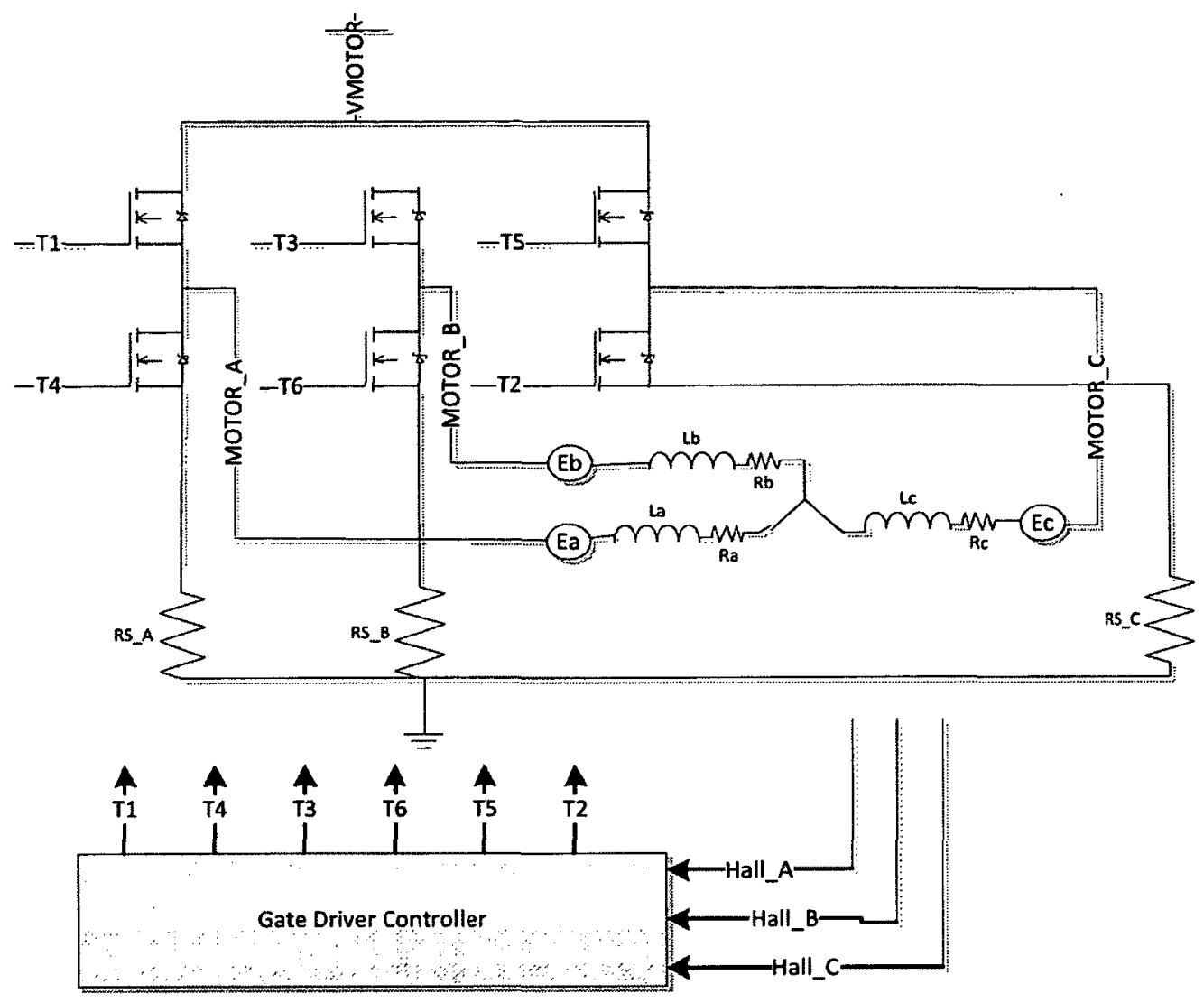

Figure $21:$ Power stage 


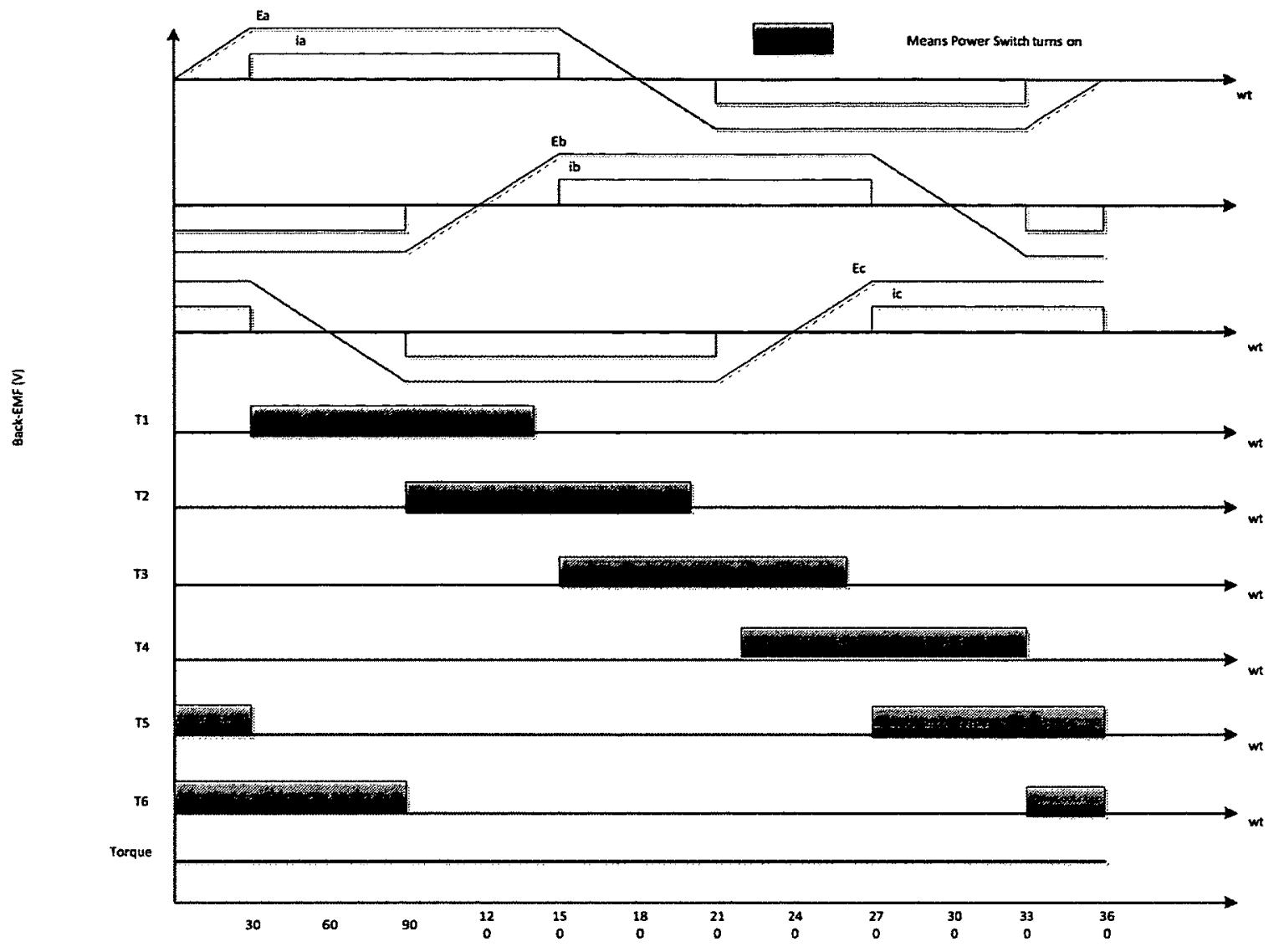

Figure 22 : Six steps current

Referring to the previous two figures 21 and 22 and taking in account that the motor has a balance equivalent electrical circuit such as $\mathrm{Ra}=\mathrm{Rb}=\mathrm{Rc}=\mathrm{R}$ and $\mathrm{La}=\mathrm{Lb}=\mathrm{Lc}=\mathrm{L}$. We can apply Kirchhoff's Voltage and current Law for each phase and write the following matrix equation (Toliyat, Cambell 2004):

$$
\left[\begin{array}{c}
v a \\
v b \\
v c
\end{array}\right]=\left[\begin{array}{ccc}
R+L s & 0 & 0 \\
0 & R+L s & 0 \\
0 & 0 & R+L s
\end{array}\right] \cdot\left[\begin{array}{c}
i a \\
i b \\
i c
\end{array}\right]+\left[\begin{array}{c}
e a \\
e b \\
e c
\end{array}\right]
$$

In equation (1), the phase resistances and inductances being constant and equal thus we can use identity matrix property and rewrite (1) to calculate the phase currents $i$. 


$$
\frac{1}{R+L s}\left[\begin{array}{c}
v a-e a \\
v b-e b \\
v c-e c
\end{array}\right]=\left[\begin{array}{l}
i a \\
i b \\
i c
\end{array}\right]
$$

\begin{tabular}{|l|l|}
\hline Variables name & Description \\
\hline $\mathrm{R}$ & $\begin{array}{l}\text { Is the magnitude of the phase resistance } \mathrm{a} \text { or } \mathrm{b} \text { or } \mathrm{c} \text {. They are assumed to } \\
\text { be equal. }\end{array}$ \\
\hline $\mathrm{L}$ & $\begin{array}{l}\text { Is the magnitude of the phase inductance } \mathrm{a} \text { or } \mathrm{b} \text { or } \mathrm{c} \text {. They are assumed } \\
\text { to be equal. }\end{array}$ \\
\hline va, vb, vc & $\begin{array}{l}\text { Are the magnitude of the phase voltage a or } \mathrm{b} \text { or } \mathrm{c}, \text { applied to the } \\
\text { armature circuit. They are assumed to be equal. }\end{array}$ \\
\hline ea, eb, ec & $\begin{array}{l}\text { Are the magnitude of the phase back emf generated in phase a or } \mathrm{b} \text { or } \mathrm{c} . \\
\text { They are assumed to be equal. }\end{array}$ \\
\hline $\mathrm{ia}, \mathrm{ib}, \mathrm{ic}$ & $\begin{array}{l}\text { Are the magnitude of the phase current a or } \mathrm{b} \text { or } \mathrm{c}, \text { developed in the } \\
\text { armature circuit. They are assumed to be equal. }\end{array}$ \\
\hline $\mathrm{s}$ & \begin{tabular}{l} 
The Laplace variable \\
\hline
\end{tabular}
\end{tabular}

Table 7 : Motor equation parameters definition

The motor is an electromechanical device containing an electrical subsystem as well as a mechanical subsystem. Thus we must apply electrical principles and Newton's laws to develop its mathematical model. The majority of electromechanical devices utilize a magnetic field (Palm III, 2010). In the case of this motor, two basic principles of magnetic coupling were used: 
1) When two power MOSFETs are activated, the motor developed a torque proportional to the phase current such as iphase (ia or ib or ic):

$$
\operatorname{Tm}(t)=K m * \operatorname{iphase}(t)
$$

A control bloc diagram to model equation (3) could be:

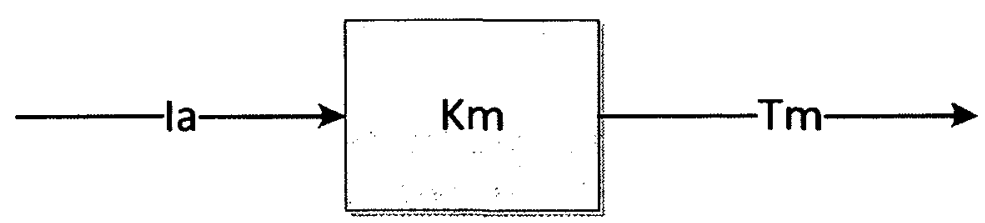

Figure 23 : Block diagram for torque

2) The electromagnetic field induces a voltage in the motor's armature that opposes the phase voltage producing the phase current. According to Faraday's law of electromagnetic induction such as ephase:

$$
\operatorname{ephase}(t)=K e * w(t)=e a=e b=e c
$$

A control bloc diagram to model equation (4) could be:

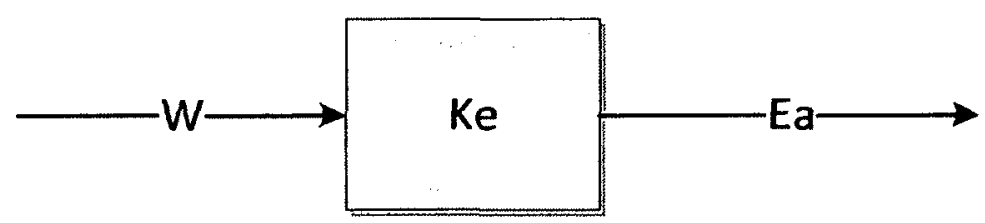

Figure 24 : Block diagram back-emf

We can rewrite equation (2) using equation (4), such as: 


$$
\frac{1}{R+L s}\left[\begin{array}{l}
v a-K e * w(t) \\
v b-K e * w(t) \\
v c-K e * w(t)
\end{array}\right]=\left[\begin{array}{l}
i a \\
i b \\
i c
\end{array}\right]
$$

A control bloc diagram to model equation (5) could be:

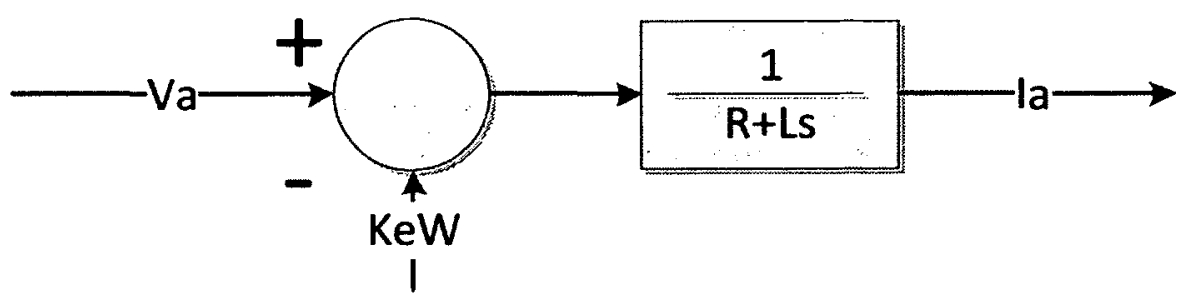

Figure 25 : Block diagram for phase current

As previously stated, the motor develops a torque proportional to the phase currents. The resulting torque turns the motor with a rotational speed $w(\mathrm{t})$ and it reacts against the moment of inertia of the rotor $\mathrm{J}$, the friction coefficient $\mathrm{Bm}$ and the load $\mathrm{Tl}$. The contribution of this mechanical influence satisfies the dynamic equation of a rotational mechanical system hence by applying Newton's Second Law, we have:

$\sum$ torques $=\mathrm{J} \dot{W}$

$$
\begin{aligned}
& \mathrm{J} \dot{W}=T m-T l-B m W \\
& W=(T m-T l) \frac{1}{J s+B m}
\end{aligned}
$$

A control bloc diagram to model equation (7) could be: 


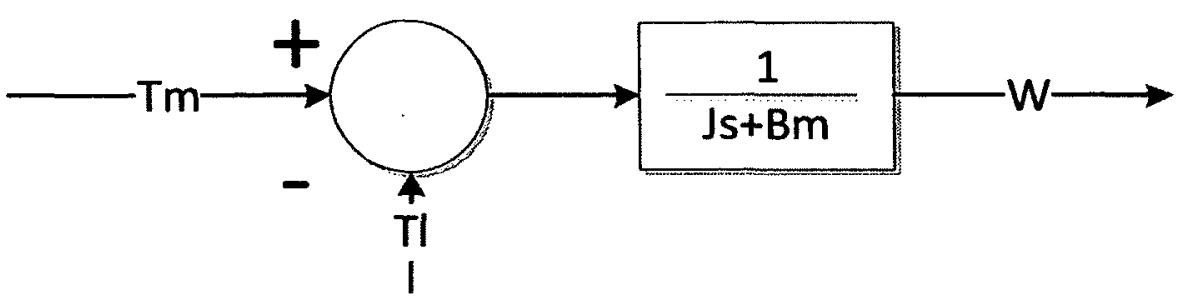

Figure 26 : Block diagram for speed

Now, by assembling the control bloc diagrams of equations (5), (3), (7) and (4) we have the following model of the motor.

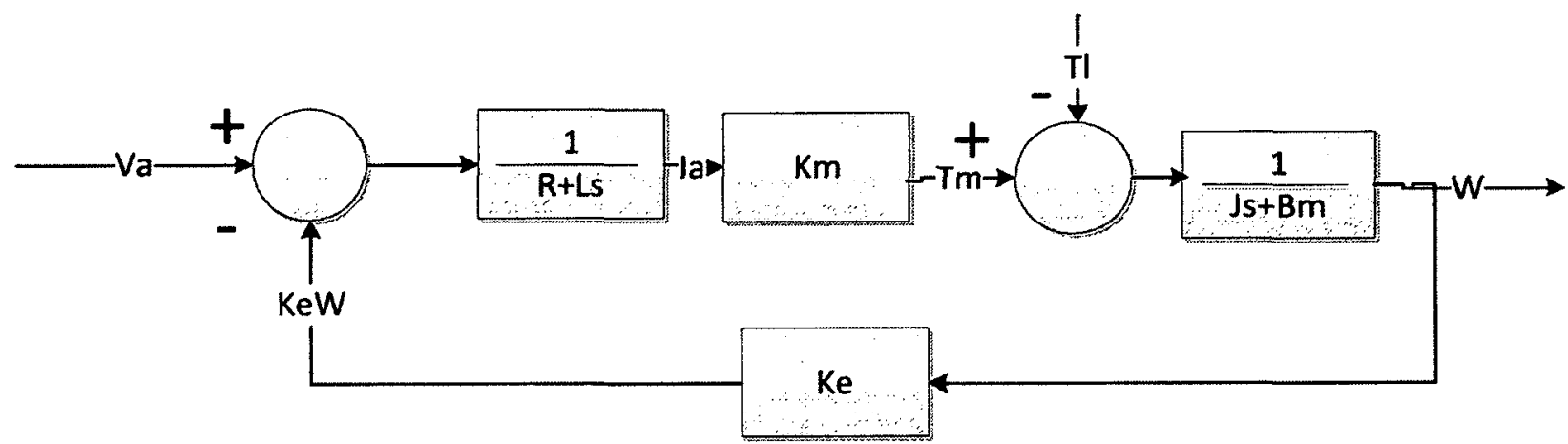

Figure 27 : Block diagram for the motor

Using the superposition method, the transfer function (Golnaraghi \& Kuo, 2010) of this model is the sum of:

$\mathrm{W}(\mathrm{s})=\frac{\mathrm{W}(\mathrm{s})}{V_{a}(s)}\left|T l=0+\frac{\mathrm{W}(\mathrm{s})}{T l(s)}\right| V_{a}(s)=0$

$\mathrm{W}(\mathrm{s})=\mathrm{W} 1+\mathrm{W} 2$

$W 1=\frac{\mathrm{W}(\mathrm{s})}{V_{a}(s)}=\frac{\frac{k_{M}}{(\mathrm{R}+\mathrm{Ls})} * \frac{1}{j s+B_{M}}}{1+K_{e}\left(\frac{k_{M}}{\mathrm{R}+\mathrm{Ls})} * \frac{1}{J s+B_{M}}\right)}$ 
$\frac{W(s)}{V_{a}(s)}=\frac{\frac{k_{M}}{(\mathrm{R}+\mathrm{Ls})} * \frac{1}{J s+B_{M}}}{1+K_{e}\left(\frac{k_{M}}{\mathrm{R}+\mathrm{Ls})} * \frac{1}{J s+B_{M}}\right)}$

$\frac{\mathrm{W}(\mathrm{s})}{V_{a}(s)}=\frac{k_{M}}{J s(\mathrm{R}+\mathrm{Ls})+B_{M}(\mathrm{R}+\mathrm{Ls})+k_{e} k_{M}}$

$\frac{W(s)}{V_{a}(s)}=\frac{k_{M}}{J L s^{2}+\left(J \mathrm{R}+B_{M} \mathrm{~L}\right) \mathrm{s}+B_{M} R+k_{e} k_{M}}$

$\frac{\mathrm{W}(\mathrm{s})}{V_{\mathrm{a}}(s)}=\frac{\frac{k_{M}}{J \mathrm{R}}}{\frac{\mathrm{L}}{\mathrm{R}} s^{2}+\left(1+\frac{B_{M}^{L}}{J \mathrm{R}}\right) s+\frac{B_{M}^{R+k_{e} k_{M}}}{J \mathrm{R}}}$

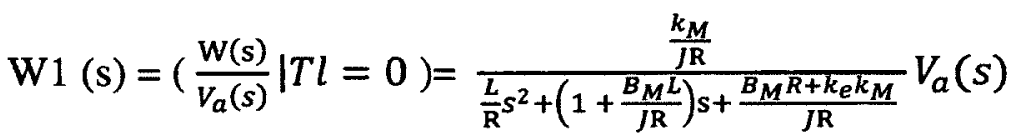

Now

$\mathrm{W} 2=\frac{\mathrm{W}(s)}{T L(s)} \mid V_{a}(s)=0$ implies the following block diagram

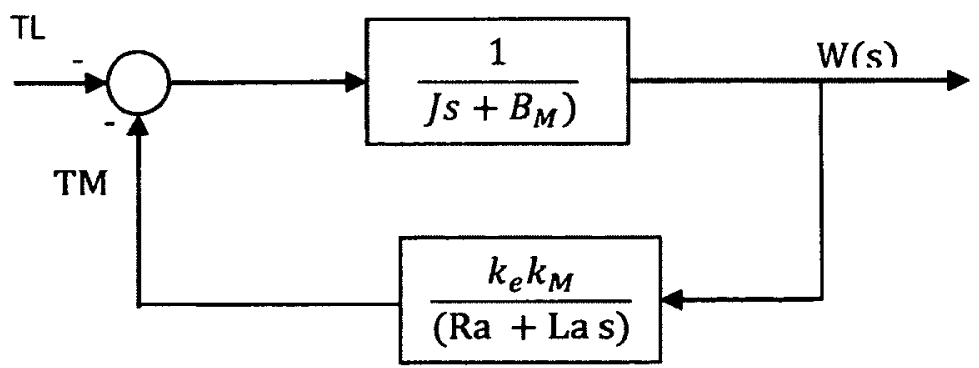

Figure 28 : Block diagram of load torque effect 
$\mathrm{W} 2=\frac{\mathrm{W}(\mathrm{s})}{T L(s)} \mid V_{a}(s)=0=\frac{-\frac{1}{\mathrm{~J} s+\mathrm{BM}}}{1+\left(\frac{k_{e} k_{M}}{\mathrm{R}+\mathrm{L} s} * \frac{1}{\mathrm{~J} s+\mathrm{BM}}\right)}$,

$\frac{W(s)}{T L(s)}=\frac{-\frac{R+L s}{J R}}{\frac{L}{R} s^{2}+\left(1+\frac{B_{M}^{L}}{J R}\right) s+\frac{B_{M} M^{R+k} e^{k} M}{J R}}$

$\frac{W(s)}{T L(s)}=\frac{-\left(1+\frac{L}{R} s\right) / J}{\frac{L}{\mathrm{R}} s^{2}+\left(1+\frac{B_{M}^{L}}{J \mathrm{R}}\right) s+\frac{B_{M}^{R+k_{e} k_{M}}}{J \mathrm{R}}} V_{a}(s)$

$\mathrm{W} 2(\mathrm{~s}) \mid V_{a}(s)=0=\frac{-\left(1+\frac{L}{R} s\right) / J}{\frac{L}{\mathrm{R}} s^{2}+\left(1+\frac{B_{M}^{L}}{J \mathbf{R}}\right) \mathrm{s}+\frac{B_{M}^{R+k_{e} k_{M}}}{J \mathrm{R}}} T L(s)$

Then for $W(s)=W 1(s)+W 2(s)$ we have

$\mathrm{W}(\mathrm{s})=\frac{\frac{k_{M}}{J \mathrm{R}}}{\frac{L}{\mathrm{R}} s^{2}+\left(1+\frac{B_{M}^{L}}{J \mathrm{R}}\right) s+\frac{B_{M}{ }^{2}+k_{e} k_{M}}{J \mathrm{R}}} V_{a}(s)-\frac{\left(1+\frac{L}{R} s\right) / J}{\frac{L}{\mathrm{R}} s^{2}+\left(1+\frac{B_{M} L}{J \mathrm{R}}\right) s+\frac{B_{M}{ }^{2}+k_{e} k_{M}}{J \mathrm{R}}} T L(s)$ (general equation*)

By replacing the constants with their respective value in the motor's datasheet, we have

$\mathrm{W}(\mathrm{s})=\frac{2.49 * 10^{7}}{s^{2}+4.11 * 10^{3} s+5.5614 * 10^{5}} V_{a}(s)-\frac{6.25 * 10^{5} s+2.57 * 10^{9}}{s^{2}+4.11 * 10^{3} s+5.5614 * 10^{5}} T L(s)$

By inspecting (general equation*) the equation of W(s) we realize that the ratio $\frac{L}{R}\left(\lambda_{e}\right)$ which is the motor electric-time constant $\lambda_{e}$ makes the system speed response transfer function second order. If we neglect $\lambda_{\mathrm{e}}$ because $\mathrm{L}$ is very small in the motor armature circuit, the speed transfer function $\mathrm{W}(\mathrm{s})$ becomes a first order transfer function as follows:

$\mathrm{W}(\mathrm{s})=\frac{\frac{k_{M}}{J \mathrm{R}}}{\mathrm{s}+\frac{B_{M}{ }^{R+k_{e} k_{M}}}{J \mathrm{R}}} V_{a}(s)-\frac{1 / J}{\mathrm{~s}+\frac{B_{M}^{R+k_{e} k_{M}}}{J \mathrm{R}}} T L(s)$, thus

To facilitate a comparison between $\frac{1}{S(s+a)}$ Laplace expression and W(s) we rearrange 
$\mathrm{W}(\mathrm{s})=\frac{K_{e f f}}{\lambda \mathrm{ms}+1} V_{a}(s)+\frac{\frac{\lambda \mathrm{m}}{J}}{\lambda \mathrm{ms}+1}$, where $K_{\text {eff }}=\frac{k_{M}}{B_{M} R_{a}+k_{e} k_{M}}$ is the motor gain constant and

$\lambda \mathrm{m}=\frac{J \mathrm{Ra}}{B_{M} R_{a}+k_{e} k_{M}}$, it is important to mention that $\lambda \mathrm{m}$ is the motor mechanical time constant.

Hence,

$\mathrm{W}(\mathrm{s})=\frac{6.0598 * 10^{3}}{\mathrm{~s}+135.4080} V_{a}(s)+\frac{625000}{\mathrm{~s}+135.4080} T L$

It is worthwhile mentioning that $k_{e}=k_{M}$ if

$\mathrm{ke}$ is in $\mathrm{V} / \mathrm{rad} / \mathrm{sec}$ and $k_{M}$ is in N-m/A.

If $\mathrm{Bm}=0$ then $\lambda \mathrm{m}=\frac{J \mathrm{Ra}}{k_{e} k_{M}}$

$\lambda \mathrm{m}=\frac{2.3 * 16 * 10^{-7}}{22.3^{2} * 10^{-6}}=7.4 \mathrm{~ms}$ (concord with the parameter in the datasheet)

\begin{tabular}{|c|c|}
\hline $\begin{array}{l}\text { Transfer function with } \lambda_{e} \text { effect, with } \\
\text { disturbances }\end{array}$ & $\begin{array}{l}\text { Transfer function without } \lambda_{e} \text { effect, with } \\
\text { disturbances }\end{array}$ \\
\hline $\begin{array}{l}\mathrm{W}(\mathrm{s})=\frac{2.49 * 10^{7}}{s^{2}+4.11 * 10^{3} s+5.5614 * 10^{5}} V_{a}(s) \\
\frac{6.25 * 10^{5} s+2.57 * 10^{9}}{s^{2}+4.11 * 10^{3} s+5.5614 * 10^{5}} T L(s)\end{array}$ & $\mathrm{W}(\mathrm{s})=\frac{6.0598 * 10^{3}}{s+135.4080} V_{a}(s)+\frac{625000}{s+135.4080} T L$ \\
\hline
\end{tabular}

